\title{
THE EFFECTS OF DIFFERENT KINDS OF RETURN ON AN INTEGRATED CHANCE-CONSTRAINED STOCHASTIC MOBILE PHONE CLOSED-LOOP SUPPLY CHAIN CONFIGURATION AND SUPPLIER SELECTION
}

\author{
by Shahrzad Ahmadi Kermanshah \\ Bachelor's Degree in Electrical Engineering, Sadjad University, Iran, 2008 \\ Master of Biomedical Engineering (Bioelectric), Amirkabir University, Iran, 2014
}

A thesis presented to Ryerson University

in partial fulfillment of the

requirement for the degree of

Master of Applied Science

in the program of

Mechanical and Industrial Engineering

Toronto, Ontario, Canada, 2019

(C) Shahrzad Ahmadi Kermanshah, 2019 


\section{AUTHOR'S DECLARATION}

I hereby declare that I am the sole author of this thesis. This is a true copy of the thesis, including any required final reversion, as accepted by my examiners.

I authorize Ryerson University to lend this thesis to other institutions or individuals for the purpose of scholarly research.

I further authorize Ryerson University to reproduce this thesis by photocopying or by other means, in total or in part, at the request of other institutions or individuals for the purpose of scholarly research.

I understand that my thesis may be made electronically available to the public. 


\begin{abstract}
The effects of different kinds of returns on an integrated chance-constrained stochastic mobile phone closed-loop supply chain configuration and supplier selection
\end{abstract}

\author{
Master of Applied Science, 2019 \\ Shahrzad Ahmadi Kermanshah \\ Mechanical and Industrial Engineering \\ Ryerson University
}

One of the important concerns in the world is E-waste. Ending up e-waste in the landfill and inappropriate disposing of it are hazardous to the environment. The goal of this research is to design and optimize a multi-period, multi-product, multi-echelon, and multi-customer ClosedLoop Supply Chain (CLSC) network for a mobile phone network considering different types of product returns. Commercial, end of life, and end-of-use returns are well-known in practice. In this research, a multi-objective mixed-integer linear programming formulation with stochastic demand and return is proposed to maximize the total profit in the mobile phone CLSC network, alongside maximizing the weights of eligible suppliers which are estimated based on a fuzzy method for efficient supplier selection and order allocation. Chance-constraint programming is applied in order to deal with the stochastic demand and return. Moreover, distance method and $\varepsilon$ constraint technique are employed to solve the proposed multi-objective problem. The application of the proposed mathematical model is illustrated in Toronto, Canada using real maps. 


\section{ACKNOWLEDGEMENTS}

I would like to appreciate Dr. Saman Hassanzadeh Amin, from the department of Mechanical and Industrial Engineering at Ryerson University for helpful suggestions, invaluable advice, comments and constructive criticism throughout all the phases of this thesis. It is recognized that without his guidance, this research would not be accomplished successfully.

I also would like to thank other members of my committee, Dr. Ahmad Ghasempoor, Dr. Mohamad Y. Jaber, Dr. Sharareh Taghipour for their encouragement throughout my master program especially for their professional comments and advice that provided me great help in the preparation of this thesis.

I also would like to thank my friend and colleague, Babak Mohamadpour Tosarkani, for his helps throughout this study.

My sincere gratitude goes to my parents, Haleh Ahmadi and Mahmoud Ahmadi, and specially to my lovely husband Hoofar Daneshvar for their inspiration and encouragement during my study.

Furthermore, I am very thankful to the department of Mechanical and Industrial Engineering at Ryerson University for giving me all the support that I needed to accomplish the Mechanical and Industrial Engineering (MASc). 


\section{Table of Contents}

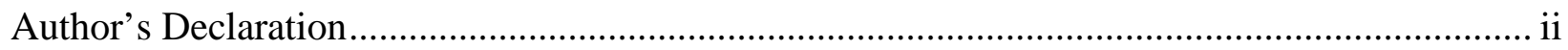

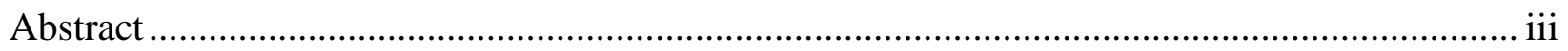

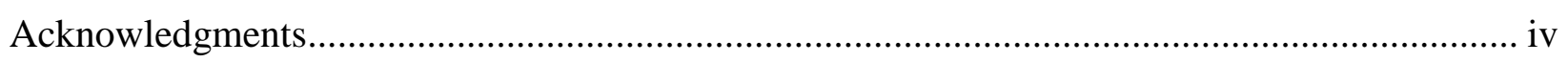

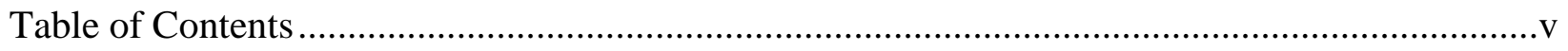

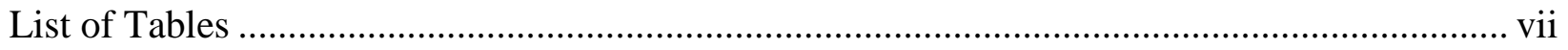

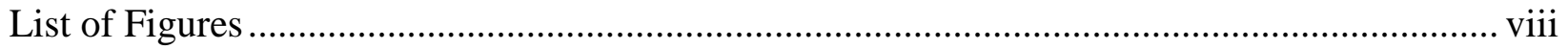

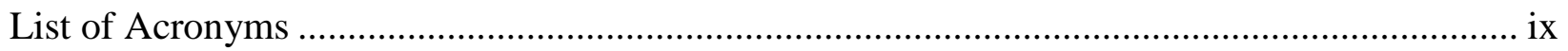

\section{CHAPTER 1. INTRODUCTION}

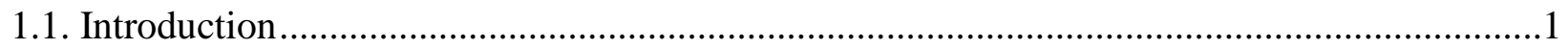

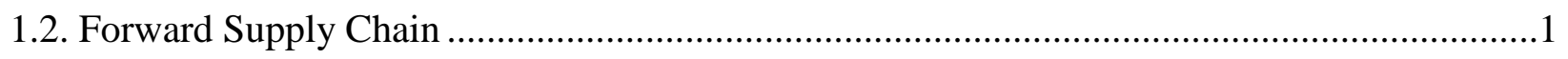

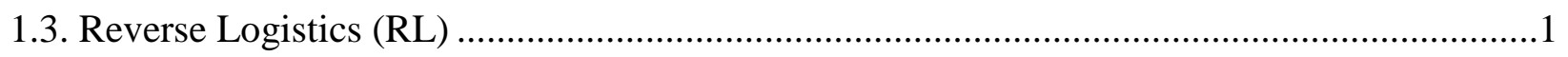

1.4. Importance of Closed-Loop Supply Chain (CLSC)........................................................

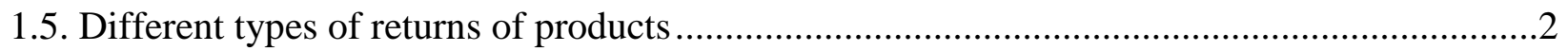

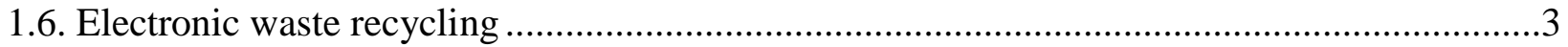

1.6.1. Importance of mobile phone recycling ..............................................................

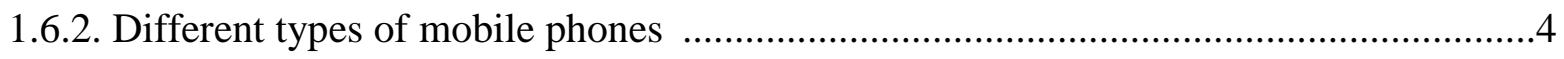

1.6.3. Recyclable materials of mobile phones .............................................................4

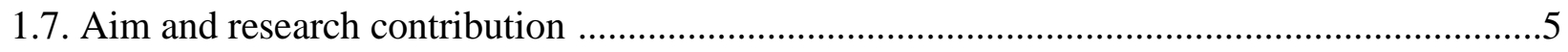

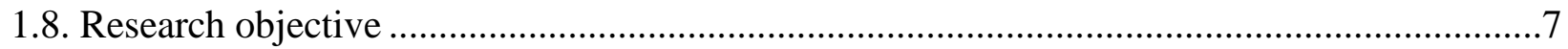

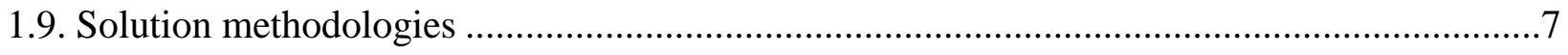

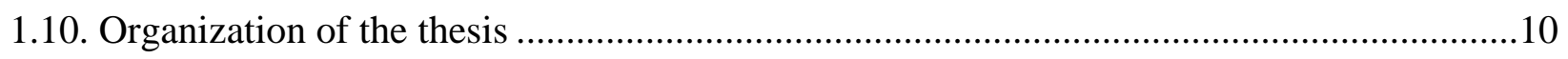

\section{CHAPTER 2. REVIEW OF LITERATURE}

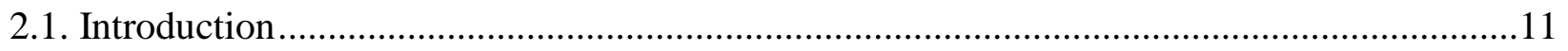

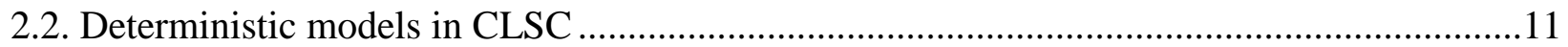

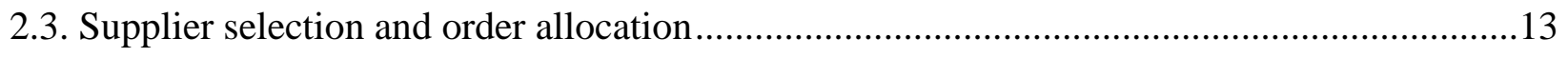

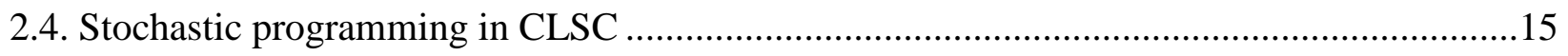

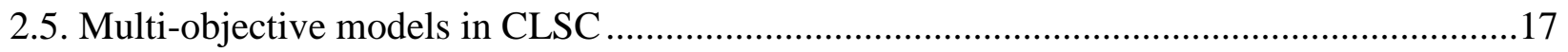




\section{CHAPTER 3. THE EFFECTS OF DIFFERENT KINDS OF RETURNS ON A MOBILE PHONE CLOSED-LOOP SUPPLY CHAIN NETWORK}

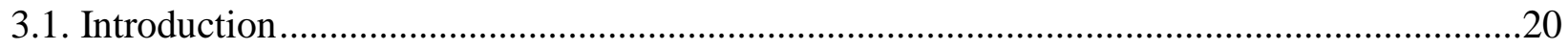

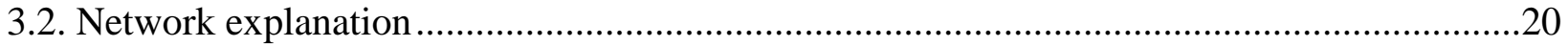

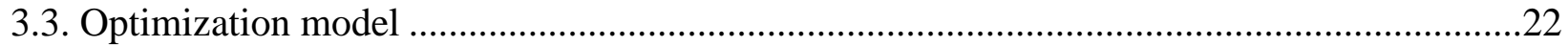

3.4. Application of the proposed model and solution approach .................................................28

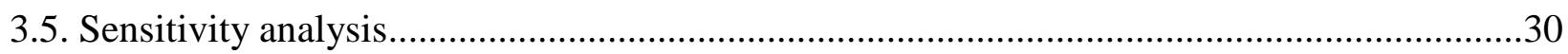

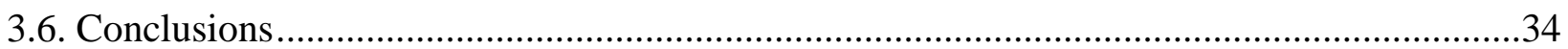

CHAPTER 4. AN INTEGRATED CHANCE-CONSTRAINED STOCHASTIC MODEL FOR A MOBILE PHONE CLOSED-LOOP SUPPLY CHAIN NETWORK WITH SUPPLIER SELECTION

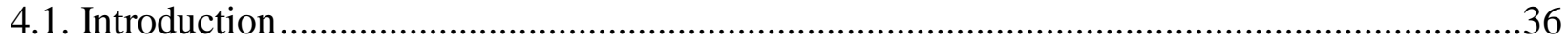

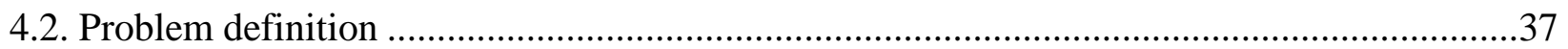

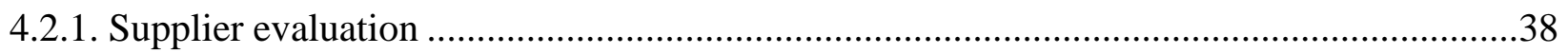

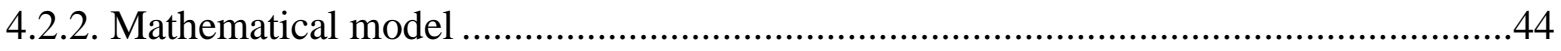

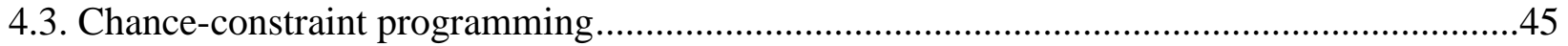

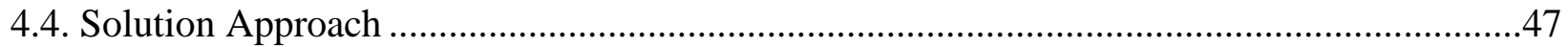

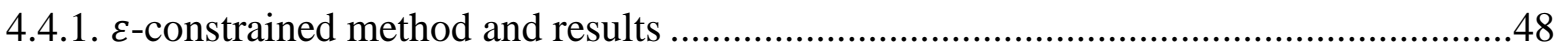

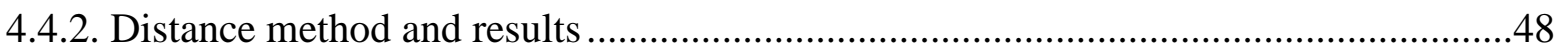

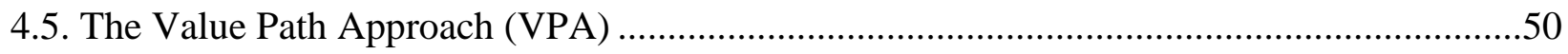

4.6. Sensitivity analysis.......................................................................................................

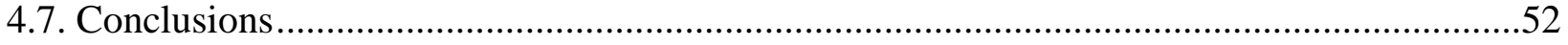

\section{CHAPTER 5. CONCLUSIONS AND FUTURE RESEARCH}

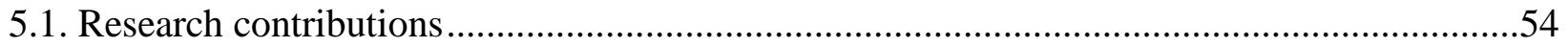

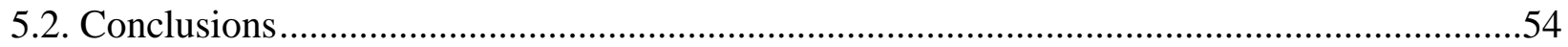

5.3. Future research ………………………………….......................................................5

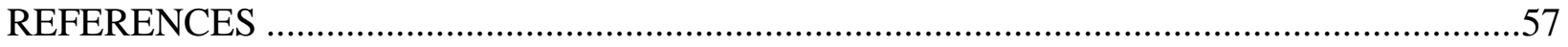




\section{LIST OF TABLES}

\section{CHAPTER 2}

Table 2.1. Review of some papers in CLSC ........................................................................ 18

\section{CHAPTER 3}

Table 3.1. Values of some parameters defined to solve the mathematical model.

Table 3.2. Some values of the model for $i=j=t=1, s=3, m=2, r=12, k=18, l=$ $13, d=6, g=5, x=1$

\section{CHAPTER 4}

Table 4.1. Weights of categories.........................................................................................42

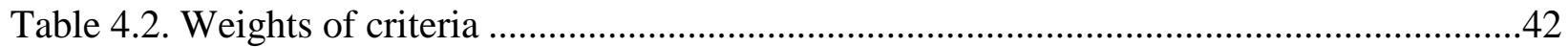

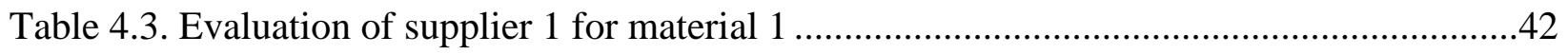

Table 4.4. Final score for supplier 1 according to material 1 ...............................................43

Table 4.5. Weight of supplier $s$ according to material $j$.........................................................43

Table 4.6. Values of some parameters defined to solve the mathematical model ........................47

Table 4.7. Values of objective functions obtained by $\varepsilon$-constraint method.................................48

Table 4.8. Values of objective functions obtained by distance method.....................................49

Table 4.9. Results of Value Path Approach (VPA) ...............................................................50

Table 4.10. Some values of the model for $i=j=t=1, s=3, m=2, r=12, k=18, l=$

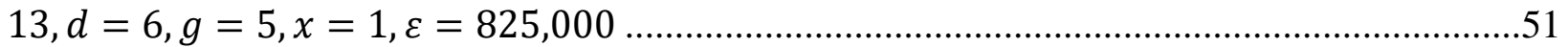




\section{LIST OF FIGURES}

\section{CHAPTER 1}

Fig. 1.1. Service flow in Closed-Loop Supply Chain Management (CLSCM) .............................1

Fig. 1.2. Closed-Loop Supply Chain model for remanufacturing .............................................2

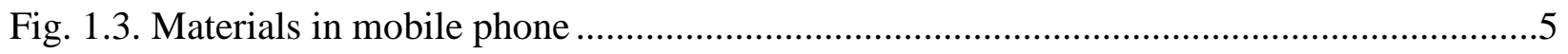

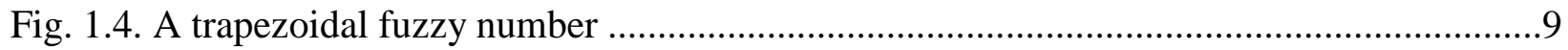

\section{CHAPTER 3}

Fig. 3.1. A closed-loop supply chain of mobile phone including recycling and reselling ............21

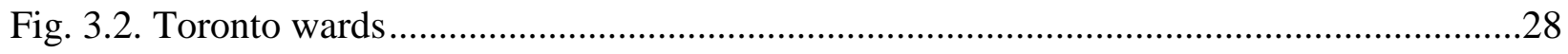

Fig. 3.3. Flow through the CLSC network based on the results ...............................................31

Fig. 3.4. The changes of the profit due to the demand changes...............................................32

Fig. 3.5. Flow through the new CLSC network (a) based on the results .....................................32

Fig. 3.6. Flow through the new CLSC network (b) based on the results.....................................33

Fig. 3.7. Flow through the new CLSC network (c) based on the results ....................................34

\section{CHAPTER 4}

Fig. 4.1. The various steps of the solution approach ...............................................................37

Fig. 4.2. A linguistic scale for providing experience level ........................................................39

Fig. 4.3. Supplier selection framework in mobile phone CLSC network ...................................40

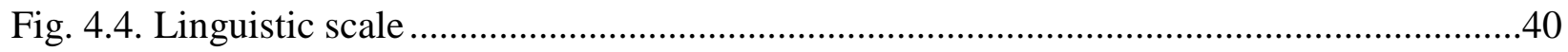

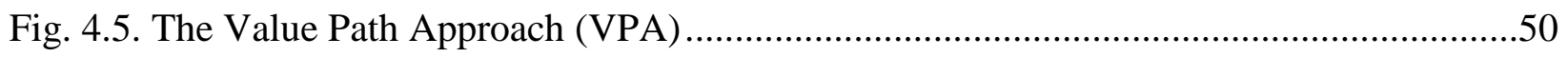

Fig. 4.6. The optimal mobile CLSC network........................................................................51

Fig. 4.7. The changes of the profit due to the change in $\alpha$................................................52 


\section{LIST OF ACRONYMS}

Analytic Hierarchy Process (AHP)

Application Programming Interfaces (APIs)

Chance-Constrained Programming (CCP)

Closed-Loop Supply Chain (CLSC)

Closed-Loop Supply Chain Management (CLSCM)

Data Envelopment Analysis (DEA)

End-Of-Life (EOL)

End-Of-Life Electronics (EOLE)

End-Of-Use (EOU)

Enterprise Resource Planning (ERP)

Fully Fuzzy Programming (FFP)

Fuzzy Weighted Average (FWA)

House of Quality (HOQ)

Multi-Attribute Decision-Making (MADM)

Ontario Electronic Stewardship (OES)

Operating Systems (OS)

Quality Function Deployment (QFD)

Returnable Transport Items (RTIs)

Reverse Logistics (RL)

Trapezoidal fuzzy number (TFN)

Value Path Approach (VPA)

Waste Electrical and Electronic Equipment (WEEE) 


\section{CHAPTER 1}

\subsection{Introduction}

Closed-Loop Supply Chain (CLSC) plays a crucial role in both industrial and environmental aspects. According to Fig.1.1, the CLSC can be explained as the combination of design, examination, and control of a network for maximization of the values of the returned products via recovery options such as recycling (Guide and Wassenhove, 2009). CLSC contains forward supply chain and reverse logistics.

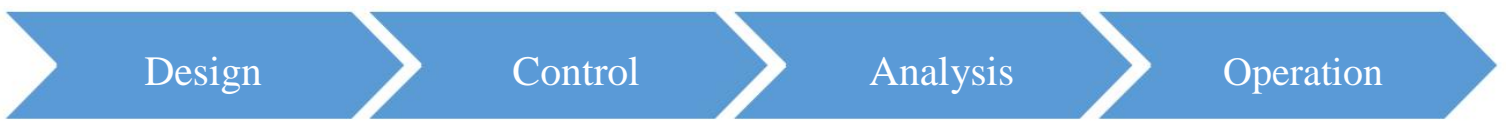

Fig. 1.1. Service flow in Closed-Loop Supply Chain Management (CLSCM)

\subsection{Forward Supply Chain}

The forward supply chain considers supplier, manufacturer, and retailer. The main objective of forward supply chain is to convert raw components to specific products with managerial insight in order to satisfy demand and minimize the total cost (Cooper et al., 1997).

\subsection{Reverse Logistics (RL)}

Reverse Logistics (RL) includes drop-off and recycling centres which are responsible for gathering, recycling, and disposing of the used products. By increasing concerns regarding the environment and green issues, reverse logistics has received many attentions. Reverse logistics consists of the procedure of organizing, enforcing, and controlling the entering flow and repository of secondary products and associated information unlike the classic supply chain orders in order to fulfill the desire of recovering and appropriate disposal (Fleischmann, 2001).

\subsection{Importance of Closed-Loop Supply Chain (CLSC)}

Product waste, especially e-waste, has become a crucial problem worldwide during the last years. Remanufacturing the usable parts of products and recycling unusable components are a solution concerning minimizing waste and benefiting the resources properly to achieve better 
sustainability. Closed-Loop Supply Chain (CLSC) includes a procedure of taking back products from customers to be reused, remanufactured, or recycled. Considering forward and reverse supply chains together results in creation of closed-loop supply chain (Govindan et al., 2015). CLSC management is the design, control, and function of a system to maximize value generation over the whole life cycle of a product with dynamic recovery of value from various types and volumes of returns over the time (Guide et al., 2003). Comprehending the fundamental parameters of CLSC is significant for substitute of traditional operations management by stateof-the-art CLSC procedure. Fig. 1.2 indicates the general scope of CLSC management process.

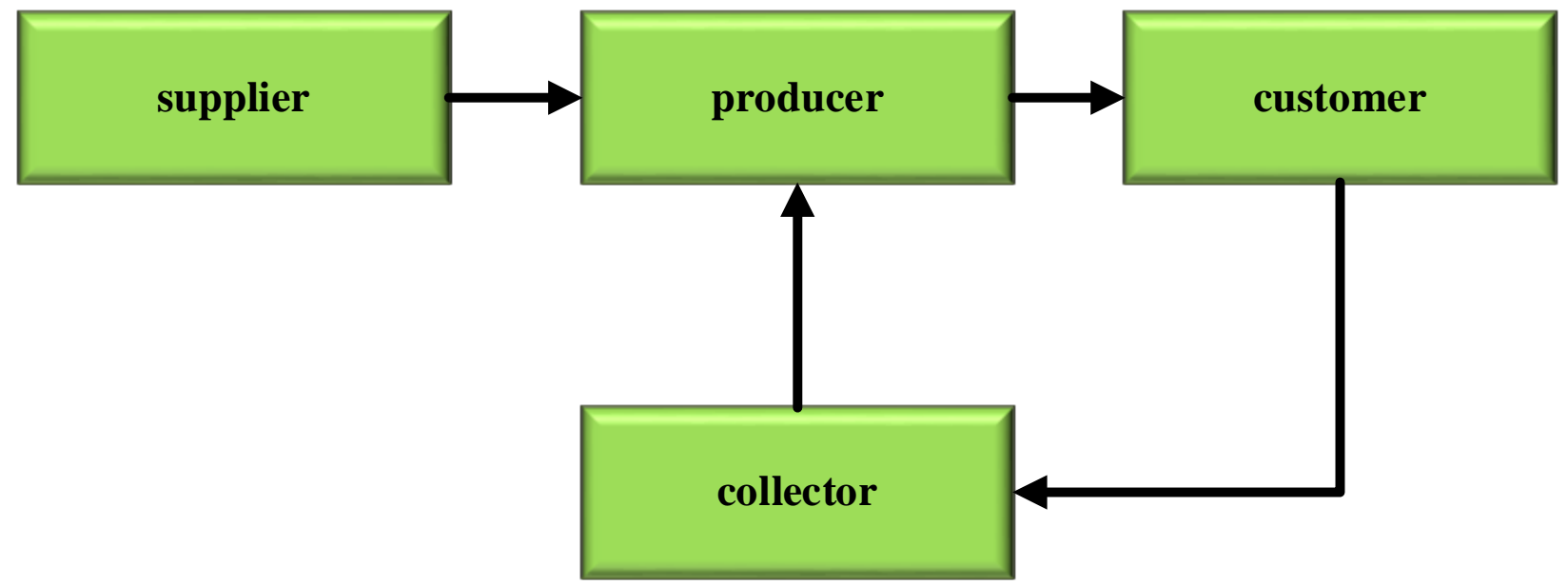

Fig. 1.2. Closed-Loop Supply Chain model for remanufacturing

Remanufacturing of returned products in CLSC makes profit. In Supply Chain Management (SCM), the objective is to maximize the profit or to minimize the cost, while both financial and environmental aspects are considered in CLSC. In this thesis, the objective is to design a mobile phone CLSC in Toronto, Canada. Ontario Electronic Stewardship (OES) is responsible for collecting End-Of-Life Electronics (EOLE) and recycling them. EOL electronics are dropped off at OES authorized collection centres. Provincial data and statistics related to electronic devices can be found in their website.

\subsection{Different types of returns of products}

According to Guide and Wassenhove (2009), various types of returns can be presented. If the product is returned to the retailer by the customer within a specific timeframe such as 30,60 , or 
90 days after purchase, it can be considered as a commercial return. End-Of-Use (EOU) returns are the replacement of a practical product by a technological upgrade. End-of life returns are available when the product becomes technically obsolete or no longer contains any utility for the current user. The mobile phone can be mentioned as an example. In North America, a mobile phone is refundable within 30 days after purchase which is considered as a commercial return. Moreover, $80 \%$ of customers are allowed to upgrade their mobile phones which still works very well, so that their previous mobile phone will be recognized as an end-of-use product return. Furthermore, several mobile phone users abandon their devices because it is technically out-ofdate or all service providers don't support the device anymore, and it becomes an end-of-life return.

The quality of commercial and EOU products is nearly the same as new products so that they can be resold to the second customers. Therefore, second customers will be encouraged to purchase a used product with a lower price as compared to a new product (John et al., 2017; Batarfi et al., 2017). The EOL products are collected by drop-off centres. After sufficient investigations, all reusable materials such as metal, glass, and plastics will be returned to be processed into new products. Unproductive items will be shipped to disposal centres to reduce the environmental pollution.

\subsection{Electronic waste recycling}

According to development of technology and increasing use of electronic products, electronic waste has become one of the most important concerns in the world (Geyer and Blass, 2010). As stated in Statistics Canada (2014), the overall amount of electronic waste generated in Canada in 2014 is estimated about 83,377 tones. Inappropriate discarding electronic devices or ending up in landfills will become hazardous due to dispersing their chemical components into soil and water reservoirs. While by recycling unusable electronics not only they will be kept out of landfills, but also it prevents them being illegally handled or exported by unreliable recyclers. Moreover, important materials that can be returned into the manufacturing supply chain will be recovered. In many countries, severe legislation and different incentives are established to guarantee take back products to reduce waste. For example, in 2003 the Waste Electrical and Electronic Equipment or WEEE directive (Directive 2002/96/EC) turned into a European law, emphasizing 
on collecting, recycling, and remanufacturing of different types of electrical products (Georgiadis and Besiou, 2010).

\subsubsection{Importance of mobile phone recycling}

Mobile phone closed-loop supply chain management is much more essential than other EOL products, since not only it encounters recycling and manufacturing recoverable materials like glass, plastics, and precious metals (Cao et al., 2016), but also hazardous elements like nickel, lead, and mercury are required to be disposed of in order to protect both the health and safety of people and the environment (Oguchi, 2013; Yu and Solvang, 2016). Therefore, designing and planning CLSC networks for mobile phone is important. Most of the components of a mobile phone are recyclable. Particularly, 40\% of Plastics, 15\% of Glasses and Ceramics, and 15\% of Coppers can be recycled (Mobile Phone Partnership Initiative, 2008; Noman and Amin, 2017). According to U.S. Environmental Protection Agency (2017), 35,274 lbs of Copper, 75 lbs of Gold, 772 lbs of Silver, 33 lbs of Palladium are extracted due to recycling each 1 million mobile phones.

\subsubsection{Different types of mobile phones}

Mobile phones can be considered as two general groups: feature phones and smartphones (Noman and Amin, 2017). Fundamental operations of a mobile phone including calling, sending and receiving messages, accessing internet, playing music, camera, etc. are provided by a feature phone. The price of these phones is usually low. However, mobile phones with progressive calculation capacities are smartphones which is performed on mobile Operating Systems (OS). The OS provides complicated Application Programming Interfaces (APIs) so that other applications can be performed perfectly on the mobile phone. Typically, smartphones are known with large screens and touchscreen feature.

\subsubsection{Recyclable materials of mobile phones}

Some key physical components of mobile phones including battery, charger, camera, and display are able to be disassembled and remanufactured easily. However, 500 to 1,000

components used to manufacture a mobile phone are made of various materials (Life Cycle 
Environmental Issues of Mobile Phones, 2005). Different types of metals such as Gold and Silver are utilized in a mobile phone. About $20 \%$ to $35 \%$ of the components of a mobile phone cannot be returned to the manufacturing process when the mobile phone is disassembled and cut into smaller pieces. Various substances used in producing a mobile phone are shown in Fig. 1.3.

\section{RECYCLING RATES OF SMARTPHONE METALS}

COLOUR KEY: <1\% RECYCLE RATE 1-10\% RECYCLE RATE 10-25\% RECYCLE RATE 25-50\% RECYCLE RATE > 50\% RECYCLE RATE NON-METAL (OR RECYCLE RATE UNKNOWN)

\section{SCREEN O-}

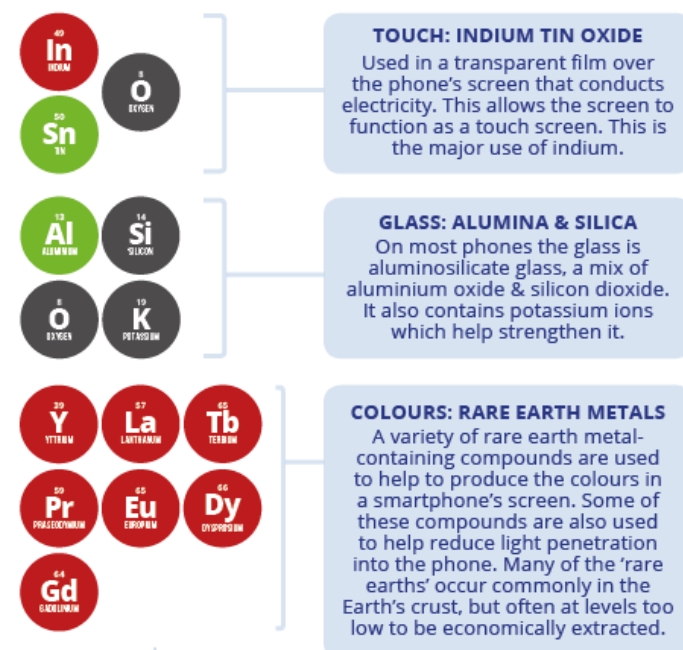

\section{BATTERY}

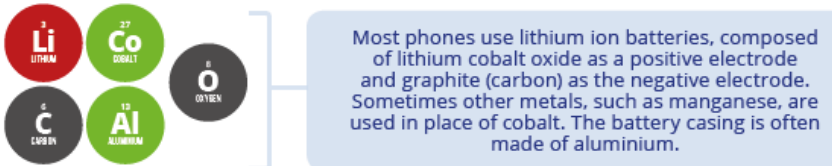

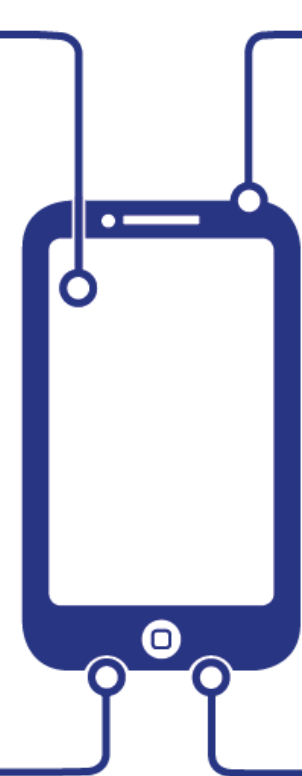

O ELECTRONICS
WIRING \& MICROELECTRONICS

Copper is used for wiring, and for with gold and silver. Tantalum is the major component in microcapacitors.

MICROPHONES \& VIBRATIONS Nickel is used in the microphone and for electrical connections. in magnets in the speaker and microphone, and the vibration unit.

\section{THE SILICON CHIP}

Pure silicon is used to manufacture the chip, which is then oxidised to produce non-conducting regions. the chip to conduct electricity.

CONNECTING ELECTRONICS

Tin \& lead were used in older solders; newer, lead-free solders use a mix of tin, copper \& silver. micro-electrical components alon
Cu A" A
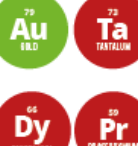

Tib $\mathrm{Nd}$

si 0

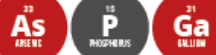

Sin $\mathrm{Pb}$

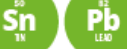

CASING

(c) COMPOUND INTEREST 2015 - WWW.COMPOUNDCHEM.COM | Twitter: @compoundchem | Facebook: www.facebook.com/compoundchem

This graphic is shared under a Creative Commons Attribution-NonCommercial-NoDerivatives licence.

Fig. 1.3. Materials in mobile phone, URL:http://www.compoundchem.com/2015/09/15/recycling-phone-elements/

\subsection{Aim and research contribution}

In this research, different types of product return, as well as various selling prices based on quality, are considered, which has been ignored in many supply chain investigations. Mobile phone industry is an example in which different types of product returns are outstanding. In order to perform supplier selection and order allocation, a method is applied by which both qualitative and quantitative criteria will be ranked. Moreover, a multi-objective mixed-integer linear 
programming formulation is provided to optimize and configure a CLSC network for mobile phone industry considering three types of returned products including commercial, EOU, and EOL, separately and their associated selling prices to make the model more applicable in the real world of mobile phones. Indeed, reselling of repaired and reconditioned products to the second customers is calculated in the model which has been ignored in many studies. The aim of this research is maximizing the total profit in the network alongside minimizing defect rate as well as maximizing the weights of suppliers where the demands of first and second customers and the rate of returned products are assumed to be stochastic. Utilizing chance-constrained programming, the deterministic equivalent of the stochastic constraints are acquired. The mathematical model comprises multiple products, multiple periods, suppliers, manufacturers, retailers, second and first customers, drop-off, consolidation, and disposal centres. Real data are applied to this model according to Statistics Canada in 2011. Using Google maps, the distances between various facilities are obtained. To my knowledge, in this study, supplier selection and order allocation are applied to a mobile phone CLSC network configuration and optimization in Toronto for the first time.

The main research contributions of this study in CLSC field are as follows:

- Development of a mathematical formulation to configure a CLSC network for mobile phone recovery and recycling in a multi-period and multi-product situation with considering different types of returned products in Toronto, Canada.

- Investigating reselling, commercial, and EOU returned products to the second customers with different selling prices.

- Applying chance-constrained programming to deal with stochastic sources in the CLSC network such as demand and rate of returned products.

- Developing a fuzzy method to estimate the quantitative and qualitative weights for supplier selection and order allocation in the proposed model.

- Providing real distances in the proposed multi-echelon model using Google maps. 


\subsection{Research objective}

The objective of this study is to configure a closed-loop supply chain network for mobile phone and to provide some methodologies in order to consider the following issues:

Uncertainty: Various parameters including cost, demand, and return are considered as nondeterministic parameters in several mathematical models. Therefore, some causes of uncertainty are examined.

Multi-objectives: In mobile phone CLSC, not only it is essential to minimize the total cost or maximize the total profit, but also it is necessary to consider green impacts of facilities. Providing a balance between these two objectives has become as a challenge for organizations. Incorporation of supplier selection strategies, not only can profoundly reduce the total cost, but also can yield a tactical key regarding raised carbon footprint issue of the suppliers (Govindan et al., 2014). Consequently, proposing multi-objective models and developing proper solution methodologies become very important.

\subsection{Solution methodologies}

In this section, some outstanding approaches which have been applied in this study are investigated.

Mixed-integer linear programming: Minimizing or maximizing a linear function subject to linear constraints is defined as a mixed-integer linear programming. Variables can be determined as either nonnegative or integer. Binary variables can be mentioned as an example of integer variables which are defined as 0 or 1 (Amin, 2012).

Multi-objective programming: several goals can be examined in multi-objective programming while in mono-objective programming, only one aim can be considered. For example, in closedloop supply chain management, the total profit can be maximized alongside with the minimization of carbon footprint. There is no single solution optimizing each objective for a multi-objective optimization problem. Therefore, there will be conflict among objective functions, and resulting a number of Pareto optimal solutions. Finding an optimal set of Pareto 
solutions, or assessing the trade-offs in satisfying the different objectives, or providing a single solution in order to satisfy the subjective desires of a human decision-maker (DM) can be the goal (Collette and Siarry, 2003).

Stochastic programming: Stochastic programming can be applied in mathematical optimization models in which uncertainty is considered. Minimization of the total expected cost or maximization of the total expected profit of a network are the main objectives of many stochastic models.

Theory of fuzzy: The fuzzy sets theory was originally introduced by Zadeh (1965). The fuzzy sets theory can be considered as a theory of scaled approach, a theory in which everything is based on grade or everything has elasticity (Zimmermann, 2001). Fuzzy sets theory allows the step-by-step evaluation of the membership of factors in a set; this is provided with the aid of a membership function defined in the real unit interval $[0,1]$.

Trapezoidal fuzzy number (TFN) is one of the most known fuzzy numbers. This TFN, also known as membership function, is convex i.e. the level begins at zero, increases to a maximum, and then drops to zero again. A trapezoidal fuzzy number $A=(a, b, c, d)$ is a fuzzy set on $\mathbb{R}$ with the membership function given by

$\mu_{A}(x)=\left\{\begin{array}{lc}\frac{x-a}{b-a} & \text { if } x \in[a, b) \\ 1 & \text { if } x \in[b, c] \\ \frac{d-x}{d-c} & \text { if } x \in(c, d] \\ 0 & \text { otherwise }\end{array}\right.$

where $a \leq b \leq c \leq d$ as shown in Fig. 1.4. 


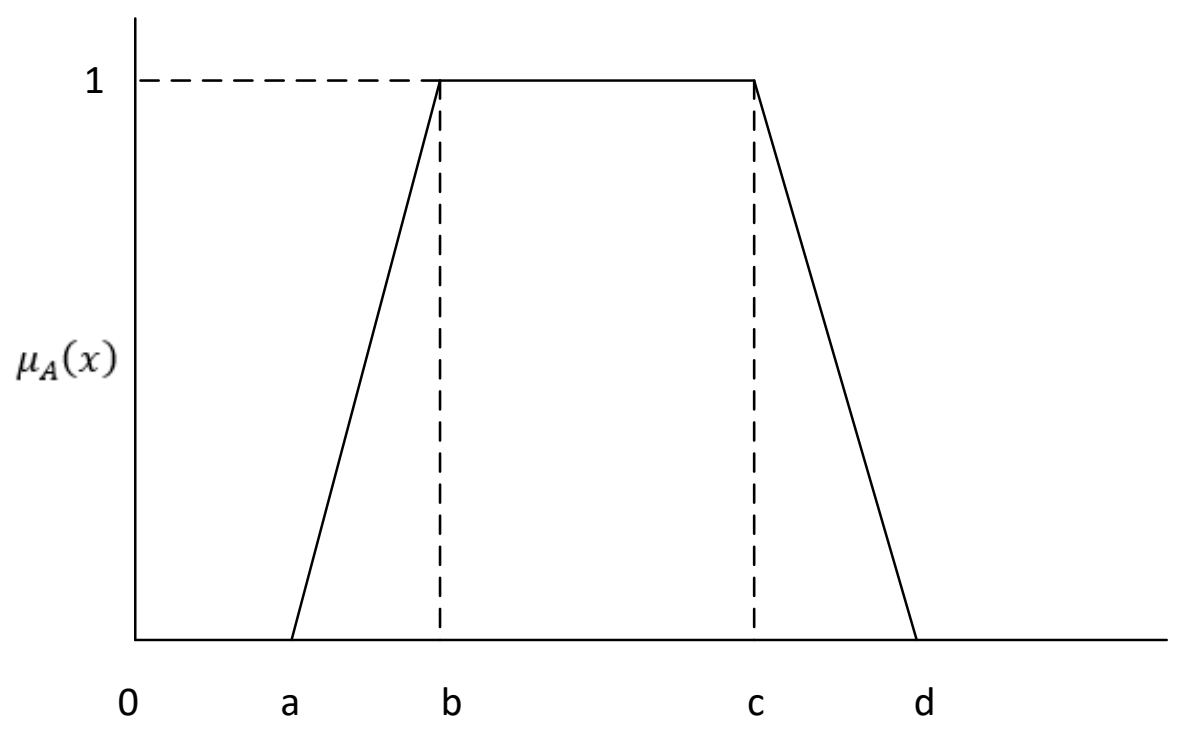

Fig. 1. 4. A trapezoidal fuzzy number

Chance-constrained programming: A lot of methodologies can be taken into account to deal with stochastic parameters in optimization models. One of the methods that has been used in many studies is Chance-Constrained Programming (CCP) proposed by Charnes et al. (1990). Assume a mathematical programming with stochastic parameters as follows:

$\left\{\begin{array}{c}\max f(x) \\ \text { subject to: } \\ g_{j}(x, \xi) \leq 0, j=1,2, \ldots, p\end{array}\right.$

where $x$ and $\xi$ are a decision vector and a stochastic vector, respectively. $f(x)$ is a non-stochastic objective function and $g_{j}(x, \xi)$ is a stochastic constraint. A stochastic decision problem can be also written as follows (Liu, 1999):

$\left\{\begin{array}{c}\max f(x) \\ \text { subject to: } \\ \operatorname{Pr}\left\{\xi \mid g_{j}(x, \xi) \leq 0\right\} \geq \alpha_{j}, j=1,2, \ldots, p\end{array}\right.$

where $\alpha_{j}$ is a predetermined confidence level to the respective stochastic constraint and $\operatorname{Pr}\{$. indicates the probability of the event in $\{$.$\} . The stochastic constraint is required to be converted$ to its deterministic equivalent. 
Supplier selection and order allocation: Supplier selection is defined as A multi-criteria decision problem that has both subjective and objective parameters (Amin and Razmi, 2009). Nowadays, a crucial decision is to select the most appropriate supplier. Several criteria such as durability and being state-of-the-art possess a higher level of importance in CLSC network especially when we are dealing with the mobile phone industry.

\subsection{Organization of the thesis}

This thesis is organized as follows: literature review is provided in Chapter 2. Then in Chapter 3 , a deterministic facility location model for mobile phone closed-loop supply chain network is defined, and its mathematical formulation is presented. Chapter 4 is assigned to extending the model to a stochastic one, then a supplier selection and order allocation methodology is discussed. Moreover, the distance method along with $\varepsilon$-constraint method are introduced to determine solutions for the proposed multi-objective model. Finally, Chapter 5 contains conclusions and future works. 


\section{CHAPTER 2. REVIEW OF LITERATURE}

\subsection{Introduction}

In this chapter, various papers and approaches in the field of RL and CLSC and supplier selection are reviewed. Stochastic programming, supplier selection method, deterministic CLSC networks, MILP, and different types of returns are the main covered parameters. Consequently, studies related to deterministic CLSC configurations are presented in Section 2.2. Next, Section 2.3 is assigned to investigation of some papers including supplier selection and order allocation. The application of stochastic programming in CLSC is provided in Section 2.4. In Section 2.5 multi-objective models in CLSC are discussed.

\subsection{Deterministic models in CLSC}

Plenty of studies in the field of CLSC design and planning can be mentioned, in which different attitudes of network configuration are considered. In most of these studies, a general network is designed, while some CLSC networks are arranged and analyzed for precise products. Kannan et al. (2009) proposed a multi-echelon inventory allocation closed-loop supply chain configuration considering built-to-order situation. They applied genetic algorithm along with particle swarm optimization to their model. Lee et al. (2009) configured a CLSC network without considering any specific product. They utilized a heuristic approach for the proposed mathematical model. They determined the optimum quantities of disassembly and operating centres considering only one supplier in their network. Cho et al. (2017) provided a mixedinteger nonlinear programming formulation to analyze EOL options of computer parts in order to maximize the total profit related to computer remanufacturing considering multiple production periods. They proposed ant colony and genetic search algorithms because the problem was NPhard. Efficiency of time and energy has been analyzed in the CLSC model proposed by Kadambala et al. (2017). They provided a multi-objective programming network to optimize customer surplus and profit, in addition to minimizing applied energy. Xu et al. (2017) provided an innovative comprehensive reverse supply chain. Various uncertainties including waste collection, carbon emission, and exchange rate and transportation cost have been considered in their work. Soleimani and Kannan (2015) developed a new solution methodology to deal with a deterministic, multi-period situation for multiple products. They regarded large-scale examples 
in their analyses to have reliable performance. The new proposed hybrid algorithm has been evaluated using CPLEX and MATLAB.

Very few papers have focused on the mobile phones CLSC network, especially in Canada. It should be mentioned that without considering a specific product, it would be hard to apply the proposed model and transfer it from theory to practice (Soleimani and Kannan, 2015). Optimization methods and simulation were combined by Franke et al. (2006) to make an integrated solution methodology for reproducing mobile phones. An environmental assessment method was executed by Huisman (2004) regarding recycling the mobile phones. Guide et al. (2005) contributed some statistics about a remanufacturing mobile phone company in U.S. Ponce-Cueto et al. (2011) analyzed a reverse logistics system for the mobile phone industry in Spain, and investigated the efficient factors included in this part. Their results illustrate that the issues in the system arise from the low recovery quantity through the legitimate networks, extensive increasing secondary markets because of the potential values of the mobile phones, and irregular logistics and supply chain networks for the returned mobile phones. Velmurugan (2016) investigated a mobile phones remanufacturing considering health and environmental impacts. In the study of Argenta et al. (2017), recovery the parts of mobile phones such as LCD screens was examined. Noman and Amin (2017) investigated various important characteristics of reverse logistics and recycling of mobile phone in Canada emphasizing on British Columbia, Ontario, and Nova Scotia. Jayant et al. (2014) considered an integrated decision analysis method consisting of TOPSIS and AHP to opt the best mobile phone service provider in an RL system. The performance of a reverse logistics firm has been measured by an agent-based modeling technique provided by Pandian (2015). The different agents considered in this network are collector agent, sorting-cum-reuse agent, supplier agent, recycler agent, distributor agent, and remanufacturing agent. These agents act independently, and their individual performances are measured.

Not only it is essential to consider multiple-products to design a CLSC network for its economic efficiency, but also various types of returns and quality levels of the returned products should be regarded. Multi-product scheme has been utilized in many papers (e.g., Salema et al., 2006; Lee and Dong, 2008; Amin and Zhang, 2013; Ramezani et al., 2013; Soleimani and Kannan, 2015; Amin et al., 2017), however a very few studies include the different classes of 
returns and their quality levels (e.g., Dat et al., 2012; Alumur et al., 2012). The important point is that various recovery choices such as recycling, remanufacturing, and repairing should be considered in the design and analysis of a CLSC network (John et al., 2017). Amin and Zhang (2012a) developed a mixed-integer formulation to optimize a general network considering commercial, EOU, and EOL returns. In their paper, it is assumed that commercial returns go to the repair site, whereas EOU and EOL returns are disassembled. John et al. (2017) presented an integer programming mathematical model to design a multi-product and multi-echelon reverse logistics for two electronic products including digital cameras and mobile phones. Different recovery options and the cost of grading in collection centre have been considered in their model. Ignoring multi-period in input parameters are the most important drawbacks of both aforementioned works. In addition, it has been assumed that EOU or commercial returns are directed toward collection centres or repair sites whereas, in reality, EOU and commercial returned mobile phones are returned to the retailers. Besides, EOL products are shipped to the collection and drop-off centres for further inspections.

\subsection{Supplier selection and order allocation}

There are many publications in the field of supplier selection and order allocation. An integrated decision model was provided by Ordoobadi (2010) in which AHP and the Taguchi loss function are utilized. In fact, the weights regarding the importance of tangible and intangible decision criteria are estimated using AHP, while suppliers are ranked by calculating the weighted Taguchi loss scores. An integration of ANP, TOPSIS, and LP was provided by Lin et al. (2011) in order to rank the suppliers for the application of Enterprise Resource Planning (ERP) system. Supplier selection and order allocation along with inventory management were considered by Mendoza and Ventura (2012). Two models were proposed by them. The order quantities were determined using the first model, while this quantity was restricted to be of equal size by the second model. Shirkouhi et al. (2013) proposed a multi-objective linear network according to a fuzzy concept with two phases. The various objectives of the proposed model were minimizing the cost and defect rate as well as emphasizing on omitting lateness of the jobs. Amid et al. (2011) proposed a fuzzy model with the aim of supplier selection in order to achieve the lowest purchasing cost and best service and quality level. The weighted max-min approach is utilized to solve this model while the weights were calculated by AHP. Amin and Zhang (2012b) 
considered three groups of qualitative and quantitative criteria including supplier-relevant, partrelevant, and process-relevant, and developed an integrated mixed-integer programming model for designing a CLSC network as well as supplier selection and order allocation. They utilized fuzzy method in order to assess the suppliers. Shaw et al. (2012) examined a supplier selection fuzzy optimization model. They considered a multi-objective model comprising of minimizing the cost, late delivery performance, rejection rate, and greenhouse effect of goods. A fuzzy multicriteria optimization model for supplier selection and purchasing order allocation according to different economic and environmental criteria in order to minimize the purchasing cost is presented by Kannan et al. (2013). Dweiri et al. (2016) utilized AHP in an automotive industry and applied a decision-making approach in order to select suppliers. Many studies used Quality Function Deployment (QFD) which is defined as a procedure for investigating and analyzing the voice of customers and converting it into the engineering concepts. Bevilacqua et al. (2006) utilized fuzzy QFD for selecting the suppliers without considering order allocation. The research of Amin and Razmi (2009) was conducted in the field of service corporation integrating three levels of supplier selection including supplier selection, assessment, and improvement. QFD was utilized to determine the best internet service provider. A fuzzy methodology was also proposed to take into account the inaccuracy of human assumptions. A novel solution methodology for supplier selection and order allocation was proposed by Scott et al. (2015) in which AHP, QFD, and chance-constraint programming were combined. Yazdani et al. (2017) utilized a QFD model to determine the connections between several criteria and customer requirement based on a relationship matrix. Babbar and Amin (2017) presented a model for supplier selection and order allocation considering both qualitative and quantitative environmental criteria. They proposed a two-stage QFD in order to examine all suppliers comprehensively. One of the most popular methods for supplier selection is Data Envelopment Analysis (DEA). A methodology was presented by Weber et al. (2000) to select proper vendors. They achieved the optimal solutions of a multi-objective supplier selection problem by adjusting the weights of the quantity of suppliers and the weights of objective functions. Then, the results of objective functions related to achieved optimal solutions were considered as inputs of DEA model in order to provide the number of suppliers. As the result, the average of DEA efficiency score was maximized. A hybrid methodology including DEA, decision tree, and neural network was developed by Wu (2009) in which the application of DEA was to categorizing suppliers into efficient and 
inefficient classes. Jafari-Songhori et al. (2011) developed an integration of DEA and multiobjective mixed-integer programming model to perform supplier selection at first, and order allocation alone. Karsak and Dursun (2014) exploited an imprecise DEA for supplier selection, in which the weights of criteria of suppliers are calculated using Fuzzy Weighted Average (FWA) applying the data from the House of Quality (HOQ) and supplier rankings according to supplier evaluation criteria. Kumar et al. (2014) applied Green DEA approach for supplier selection among all suppliers who fulfill the emission standards and poses high environmental efficiency. A multi-objective DEA model based on type-2 fuzzy sets theory was proposed by Zhou et al. (2016) so that the most proper sustainable suppliers were assessed and chosen. Moheb-Alizadeh and Handfield (2017) utilized a bi-objective DEA to assess the efficiency and sustainability of suppliers in a multi-objective mixed-integer non-linear programming network.

\subsection{Stochastic programming in CLSC}

Stochastic programming is utilized in closed-loop supply chain design to deal with sources of uncertainties such as demand, cost, return, etc. Uncertainty in demand is the most important one. Inaccurate prediction of demand or demand volatility is described as demand uncertainty. Hence, considering uncertain demand in both functional and research aspects is important (Davis, 1993; Zhang and Ma, 2009; Peidro et al., 2009). A stochastic closed-loop supply chain network considering uncertain demand and return was proposed by Inderfurth (2005). Moreover, an additional parameter was defined in their model with the aim of measuring the uncertainty in quality. A stochastic model for configuration of a CLSC network consisting of both supply and return channels was provided by Listes (2007). Their solution approach was a decomposition methodology according to branch-and-cut method. Lieckens and Vandaele (2007) developed a mixed-integer nonlinear programming network considering stochastic lead time and queuing theory. However, multi-product scenario is ignored in their work. Paksoy et al. (2011) presented an optimization model in order to evaluate the environmental factors and efficiency in a multiproduct CLSC network. Stochastic programming was applied to examine the trade-off solution in a realistic network. Amin and Zhang (2013) proposed a three-stage model. They applied a new Quality Function Deployment (QFD) model to evaluate various facilities including suppliers, refurbishing sites, etc. In addition, they proposed a closed-loop supply chain network using a stochastic mixed-integer nonlinear programming model. They consider the demand as the 
uncertain parameter. Kenne et al. (2012) introduced a manufacturing/remanufacturing policy within a CLSC network. Their objective was to minimize the total cost of holding and blocking for manufacturing and remanufacturing goods. The optimal control theory was applied to develop the optimality conditions according to stochastic dynamic programming. Kim et al. (2014) developed a two-stage closed-loop supply chain in which manufactured products are shipped from supplier to the buyer using Returnable Transport Items (RTIs) so that empty RTIs are gathered at the buyer point and sent back to the supplier. They assumed that the return time of RTIs is stochastic. Mitra (2012) considered the inventory management issue in closed-loop supply chains and proposed deterministic and stochastic two-echelon models in which demand and return are correlated with respect to generalized cost structures. Their results illustrated that in spite of a reduction in the variability of the demand in case of the higher rate of return and the higher correlation between demand and return, the cost is not essentially saved. However, the costs movement will be dependent on some parameters of the network. Vahdani and Mohammadi (2015) developed a bi-objective optimization model with the objective of decreasing the total cost and waiting time in the line. Their solution approach was a hybrid methodology with respect to stochastic programming and robust optimization to cope with the uncertainty in the model. Francie et al. (2015) proposed a CLSC for a printer cartridge with the application of stochastic programming. Their goal was to minimize the total cost induced by customer waiting and holding inventories according to finished and returned products. Jeihoonian et al. (2016) developed a two-stage stochastic programming model in order to configure a closed-loop supply chain network which is in accordance with modular structured products. In their model, the quality level of the return stream was uncertain. An accelerated Lshaped algorithm is utilized in their work to deal with the stochastic program. Keyvanshokooh et al. (2016) proposed a novel hybrid robust-stochastic programming methodology in which stochastic scenarios were applied for transportation expenses and polyhedral uncertainty sets for demand and return. The proposed model was solved using an accelerated stochastic Benders decomposition algorithm. Feitó-Cespón et al. (2017) combined stochastic and multi-criteria modeling in order to investigate different objectives to consider the uncertainty in a maintainable supply chain network. Uncertainties had the minimum effect on decision-making, and the provided solution was evaluated utilizing a performance indicator. Haddadsisakht and Ryan (2018) developed a three-stage hybrid robust/stochastic program considering the combination of 
probabilistic scenarios for the amount of demands and returns along with the uncertainty sets for the carbon tax rates. They provided the bender cuts according to the novel duality developments for robust linear programming.

\subsection{Multi-objective models in CLSC}

Nowadays according to the importance of environmental issues, in addition to the objectives related to the cost or profit, the objectives of green factors has attained a lot of attentions. Hence, multi-objective and aim programming models and closed-loop supply chain networks are developed. Krikke et al. (2003) considered both the design structure of the logistics network and the design structure of a product, i.e. modularity, reparability, and recyclability in their proposed quantitative model for decision-making support. Linear-energy and waste functions are utilized

to estimate the environmental impacts. Real R and D data of a Japanese consumer electronics company for refrigerators was applied to their closed-loop supply chain network. The three objective functions are minimization of the total costs along with energy consumption and residual waste. Uster et al. (2007) configured a multi-product CLSC network for the purpose of locating the collection centres and remanufacturing sites with respect to coordination of the forward and reverse flows in the system. Their objective was to minimize the operating transportation and fixed expenses of facility locations. Benders decomposition methodology was their approach to solve the model. Pishvaee et al. (2010) proposed a bi-objective mixed-integer programming model. Their goal was to maximize the total cost as well as to maximize the responsiveness of a logistics network. Their solution approach to deal with the bi-objective model was a memetic algorithm. Das and Posinasetti (2015) developed multi-product CLSC network formulating a mathematical model considering the environmental issues. Maximization of the profit along with optimization of consumed energy and harmful emission were their objectives. They utilized goal programming to solve the proposed multi-objective model. Özkır and Başligil (2013) introduced a CLSC network with three objective formulations. They aimed to maximize satisfaction level of trade with regard to maximizing satisfaction degrees of customers and maximizing the total profit of the network. Tosarkani and Amin (2018a) designed a CLSC network for a battery recycling system. They provided a multi-component, multiechelon, multi-product, and multi-period model under imprecise information. An FFP method has been applied for this model. This network was realistic based on real distances and real 
information related to Vancouver, Canada. Besides, by expanding the mathematical model to the multi-objective, green factors regarding manufacturers and battery recovery centres have been considered. Ghassemi et al. (2018) developed an integrated framework including a MultiAttribute Decision-Making (MADM) method and a multi-objective formulation to provide the material flow of parts and products among various facilities in a CLSC network.

Table 2.1 represents the analysis of several papers in the literature. Some keywords such as reverse logistics, mobile phone, different types of return, CLSC, etc. have been used to search papers. www.sciencedirect.com, Taylor and Francis, and Google Scholar have been utilized to find papers.

Table 2.1.

Review of some papers in CLSC

\begin{tabular}{|c|c|c|c|c|c|c|c|c|}
\hline \multirow[b]{2}{*}{ References } & \multirow[b]{2}{*}{ Uncertainty } & \multirow{2}{*}{$\begin{array}{l}\text { Type of } \\
\text { Products }\end{array}$} & \multirow{2}{*}{$\begin{array}{l}\text { Multi- } \\
\text { Period }\end{array}$} & \multicolumn{3}{|c|}{ objectives } & \multirow{2}{*}{$\begin{array}{c}\text { Real } \\
\text { Locations }\end{array}$} & \multirow{2}{*}{$\begin{array}{c}\text { All Types } \\
\text { of Product } \\
\text { Return }\end{array}$} \\
\hline & & & & $\begin{array}{l}\text { Cost/ } \\
\text { profit }\end{array}$ & $\begin{array}{l}\text { Supplier } \\
\text { selection }\end{array}$ & $\begin{array}{l}\text { Green } \\
\text { factors }\end{array}$ & & \\
\hline $\begin{array}{l}\text { Pishvaee and } \\
\text { Razmi (2012) } \\
\end{array}$ & Input data & - & - & $\sqrt{ }$ & - & $\sqrt{ }$ & $\sqrt{ }$ & - \\
\hline $\begin{array}{c}\text { Amin et al. } \\
(2017)\end{array}$ & $\begin{array}{c}\text { Demand, } \\
\text { return }\end{array}$ & Tire & $\sqrt{ }$ & $\sqrt{ }$ & - & - & $\sqrt{ }$ & - \\
\hline $\begin{array}{c}\text { Vahdani and } \\
\text { Mohammadi } \\
(2015)\end{array}$ & $\begin{array}{l}\text { Cost and } \\
\text { capacity }\end{array}$ & - & - & $\sqrt{ }$ & - & - & - & - \\
\hline $\begin{array}{l}\text { Cardoso et al. } \\
(2013)\end{array}$ & Demand & - & $\sqrt{ }$ & $\sqrt{ }$ & - & - & - & - \\
\hline $\begin{array}{l}\text { Soleimani and } \\
\text { Kannan (2015) }\end{array}$ & - & $\begin{array}{l}\text { Hospital } \\
\text { Furniture }\end{array}$ & $\sqrt{ }$ & $\sqrt{ }$ & - & - & - & - \\
\hline Xu et al. (2017) & $\begin{array}{c}\text { Waste } \\
\text { collection } \\
\text { level } \\
\end{array}$ & - & $\sqrt{ }$ & $\sqrt{ }$ & - & - & - & - \\
\hline $\begin{array}{l}\text { Amin and Zhang } \\
\text { (2013) }\end{array}$ & $\begin{array}{l}\text { Decision- } \\
\text { making } \\
\text { process } \\
\end{array}$ & - & $\sqrt{ }$ & $\sqrt{ }$ & $\sqrt{ }$ & - & - & - \\
\hline $\begin{array}{c}\text { Subulan et al. } \\
\text { (2015) }\end{array}$ & - & Tire & $\sqrt{ }$ & $\sqrt{ }$ & - & $\sqrt{ }$ & $\sqrt{ }$ & \\
\hline $\begin{array}{l}\text { Mohajeri and } \\
\text { Fallah (2016) }\end{array}$ & $\begin{array}{c}\text { Recovery rate, } \\
\text { landfilling } \\
\text { rate, demand }\end{array}$ & $\begin{array}{l}\text { Laptop } \\
\text { industry }\end{array}$ & - & $\sqrt{ }$ & - & - & $\sqrt{ }$ & - \\
\hline \multirow[b]{2}{*}{ References } & \multirow[b]{2}{*}{ Uncertainty } & \multirow{2}{*}{$\begin{array}{l}\text { Type of } \\
\text { Products }\end{array}$} & \multirow{2}{*}{$\begin{array}{l}\text { Multi- } \\
\text { Period }\end{array}$} & \multicolumn{3}{|c|}{ objectives } & \multirow{2}{*}{$\begin{array}{c}\text { Real } \\
\text { Locations }\end{array}$} & \multirow{2}{*}{$\begin{array}{c}\text { All Types } \\
\text { of Product } \\
\text { Return }\end{array}$} \\
\hline & & & & $\begin{array}{l}\text { Cost/ } \\
\text { profit }\end{array}$ & $\begin{array}{l}\text { Supplier } \\
\text { selection }\end{array}$ & $\begin{array}{l}\text { Green } \\
\text { factors }\end{array}$ & & \\
\hline $\begin{array}{c}\text { Ramezani et al. } \\
\text { (2014) }\end{array}$ & All parameters & - & $\sqrt{ }$ & $\sqrt{ }$ & - & - & - & - \\
\hline $\begin{array}{l}\text { Jeihoonian et al. } \\
\text { (2017) }\end{array}$ & $\begin{array}{l}\text { Quality of } \\
\text { returned } \\
\text { products }\end{array}$ & - & - & $\sqrt{ }$ & - & - & - & - \\
\hline
\end{tabular}




\begin{tabular}{|c|c|c|c|c|c|c|c|c|}
\hline $\begin{array}{l}\text { Özceylan et al. } \\
\text { (2017) }\end{array}$ & - & $\begin{array}{l}\text { Automotive } \\
\text { Industry }\end{array}$ & $\sqrt{ }$ & $\sqrt{ }$ & - & - & $\sqrt{ }$ & - \\
\hline John et al. (2017) & - & $\begin{array}{c}\text { Mobile Phone } \\
\text { and Camera }\end{array}$ & - & $\sqrt{ }$ & - & - & $\sqrt{ }$ & - \\
\hline $\begin{array}{l}\text { Moghadam } \\
\text { (2015) }\end{array}$ & $\begin{array}{l}\text { Customers' } \\
\text { demand, } \\
\text { suppliers' } \\
\text { capacity, } \\
\text { returned } \\
\text { products }\end{array}$ & - & - & - & $\sqrt{ }$ & - & - & - \\
\hline $\begin{array}{c}\text { Das and } \\
\text { Posinasetti } \\
(2015) \\
\end{array}$ & - & - & - & $\sqrt{ }$ & - & $\sqrt{ }$ & - & - \\
\hline $\begin{array}{l}\text { Garg et al. } \\
\text { (2015) }\end{array}$ & - & - & - & $\sqrt{ }$ & - & $\sqrt{ }$ & $\sqrt{ }$ & - \\
\hline $\begin{array}{c}\text { Zeballos et al. } \\
(2014)\end{array}$ & $\begin{array}{c}\text { Supply and } \\
\text { demand }\end{array}$ & - & $\sqrt{ }$ & $\sqrt{ }$ & - & - & - & - \\
\hline $\begin{array}{l}\text { Dutta et al. } \\
\text { (2016) }\end{array}$ & Demand & - & $\sqrt{ }$ & $\sqrt{ }$ & - & - & - & - \\
\hline $\begin{array}{c}\text { Shakourloo et al. } \\
\text { (2016) }\end{array}$ & - & - & - & $\sqrt{ }$ & $\sqrt{ }$ & - & - & - \\
\hline $\begin{array}{l}\text { Chen et al. } \\
\text { (2017) }\end{array}$ & - & Solar energy & - & $\sqrt{ }$ & - & $\sqrt{ }$ & - & - \\
\hline $\begin{array}{c}\text { Pham and } \\
\text { Yenradee (2017) }\end{array}$ & $\begin{array}{l}\text { Demand, } \\
\text { location- } \\
\text { production } \\
\text { opening cost, } \\
\text { setup cost }\end{array}$ & Toothbrush & $\sqrt{ }$ & $\sqrt{ }$ & - & - & - & - \\
\hline $\begin{array}{l}\text { Ruimin et al. } \\
\text { (2016) }\end{array}$ & $\begin{array}{l}\text { Demand, cost } \\
\text { parameters }\end{array}$ & - & - & $\sqrt{ }$ & - & $\sqrt{ }$ & $\sqrt{ }$ & - \\
\hline $\begin{array}{l}\text { Talaei et al. } \\
\text { (2016) }\end{array}$ & $\begin{array}{c}\text { Demand, } \\
\text { variable cost }\end{array}$ & - & - & $\sqrt{ }$ & - & - & - & - \\
\hline $\begin{array}{l}\text { Feitó-Cespón } \\
\text { et al. (2017) }\end{array}$ & $\begin{array}{l}\text { demand and } \\
\text { waste } \\
\text { generation }\end{array}$ & - & - & $\sqrt{ }$ & - & - & - & - \\
\hline $\begin{array}{l}\text { Moheb-Alizadeh } \\
\text { and Handfield } \\
\text { (2017) }\end{array}$ & Demand & - & $\sqrt{ }$ & $\sqrt{ }$ & $\sqrt{ }$ & - & - & - \\
\hline $\begin{array}{l}\text { Tosarkani and } \\
\text { Amin (2018a) }\end{array}$ & $\begin{array}{l}\text { All parameter } \\
\text { and decision } \\
\text { variables }\end{array}$ & Battery & $\sqrt{ }$ & $\sqrt{ }$ & - & $\sqrt{ }$ & $\sqrt{ }$ & - \\
\hline $\begin{array}{c}\text { Babbar and } \\
\text { Amin (2018) }\end{array}$ & $\begin{array}{c}\text { Demand and } \\
\text { unit costs }\end{array}$ & beverages & $\sqrt{ }$ & $\sqrt{ }$ & $\sqrt{ }$ & $\sqrt{ }$ & - & - \\
\hline My model & & Mobile Phone & $\sqrt{ }$ & & & & $\sqrt{ }$ & $\sqrt{ }$ \\
\hline
\end{tabular}




\section{CHAPTER 3. THE EFFECTS OF DIFFERENT KINDS OF RETURNS ON A MOBILE PHONE CLOSED-LOOP SUPPLY CHAIN NETWORK}

\subsection{Introduction}

In this chapter, a deterministic model for mobile phone industry is provided. A multi-period, multi-product, multi-echelon, and multi-customer Closed-Loop Supply Chain (CLSC) network for a mobile phone network is designed and optimized considering different types of product returns. The aim of this study is to determine the number and location of suppliers, manufacturers, retailers, and drop-off centres as well as the amount of materials and products that are required to be purchased or produced, respectively in order to maximize the total profit of the CLSC network. Different types of returns, as well as various selling prices, are considered in the proposed model.

In the following sections, at first, the mobile phone CLSC network is analyzed in Section 3.2. Then, a mathematical model related to the proposed model is described in Section 3.3. Section 3.4, is assigned to explaining several assumptions about the amount of demand and return and the location of demand markets as well as the solution of the proposed model. Various sensitivity analyses and their related discussions are provided in Section 3.5. Finally, this chapter is summarized in Section 3.6.

\subsection{Network explanation}

Fig. 3.1 shows a closed-loop supply chain network for mobile phone recycling and reselling considering multi-materials and multi-products in multiple periods. The provided network includes suppliers, manufacturers, retailers, first and second customers, drop-off centres, consolidation centres, and disposal centres. Manufacturers purchase the main materials of mobile phone from suppliers and generate four categories of products. Then, the outputs are transported to the retailers. It is required that the retailers satisfy the demands of both first and second customers by storing the least possible aggregating inventory to decrease related costs. 


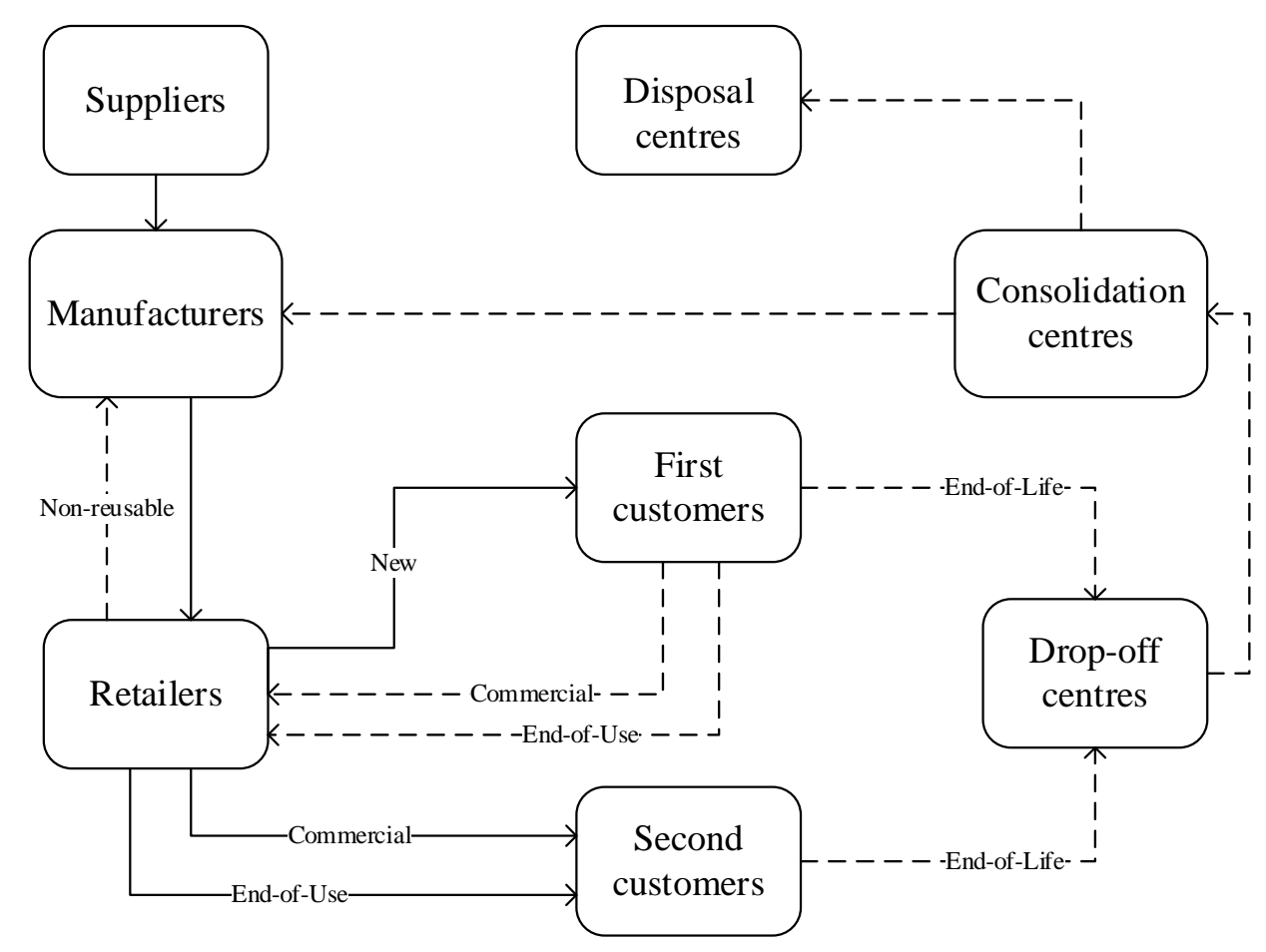

Fig. 3.1. A closed-loop supply chain of mobile phone including recycling and reselling

First customers purchase new mobile phones from retailers. Some of them can be returned to the retailers as commercial or EOU, whereas some others are directed toward drop-off centres (EOL). The mobile phones returned to the retailer are resold to the second customers with a lower price. EOL mobile phones are shipped to consolidation centres from drop-off centres for more investigations and decomposition to the main materials. Some of these materials can be recycled and forwarded to the manufacturers for further consumption, while unusable components are shipped to the disposal centres. In this problem, the manufacturer manages the network. In the other words, the network has been designed for the manufacturer.

In this work, it is emphasized to clarify the following issues: Which suppliers are appropriate for providing materials? Which locations should be selected for manufacturers? Which retailers should be opened? Which drop-off centres must be responsible for collecting EOL products? Which consolidation centres are suitable for decomposing of mobile phones? How many materials should be purchased from selected suppliers? How many products are transported between various facilities? 


\subsection{Optimization model}

A mixed-integer linear programming formulation is provided which deals with the problem of mobile phone CLSC. Different components of the mathematical model are defined in this section.

Sets

\begin{tabular}{|c|c|}
\hline$M$ & set of manufacturers $(1 \ldots m \ldots M)$ \\
\hline$S$ & set of suppliers $(1 \ldots S \ldots S)$ \\
\hline$R$ & set of retailers $(1 \ldots r \ldots R)$ \\
\hline$K$ & set of first customers $(1 \ldots k \ldots K)$ \\
\hline$L$ & set of second customers $(1 \ldots l \ldots L)$ \\
\hline$D$ & set of drop-off centres $(1 \ldots d \ldots D)$ \\
\hline$X$ & 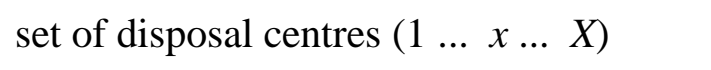 \\
\hline$I$ & 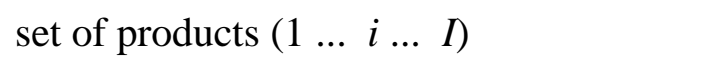 \\
\hline$J$ & set of materials $(1 \ldots j \ldots J)$ \\
\hline$G$ & set of consolidation centres $(1 \ldots g \ldots G)$ \\
\hline$T$ & set of periods $(1 \ldots t \ldots T)$ \\
\hline
\end{tabular}

Parameters

$f a_{m} \quad$ fixed-cost of manufacturer $m$

$f b_{s} \quad$ fixed-cost of supplier $s$

$f c_{r} \quad$ fixed-cost of retailer $r$

$f d_{d} \quad$ fixed-cost of drop-off centre $d$

$f e_{g} \quad$ fixed-cost of consolidation centre $g$

$A c_{\text {kit }}$ demand of product $i$ by first customer $k$ in period $t$

$A s_{\text {lit }} \quad$ demand of product $i$ by second customer $l$ in period $t$

$P_{i}^{n} \quad$ unit price of selling new product $i$

$P_{i}^{u} \quad$ unit price of selling used return product $i$

$P_{i}^{c} \quad$ unit price of selling commercial return product $i$

$k a_{\text {smt }} \quad$ unit transportation cost from supplier $s$ to manufacturer $m$ in period $t$

$k b_{m r t}$ unit transportation cost from manufacturer $m$ to retailer $r$ in period $t$ 


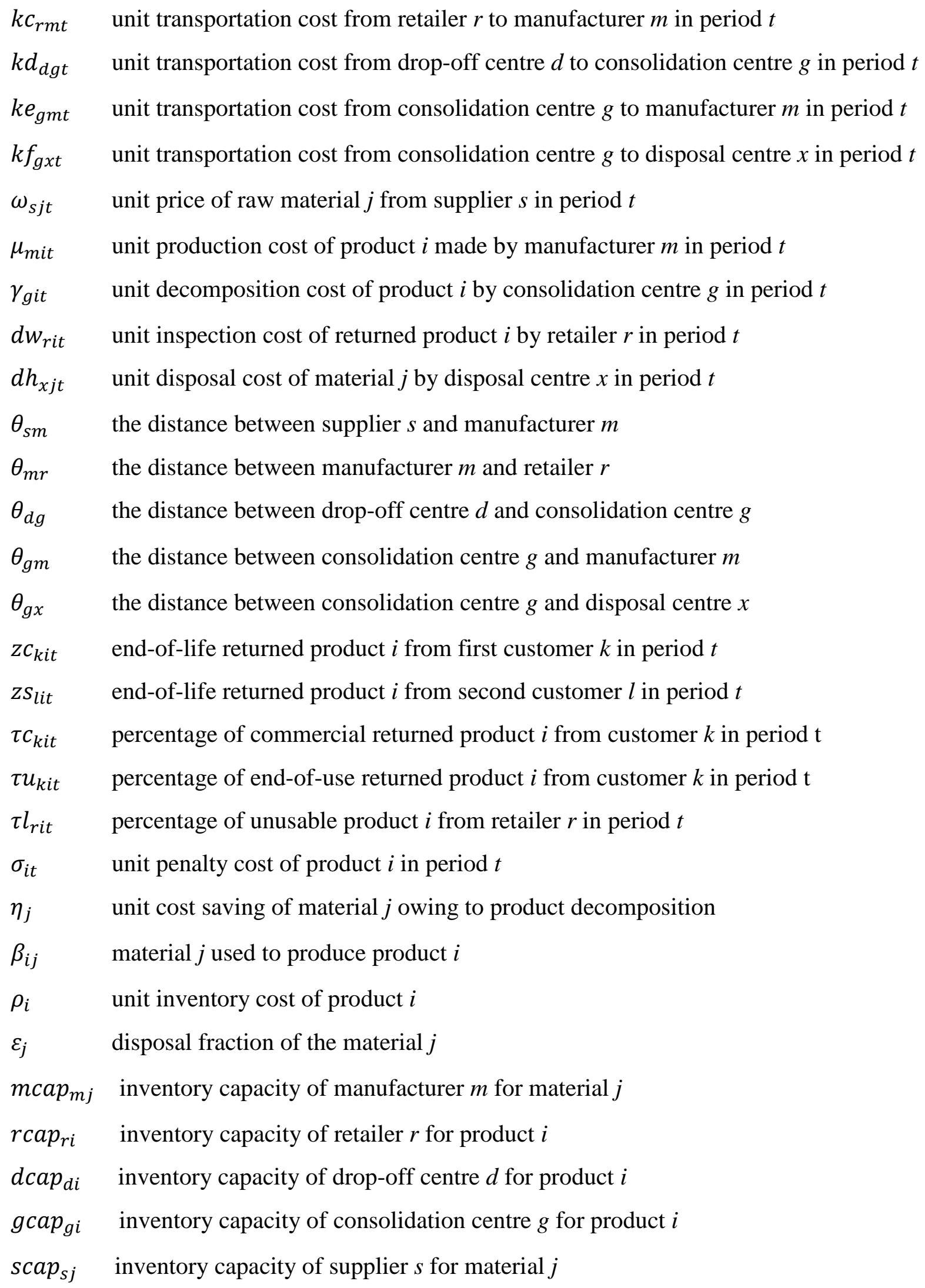




\section{Decision Variables}

$a_{r k i t}^{n} \quad$ quantity of new product $i$ sold by retailer $r$ to first customer $k$ in period $t$

$a_{\text {rlit }}^{u} \quad$ quantity of used product $i$ sold by retailer $r$ to second customer $l$ in period $t$

$a_{\text {rlit }}^{c} \quad$ quantity of commercial return $i$ sold by retailer $r$ to second customer $l$ in period $t$

$q_{\text {smjt }} \quad$ quantity of raw material $j$ shipped from supplier $s$ to manufacturer $m$ in period $t$

$a_{\text {mrit }} \quad$ quantity of product $i$ from manufacturer $m$ to retailer $r$ in period $t$

$b_{\text {krit }}^{c} \quad$ quantity of commercial return product $i$ from first customer $k$ to retailer $r$ in period $t$

$b_{\text {krit }}^{u} \quad$ quantity of used product $i$ from first customer $k$ to retailer $r$ in period $t$

$a_{r m i t}^{l} \quad$ quantity of unusable product $i$ from retailer $r$ to manufacturer $m$ in period $t$

$e f_{\text {kdit }} \quad$ quantity of product $i$ from first customer $k$ to drop-off centre $d$ in period $t$

$e s_{\text {ldit }} \quad$ quantity of product $i$ from second customer $l$ to drop-off centre $d$ in period $t$

$n_{\text {dgit }} \quad$ quantity of product $i$ from drop-off centre $d$ to consolidation centre $g$ in period $t$

$\varphi_{g m j t}$ quantity of raw material $j$ from consolidation centre $g$ to manufacturer $m$ in period $t$

$u_{g x j t}$ quantity of material $j$ from consolidation centre $g$ to disposal centre $x$ in period $t$

$I n_{\text {rit }}$ quantity of new product $i$ holding as the inventory in retailer $r$ in period $t$

$y a_{m} \quad 1$ if manufacturer $m$ is open; 0 otherwise

$y b_{s} \quad 1$ if supplier $s$ is open; 0 otherwise

$y c_{r} \quad 1$ if retailer $r$ is open; 0 otherwise

$y d_{d} \quad 1$ if drop-off centre $d$ is open; 0 otherwise

$y e_{g} \quad 1$ if consolidation centre $g$ is open; 0 otherwise 


$$
\begin{aligned}
\text { Max profit }= & \sum_{r} \sum_{k} \sum_{l} \sum_{i} \sum_{t}\left(P_{i}^{n} a_{r k i t}^{n}+P_{i}^{u} a_{r l i t}^{u}+P_{i}^{c} a_{r l i t}^{c}\right) \\
& -\left[\sum_{m} f a_{m} y a_{m}+\sum_{s} f b_{s} y b_{s}+\sum_{r} f c_{r} y c_{r}+\sum_{d} f d_{d} y d_{d}+\sum_{g} f e_{g} y g_{g}\right. \\
& +\sum_{s} \sum_{m} \sum_{j} \sum_{t}\left(\omega_{s j t}+k a_{s m t} \theta_{s m}\right) q_{s m j t} \\
& +\sum_{m} \sum_{r} \sum_{i} \sum_{t}\left(\mu_{m i t}+k b_{m r t} \theta_{m r}\right) a_{m r i t}+\sum_{r} \sum_{i} \sum_{t} \rho_{i} I n_{r i t} \\
& +\sum_{r} \sum_{m} \sum_{k} \sum_{i} \sum_{t}\left(\left(d w_{r i t}+\sigma_{i t}\right) b_{k r i t}^{c}+d w_{r i t} b_{k r i t}^{u}+\left(d w_{r i t}\right.\right. \\
& \left.\left.+k c_{r m t} \theta_{m r}\right) a_{r m i t}^{l}\right)+\sum_{d} \sum_{g} \sum_{i} \sum_{t}\left(\gamma_{g i t}+k d_{d g t} \theta_{d g}\right) n_{d g i t} \\
& \left.+\sum_{m} \sum_{g} \sum_{x} \sum_{j} \sum_{t}\left(\left(k e_{g m t} \theta_{g m}-\eta_{j}\right) \varphi_{g m j t}+\left(k f_{g x t} \theta_{g x}+d h_{x j t}\right) u_{g x j t}\right)\right]
\end{aligned}
$$

s.t.

$$
\begin{array}{lc}
\sum_{r} \sum_{i} \beta_{i j} a_{m r i t}=\sum_{s} q_{s m j t}+\sum_{g} \varphi_{g m j t}+\sum_{r} \sum_{i} \beta_{i j} a_{r m i t}^{l} & \forall j, m, t \\
\sum_{m} a_{m r i t}+I n_{r(t-1) i}=I n_{r i t}+\sum_{k} a_{r k i t}^{n} & \forall i, r, t \\
\sum_{r} a_{r k i t}^{n} \leq A c_{k i t} & \forall i, k, t \\
\sum_{r} a_{r l i t}^{u}+\sum_{r} a_{r l i t}^{c} \leq A s_{l i t} & \forall i, l, t \\
\sum_{m} a_{m r i t}+I n_{r i t} \geq \sum_{k} a_{r k i t}^{n} & \forall i, r, t \\
\sum_{r} a_{r k i t}^{n} \geq \sum_{d} e f_{k d i t} & \forall i, k, t \\
\sum_{r} a_{r l i t}^{u}+\sum_{r} a_{r l i t}^{c} \geq \sum_{d} e s_{l d i t} & \forall i, l, t
\end{array}
$$




$$
\begin{aligned}
& \sum_{k} e f_{\text {kdit }}+\sum_{l} e s_{\text {ldit }}=\sum_{g} n_{\text {dgit }} \quad \forall i, d, t \\
& \sum_{d} \beta_{i j} n_{\text {dgit }}=\sum_{m} \varphi_{g m j t}+\sum_{x} u_{g x j t} \quad \forall i, j, g, t \\
& \sum_{d} e f_{k d i t}=z c_{k i t} \quad \forall i, k, t \\
& \sum_{d} e s_{\text {ldit }}=z s_{\text {lit }} \quad \forall i, l, t \\
& \sum_{r} b_{k r i t}^{c}=\tau c_{k i t} \sum_{r} a_{r k i t}^{n} \quad \forall i, k, t \\
& \sum_{r} b_{k r i t}^{u}=\tau u_{k i t} \sum_{r} a_{r k i t}^{n} \quad \forall i, k, t \\
& \sum_{m} a_{r m i t}^{l}=\tau l_{r i t} b_{k r i t}^{u} \quad \forall i, k, r, t \\
& \varepsilon_{j} \sum_{d} \sum_{i} \beta_{i j} n_{\text {dgit }} \leq \sum_{m} \varphi_{\text {gmjt }} \quad \forall j, g, t \\
& \sum_{s} \sum_{j} q_{s m j t}+\sum_{g} \sum_{j} \varphi_{g m j t}+\sum_{r} \sum_{i} \sum_{j} \beta_{i j} a_{r m i t}^{l} \leq y a_{m} \sum_{j} \operatorname{mcap}_{m j} \quad \forall m, t \\
& \sum_{m} \sum_{i} a_{m r i t}+\sum_{i} I n_{r i t}+\sum_{k} \sum_{i} b_{k r i t}^{c}+\sum_{k} \sum_{i} b_{k r i t}^{u} \leq y c_{r} \sum_{i} \operatorname{rcap}_{r i} \quad \forall r, t \\
& \sum_{k} \sum_{i} e f_{\text {kdit }}+\sum_{l} \sum_{i} e s_{\text {ldit }} \leq y d_{d} \sum_{i} d c a p_{d i} \quad \forall d, t \\
& \sum_{d} \sum_{i} n_{\text {dgit }} \leq y e_{g} \sum_{i} \text { gcap }_{g i} \quad \forall g, t \\
& \sum_{m} \sum_{j} q_{s m j t} \leq y b_{s} \sum_{j} s c a p_{s j} \quad \forall s, t \\
& y a_{m}, y b_{s}, y c_{r}, y d_{d}, y e_{g} \in\{0,1\} \quad \forall m, s, r, d, g \\
& a_{r k i t}^{n}, a_{r l i t}^{u}, a_{r l i t}^{c}, q_{s m j t}, a_{m r i t}, b_{k r i t}^{c}, b_{k r i t}^{u} \text {, } \\
& a_{r m i t}^{l}, e_{(k+l) d i t}, n_{d g i t}, \varphi_{g m j t}, u_{g x j t}, I n_{r i t} \geq 0 \quad \forall i, j, s, m, r, k, l, d, g, x, t
\end{aligned}
$$

The objective function is designed to maximize the entire profit in the mobile phone CLSC network. The first section is about the net income provided by selling products including selling 
new products in addition to commercial and used returned products. The second part is deducted from the total fixed-costs regarding the locations of the suppliers, manufacturers, retailers, dropoff centres, and consolidation centres. The third portion describes purchasing and transporting expenditures of materials from suppliers to the manufacturers. Production and shipping costs among manufacturers and retailers are implied in the fourth portion. The expenses associated with the retailers include inventory cost, inspection cost of the returned products by the first customers, shipping cost of un-reusable goods to the manufacturers, and penalty cost, $\sigma_{i t}$. The commercial returned products are resold to the second customers with a lower price from that of a new product. This difference is considered as a penalty cost for retailers. In fact, $\sigma_{i t}=p_{i}^{n}-$ $p_{i}^{c}$. The expenses of transporting EOL products from drop-off centres to the consolidation centres as well as decomposition cost by the consolidation centres are considered in the next part of the objective function. It is assumed that after decomposition of EOL products to the principal materials, the usable materials will be shipped to the manufacturer to be consumed in the future products. Therefore, a revenue can be defined, $\eta_{j}$, which is the cost saving owing to the product decomposition. Finally, the costs related to shipping unrecoverable materials from consolidation centres to the disposal centres, and the disposal cost are stated in the objective function.

The first constraint implies that the materials consumed to produce a product should be equal to the total materials purchased from suppliers and materials came from consolidation centres along with materials provided by unusable returned products from retailers. Constraint (3.2) shows that the quantity of the products sent from manufacturers to the retailers $\left(a_{m r i t}\right)$ and inventory in period $t$ are identical to the inventory in period $(t-1)$ and the amount of products sold by retailers to the first customer $\left(a_{r k i t}^{n}\right)$. Constraints (3.3) and (3.4) satisfy the demands related to customers (first and second customers). Constraint (3.5) illustrates that the number of products transported from the manufacturers to the retailers plus the current inventory should exceed the number of products sold to the first customers. Constraints (3.6) and (3.7) signify the trade-off between the products sold to the first and second customers and the returned products. Constraint (3.8) is the network constraint. Constraint (3.9) specifies the balance between the materials of the returned products and the recovered materials directed to manufacturers in addition to unrecoverable materials shipped to the disposal centres. Returned products are defined in Constraints (3.10), $(3,11),(3,12),(3,13)$, and $(3,14)$. Constraint $(3.15)$ implies the disposal part of the returned products. Constraints (3.16), (3.17), (3.18), (3.19), (3.20) are related 
to the capacities of the manufacturers, retailers, drop-off centres, consolidation centres, and suppliers, respectively. Eventually, Constraints (3.21) and (3.22) describe non-negative and binary variables.

\subsection{Application of the proposed model and solution approach}

The optimization model is applied to configure a mobile phone CLSC network in Toronto, Canada. Toronto is divided into 44 wards which have been illustrated in Fig. 3.2. In this study, each ward is considered as a potential first customer. It is supposed that there are 22 second demand markets. Furthermore, it is assumed that there exist 4 potential manufacturer locations, 5 suppliers, 15 locations for retailers, 7 locations for drop-off centres, 5 locations for consolidation centres, and 3 potential sites for disposal centres. Moreover, 4 types of mobile phones and 6 types of materials are considered in the model. The distances among various facilities are estimated using Google Maps.

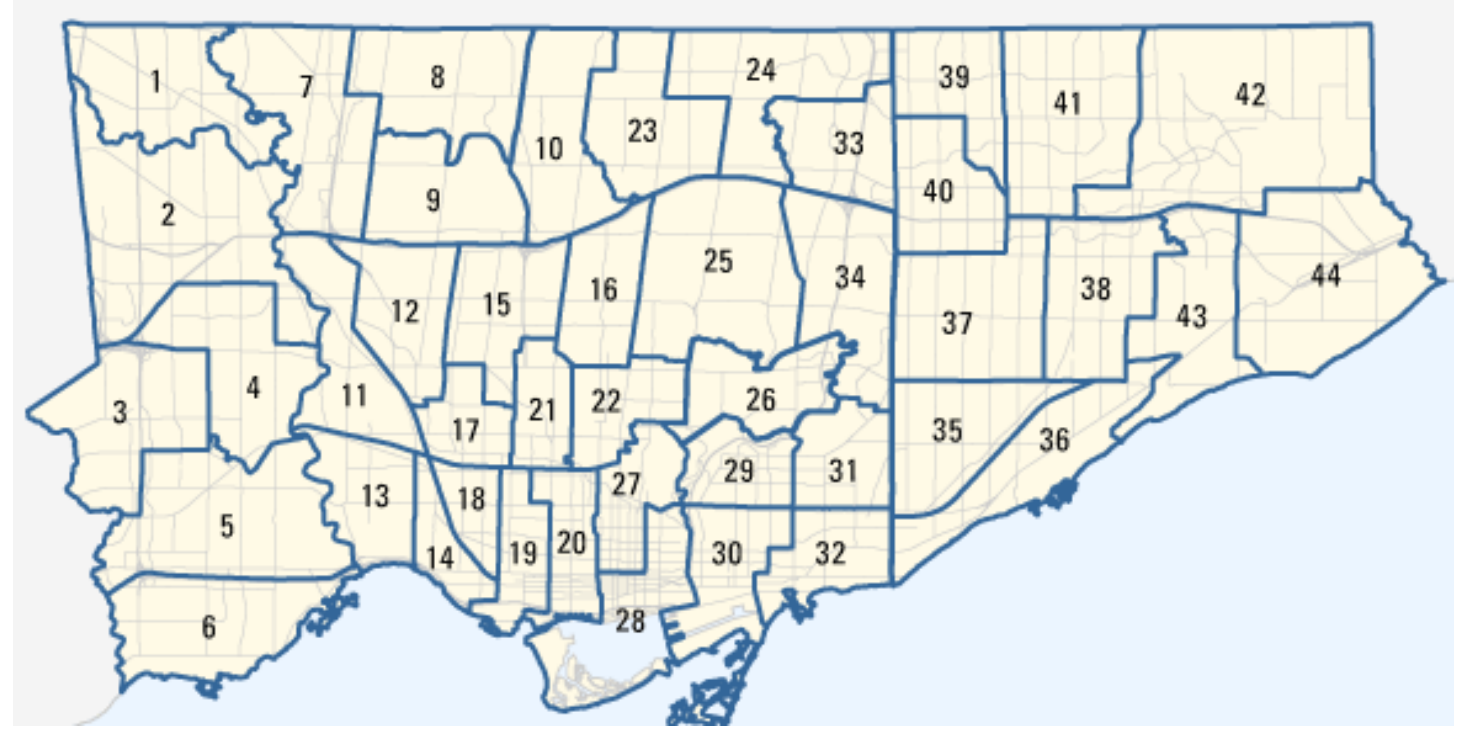

Fig. 3.2. Toronto wards

The demand of the first and second customers for product $i\left(A c_{k i t}\right.$ and $\left.A s_{\text {lit }}\right)$ are assumed to be 0.01 and 0.005 of the population of each ward, respectively. Toronto wards population is considered based on 2011 census of Canada. It is assumed that the returns of both markets, $k$ and 
$l$ for product $i$ in period $t$ is ten percent of each market demand. Other parameters are assigned based on Table 3.1.

Table 3.1.

Values of some parameters defined to solve the mathematical model

\begin{tabular}{lll}
\hline$M=4$ & $f a_{m}=100,000,000$ & $\sigma_{i t}=20$ \\
$S=5$ & $f b_{s}=100,000$ & mcap $_{m j}=500,000$ \\
$R=15$ & $f c_{r}=f d_{d}=f e_{g}=150,000$ & rcap $_{r i}=14,000$ \\
$K=44$ & $P_{i}^{n}=100$ & ccap $_{d i}=10,000$ \\
$L=22$ & $P_{i}^{n}=100$ & gcap $_{g i}=10,000$ \\
$D=7$ & $P_{i}^{u}=50$ & $\operatorname{scap}_{s j}=150,000$ \\
$I=4$ & $P_{i}^{c}=80$ & $\eta_{j}=10$ \\
$J=6$ & $k a_{s m t}=k e_{g m t}=k f_{g x t}=0.002$ & $\varepsilon_{j}=0.1$ \\
$G=5$ & $k b_{m r t}=k c_{r m t}=k d_{d g t}=0.005$ & $\rho_{i}=35$ \\
$T=2$ & $\mu_{m i t}=15$ & \\
\hline
\end{tabular}

The mathematical model is solved using IBM ILOG CPLEX 12.7.1.0. The computation time is 11.36 seconds. There exist 10,294 constraints, 34,076 single variables, 41 binary variables, and 165,266 non-zero coefficients. The model output is summarized in Table 3.2. The optimal mobile phone CLSC network for Product 1 is depicted in Fig. 3.3. It is shown in Fig. 3.3 that Suppliers 3 and 4 are selected to provide raw materials for open Manufacturers 2 and 3. These chosen manufacturers ship new mobile phones to Retailers 1, 2, 3, 4, 6, 12, 13, 14, 15. Not only the first and second customers deliver used mobile phones to Drop-off centre 6, but also this open drop-off centre sends reusable materials to the selected manufacturers. However, the unusable components will be shipped to Consolidation centre 5 by Drop-off centre 6 .

Table 3.2.

Some values of the model for $i=j=t=1$

\begin{tabular}{lll}
$s=3, m=2, r=12, k=18, l=13, d=6, g=5, x=1$ \\
\hline Single Variables & Value & Binary Variables \\
\hline Objective & $24,236,760.294$ & Suppliers: 3,4 \\
$a_{r k i t}^{n}$ & $1,241.125$ & Manufacturers: 2, 3 \\
$a_{\text {rlit }}^{c}$ & 231.5 & Retailers: $1,2,3,4,6,12,13$, \\
\hline
\end{tabular}




\begin{tabular}{lll}
\hline$a_{r \text { rit }}^{u}$ & 222.3 & Drop-off centres: 6 \\
$q_{\text {smjt }}$ & $59,886.66$ & Consolidation centres: 5 \\
$a_{\text {mrit }}$ & $22,647.183$ & \\
$b_{k r i t}^{c}$ & 744.675 & \\
$b_{k r i t}^{u}$ & 992.9 & \\
$a_{r m i t}^{l}$ & 151.52 & \\
$e f_{\text {kdit }}^{u}$ & 284.35 & \\
$e s_{\text {ldit }}$ & 249.1 & \\
$\varphi_{\text {gmjt }}$ & $6,565.54$ & \\
$u_{\text {gxjt }}$ & $9,848.31$ & \\
\hline
\end{tabular}

\subsection{Sensitivity analysis}

To evaluate the sensitivity of the mathematical model, one of the most vital parameters, customer's demand ( $A c_{k i t}$ and $A s_{l i t}$ ), is changed, and the results are analysed. The effect of $20 \%$ increase in the demand for Product 1 (to avoid complexity) of the first and second customers in the first ward (Etobicoke North) is investigated. The changes in the profit according to the changes in the demand are illustrated in Fig. 3.4. It is clear that as the demand increases, the profit raises. Furthermore, by increasing the demand, the chosen retailers are 1, 2, 3, 4, 5, 6, 10, $11,12,13,14$, and 15 . More open retailers are required in order to satisfy the demand. 


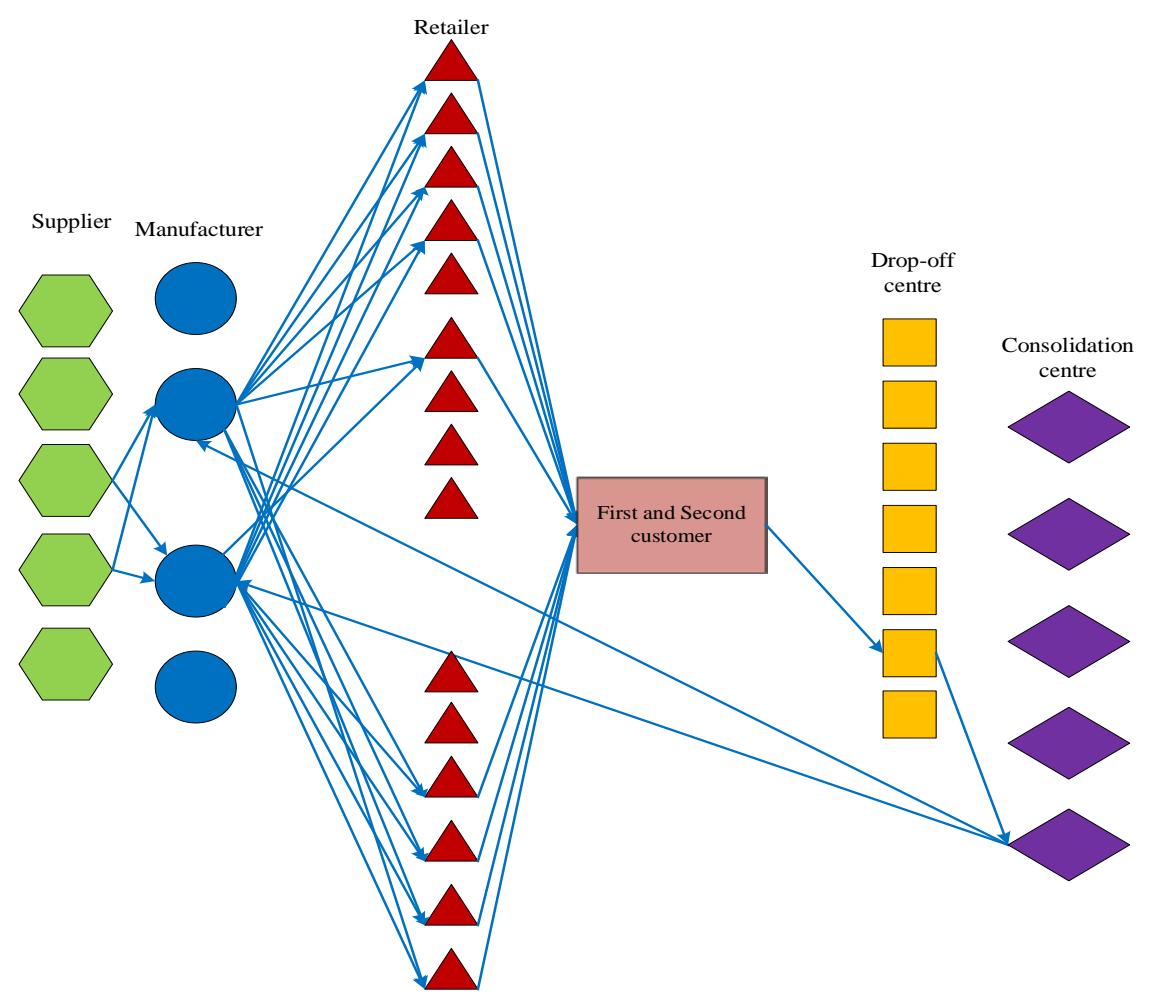

Fig. 3.3. Flow through the CLSC network based on the results

Also, the effect of $20 \%$ increase in the returned product from first and second customers in Ward 1 (Etobicoke North) to the drop-off centres is examined. Previously, Drop-off centre 6 was preferred because the location of this drop-off centre is in the area with the highest rate of product return (Willowdale). Nevertheless, by increasing the returned product, the selected dropoff centres are 2 and 6 since Drop-off centre 2 is near Ward 1 in which the returned product rate is increased.

Fig. 3.5 illustrates the new mobile phone CLSC network as the result of the increase in the demand and the returned product, simultaneously. According to Fig. 3.5, it can be seen that by the increase in the demand and rate of returned product, the selected suppliers and manufacturers remain same. However, comparing to Fig. 3.3, three more retailers are chosen to satisfy the increase in demand, and one more drop-off centre is open because of the increase in the rate of the returned product. 


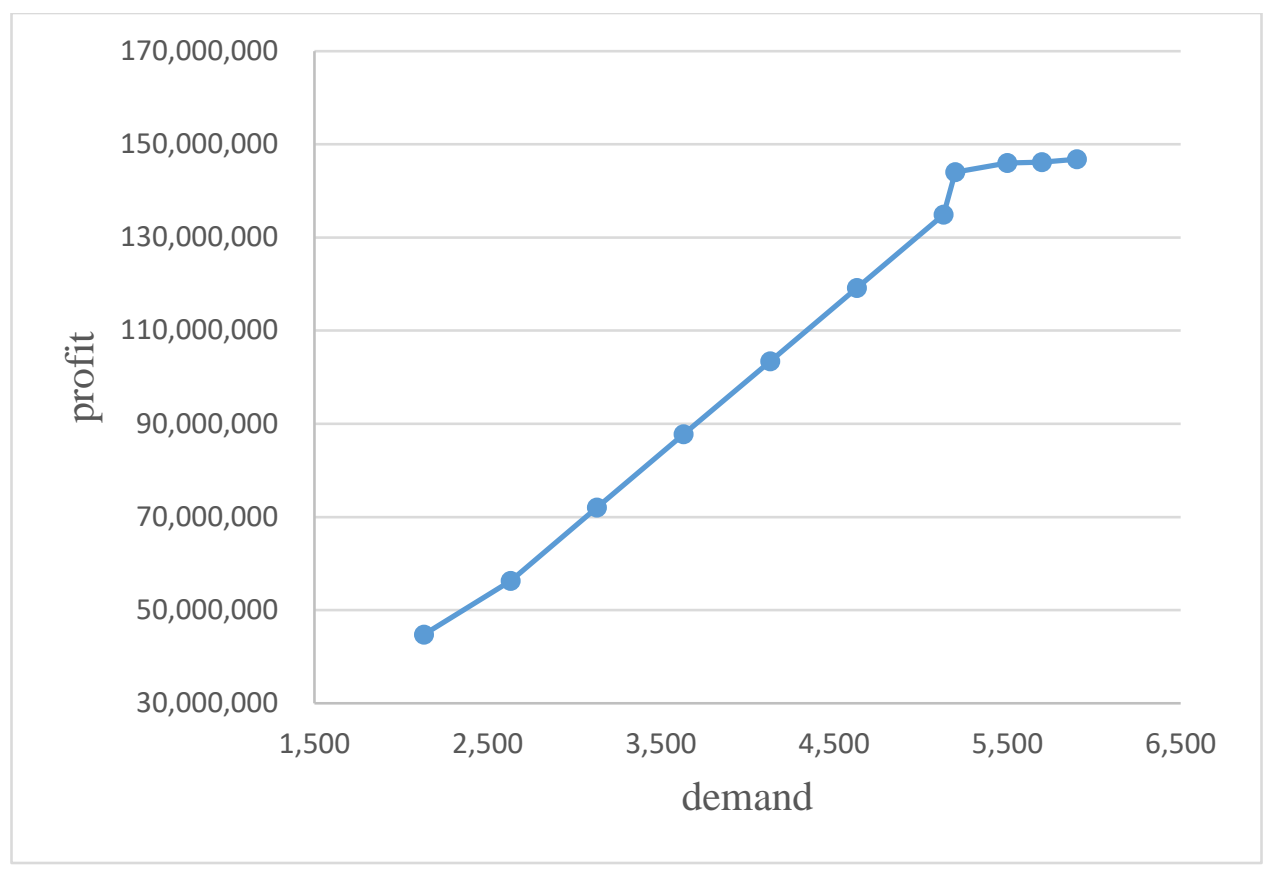

Fig. 3.4. The changes of the profit due to the demand changes

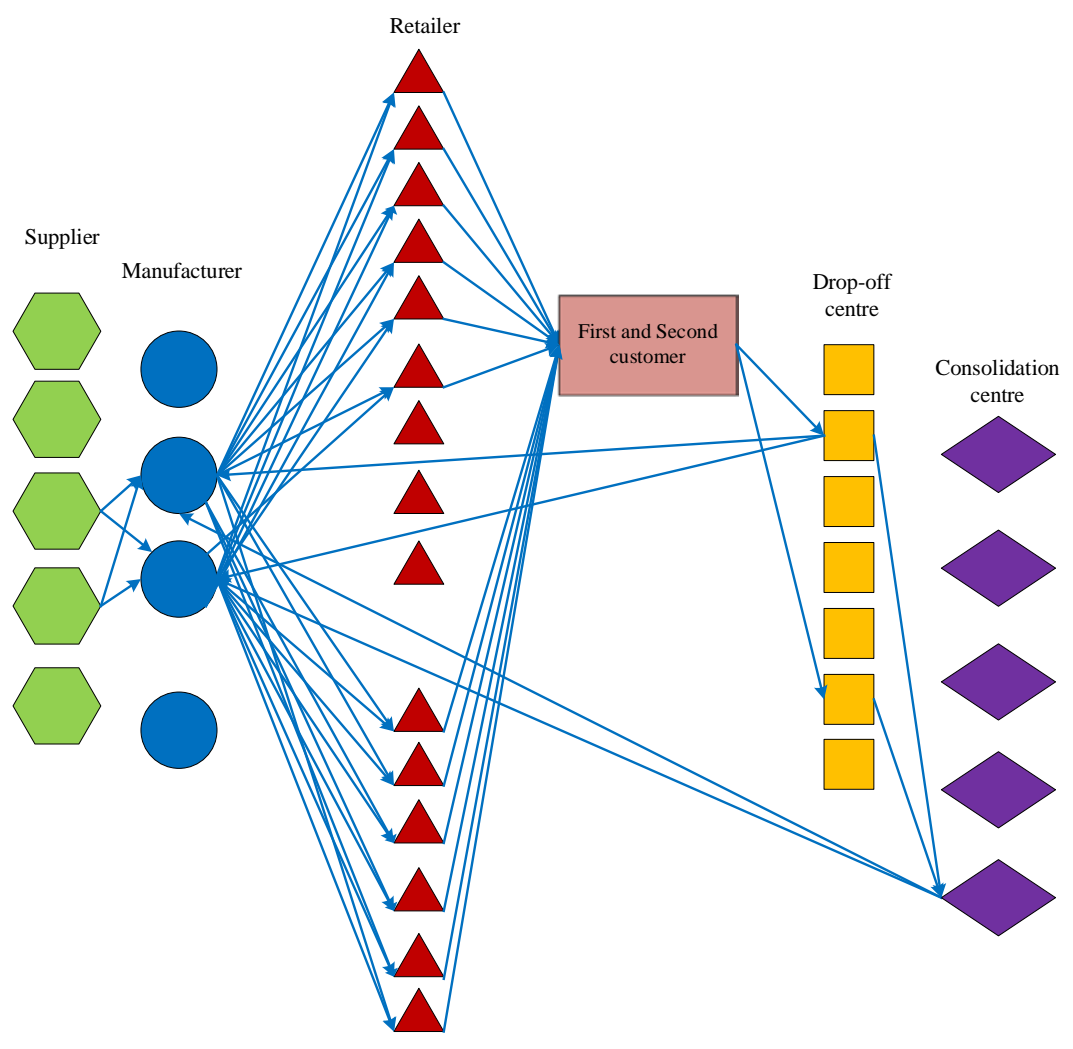

Fig. 3.5. Flow through the new CLSC network (a) based on the results 
Afterward, the effect of an increase in the fixed-cost related to the Consolidation centre 5 is examined. The result of this increase is depicted in Fig. 3.6. According to Fig. 3.3 and Fig. 3.5, Drop-off centre 6 and Consolidation centre 5 are selected. However, as the result of $10 \%$ increase in the fixed-cost of Consolidation centre 5, although the previous suppliers, manufacturers, and retailers are selected, Consolidation centre 2 is chosen instead of Consolidation centre 5. Consequently, Drop-off centre 6 is replaced by Drop-off centre 4, since the distance between Drop-off centre 4 and Consolidation centre 2 is less.

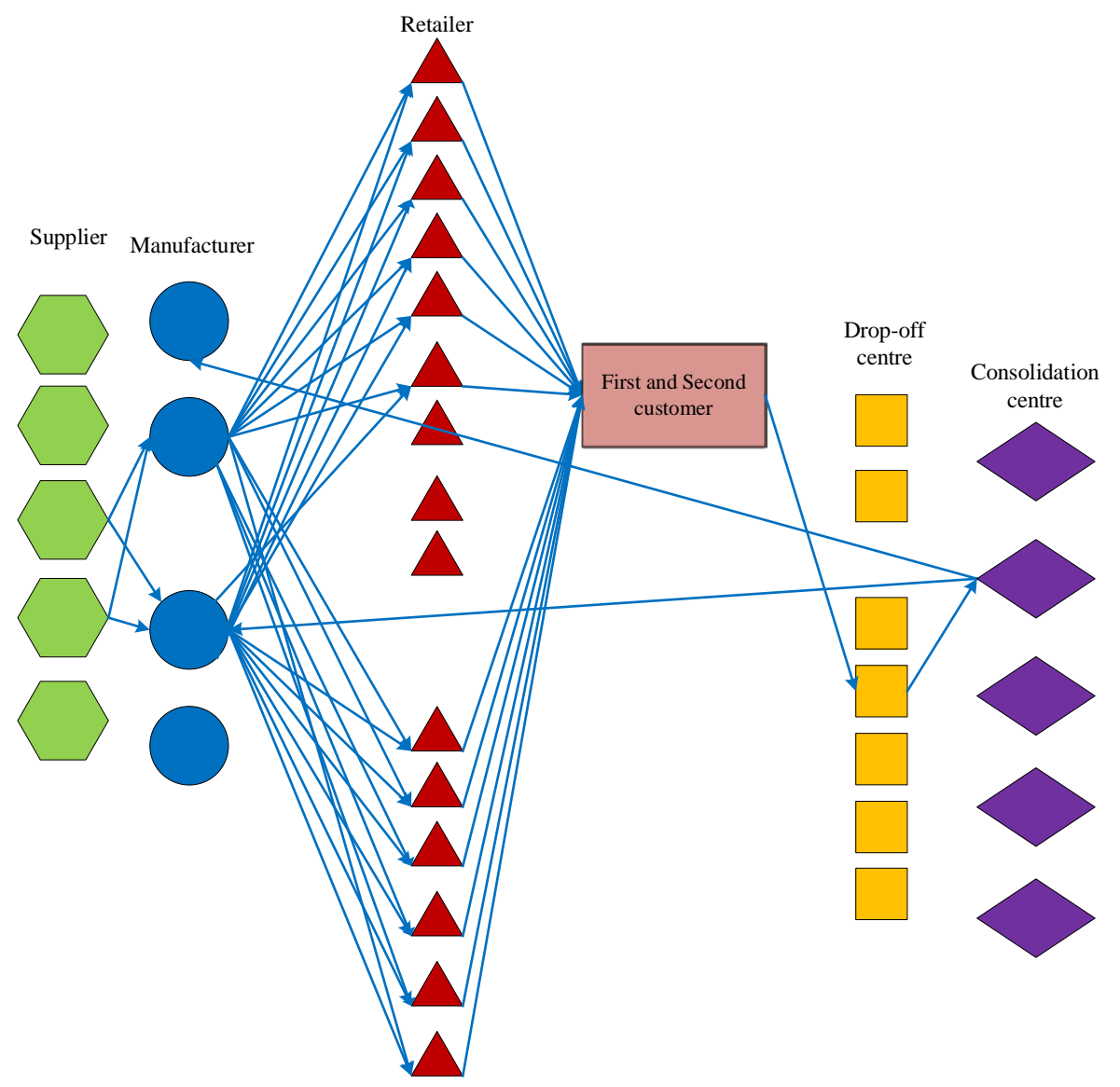

Fig. 3.6. Flow through the new CLSC network (b) based on the results

On the other hand, the impact of $10 \%$ increase in the capacity of Supplier 3 is shown in Fig. 3.7. Therefore, considerable variations are applied to the network. As the result of an increase in the capacity of Supplier 3, only this supplier is selected and no more supplier is needed. 


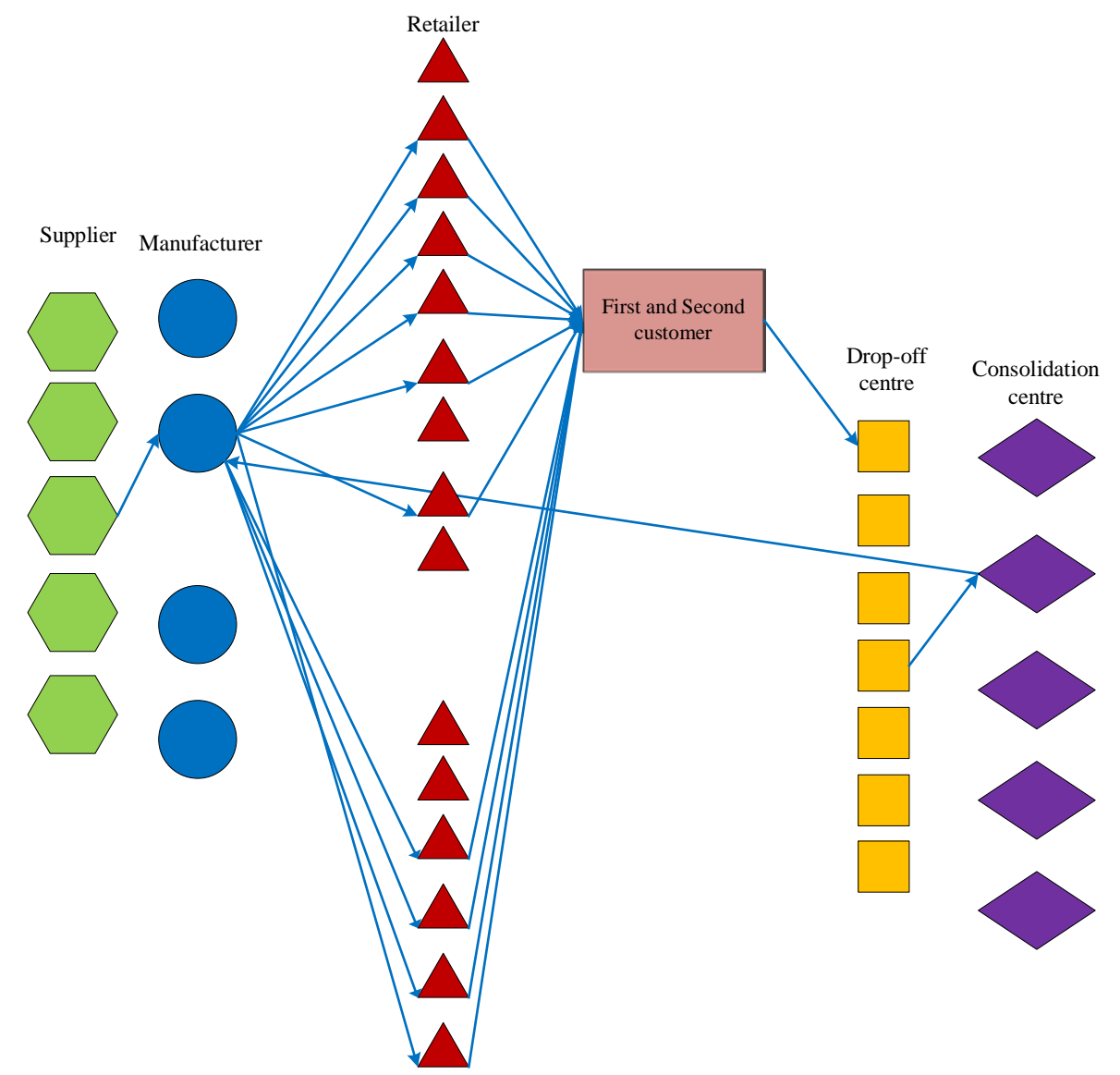

Fig. 3.7. Flow through the new CLSC network (c) based on the results

\subsection{Conclusions}

In this chapter, a deterministic closed-loop supply chain network for mobile phone industry has been developed. A multi-period, multi-product, multi-echelon, and multi-customer model considering different types of product returns is considered. The application of the proposed mathematical model is illustrated in Toronto, Canada using real maps. Furthermore, it is assumed that there exist 4 potential manufacturer locations, 5 suppliers, 15 locations for retailers, 7 locations for drop-off centres, 5 locations for consolidation centres, and 3 potential sites for disposal centres. Moreover, 4 types of mobile phones and 6 types of materials are considered in the model. It is assumed that the returns of both markets, $k$ and $l$ for product $i$ in period $t$ is ten percent of each market demand. The optimal solution of the objective function as well as the 
values of different decision variables are provided with respect to multiple periods. Moreover, 2 suppliers, 2 manufacturers, 9 retailers, 1 drop-off centre, and 1 consolidation centre are selected.

According to Table 3.2, Retailers 1, 2, 3, 4, 6, 12, 13, 14, and 15 were selected since not only these retailers are closer to the open manufacturers (2 and 3), but also the market demand in the vicinity of these retailers is higher. Furthermore, according to the sensitivity analysis, the capacity of suppliers can be considered as a very sensitive parameter. On the other hand, as the result of increasing the capacity of suppliers, one supplier, and one manufacturer will be sufficient to produce mobile phones which reduces the fixed-costs. Moreover, two open consolidation centres can provide more recycled materials which will decrease the need to purchase raw components from suppliers. Hence, the total profit will be improved and the environmental issues will be decreased.

In this study, it is assumed that demand and product return rate are deterministic and constant. Furthermore, the only objective of the model is maximization of the entire profit. According to these limitations, taking into account stochastic programming in order to accomplish uncertainties in specific parameters such as quantity of the returned products and customer demands, and adding more objectives considering green factors can be mentioned as the future extensions of this work. 


\section{CHAPTER 4. AN INTEGRATED CHANCE-CONSTRAINED STOCHASTIC MODEL FOR A MOBILE PHONE CLOSED-LOOP SUPPLY CHAIN NETWORK WITH SUPPLIER SELECTION}

\subsection{Introduction}

Purchasing raw materials from supplier is a curtail issue for all producers and companies. Therefore, the purchasing cost should be considered in selecting suppliers. In addition to cost of raw materials, several other factors can affect supplier selection. For instance, state-of-the-art technology of raw materials is a prominent criterion regarding manufacturing a mobile phone. Therefore, so many criteria can be mentioned which should be taken into account in order to assess the suppliers to select the most proper ones. Supplier selection is a multi-criteria decisionmaking problem including either qualitative or quantitative factors or both (Amin and Razmi, 2009).

Most studies have considered supplier selection in forward logistics. Therefore, various significant factors related to closed-loop supply chain will be ignored. Very few studies have investigated supplier selection in closed-loop supply chain networks. According to Kahraman et al. (2003), various factors of supplier selection can be categorized into four different groups consisting of criteria of supplier, material, service, and cost. Product performance criteria play a very important role in closed-loop supply chain since several characteristics of raw materials including durability and strength make the materials to be reusable for manufacturers. Using environmental friendly materials, reduction of waste, energy consumption, and eco-design are characteristics that can be considered under another group as environmental criteria in closedloop networks.

On the other hand, various factors in designing a CLSC network are uncertain, and considering them as deterministic is not realistic. Therefore, decision-makers are required to take into account these uncertain criteria. To do so, stochastic programming plays a crucial role in optimization issues. In this thesis, the goal is to develop a chance-constrained stochastic model in order to investigate the uncertainty of demand and return along with supplier selection for mobile phone closed-loop supply chain network. 
This chapter is organized as follows: Section 4.2 is devoted to the problem definition and supplier evaluation. Section 4.3 includes chance-constrained programming. The solution approach including the distance method and the $\varepsilon$-constraint method along with the results are presented in Section 4.4. Section 4.5 describes the value path approach. Sensitivity analysis is presented in Section 4.6. Finally, Section 4.7 is assigned to conclusions.

\subsection{Problem definition}

According to the network described in Chapter 3, suppliers are evaluated. The various steps of the solution approach are illustrated in Fig. 4.1. The first phase is devoted to the determination of the weights of suppliers using a fuzzy method. In the second phase, the closed-loop supply chain network proposed in Chapter 3 is extended as multi-objective so that the demand and return are considered to be stochastic. The final stage calculates the value of the variables.

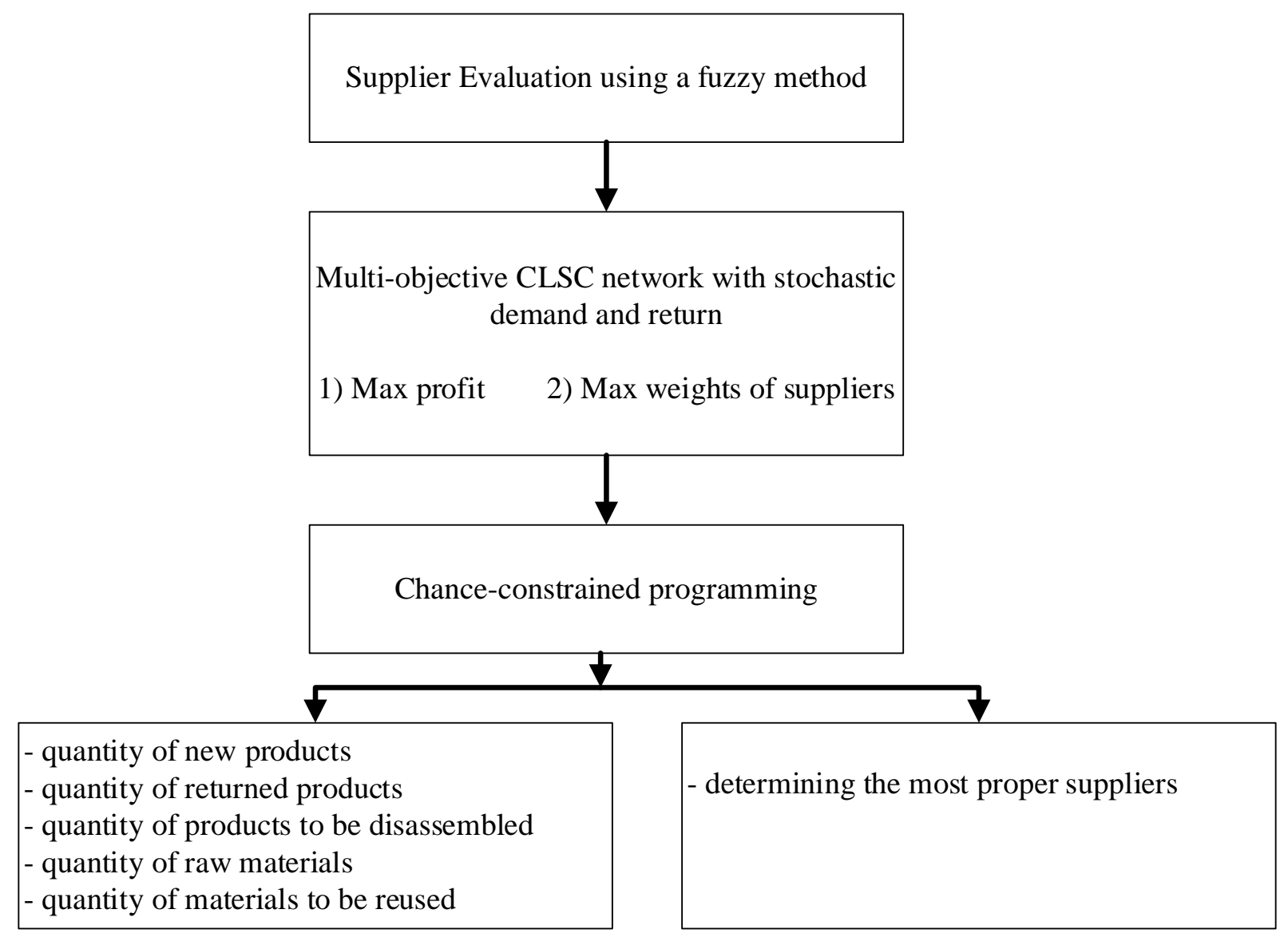

Fig. 4.1. The various steps of the solution approach 


\subsubsection{Supplier evaluation}

Preference of human for making decision in many real situations is uncertain. Therefore, applying exact numerical values for comparison can be unfavorable. On the other hand, evaluation of factors may be influenced by characteristics of the decision-makers. For such reasons, fuzzy methods can be applied in the process of making decision.

Amin and Zhang (2012b) developed a fuzzy model to rank the suppliers. In this section, a fuzzy approach which is based on their proposed method is developed and applied. My method considers linguistic variables and trapezoidal fuzzy numbers (TFNs) in order to calculate the weights of suppliers. Using this method, various criteria can be categorized in different groups and the importance of each group can be ranked. Especially for configuring a CLSC network for mobile phones, this issue becomes significant. A group of decision-makers including three managers with different levels of experience and expertise assign weights to different categories and criteria. Since the opinions of experienced decision-makers are more reliable, it is necessary to consider the level of experience of decision-makers to assess the weights of criteria. In order to evaluate the level of experience of each decision-maker, a linguistic variable is defined as depicted in Fig. 4.2. The membership function is a number between 0 and 1 . The lowest level of experience is determined by $(0,0,3,6)$, while the average level of experience is given by $(0,3$, $9,12)$, and the highest level of experience is assigned by $(6,9,12,12)$. Therefore, $\omega e_{1}=$ $(0,3,9,12), \omega e_{2}=(6,9,12,12)$, and $\omega e_{3}=(6,9,12,12)$, where $\omega e_{D M}$ is the level of experience (weight) of each decision-maker and $D M(d m=1,2,3, \ldots, D M)$ is the number of decision-makers. The number of criteria and the number of suppliers are given by $N$ ( $n=$ $1,2,3, \ldots, N)$ and $S(s=1,2,3, \ldots, S)$, respectively. Each Supplier $s$ provides $J$ materials $(j=$ $1,2,3, \ldots, J)$. The steps of this process are as follows:

Step 1: In this step, appropriate criteria should be determined. Supplier, material, service, and environmental are the main categories of my framework which are shown in Fig. 4.3. In mobile phone CLSC network design, several criteria related to components such as defect rate, small size, being state-of-the-art, durability, and strength are significant. Moreover, because of the hazardous substances applied in mobile phones manufacturing, it is crucial for their materials to be recyclable and reusable. In addition, the latest technology should be taken into account to provide environmental friendly and less polluting components. 
Step 2: Assume that the opinion of each decision-maker is expressed by the linguistic variables $\Lambda=\{V L, L, M L, M, M H, H, V H\}$. Utilizing trapezoidal fuzzy numbers, these variables are quantified as shown in Fig. 4.4. Each decision-maker evaluates all categories and provides a level of importance for them using linguistic scales. Using Fig. 4.4, a TFN is assigned to each linguistic variable. The weight of decision-makers is multiplied by the weight of each category in order to contribute the level of experience of each decision-maker in their opinions regarding each category. Suppose $\lambda_{p}$ represents the weight of each category, where $p$ is defined as each category $(p=1,2,3,4)$. Therefore, the aggregated weight of each category is calculated by Eq. (4.1). The results are shown in Table 4.1.

1

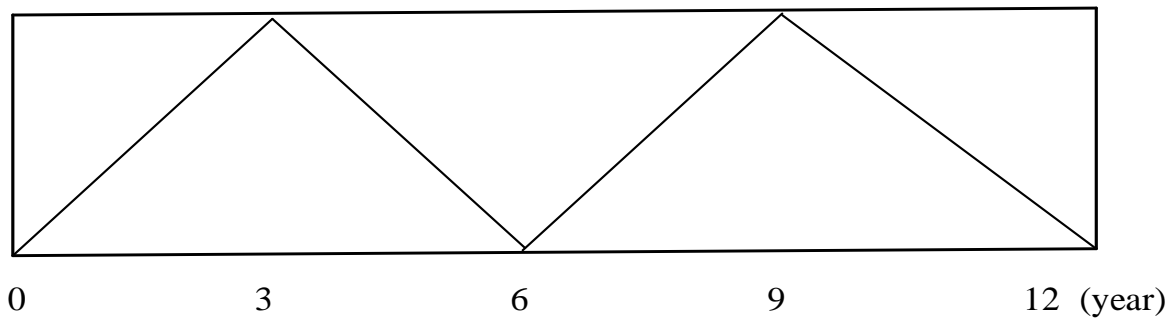

Fig. 4.2. A linguistic scale for providing experience level 


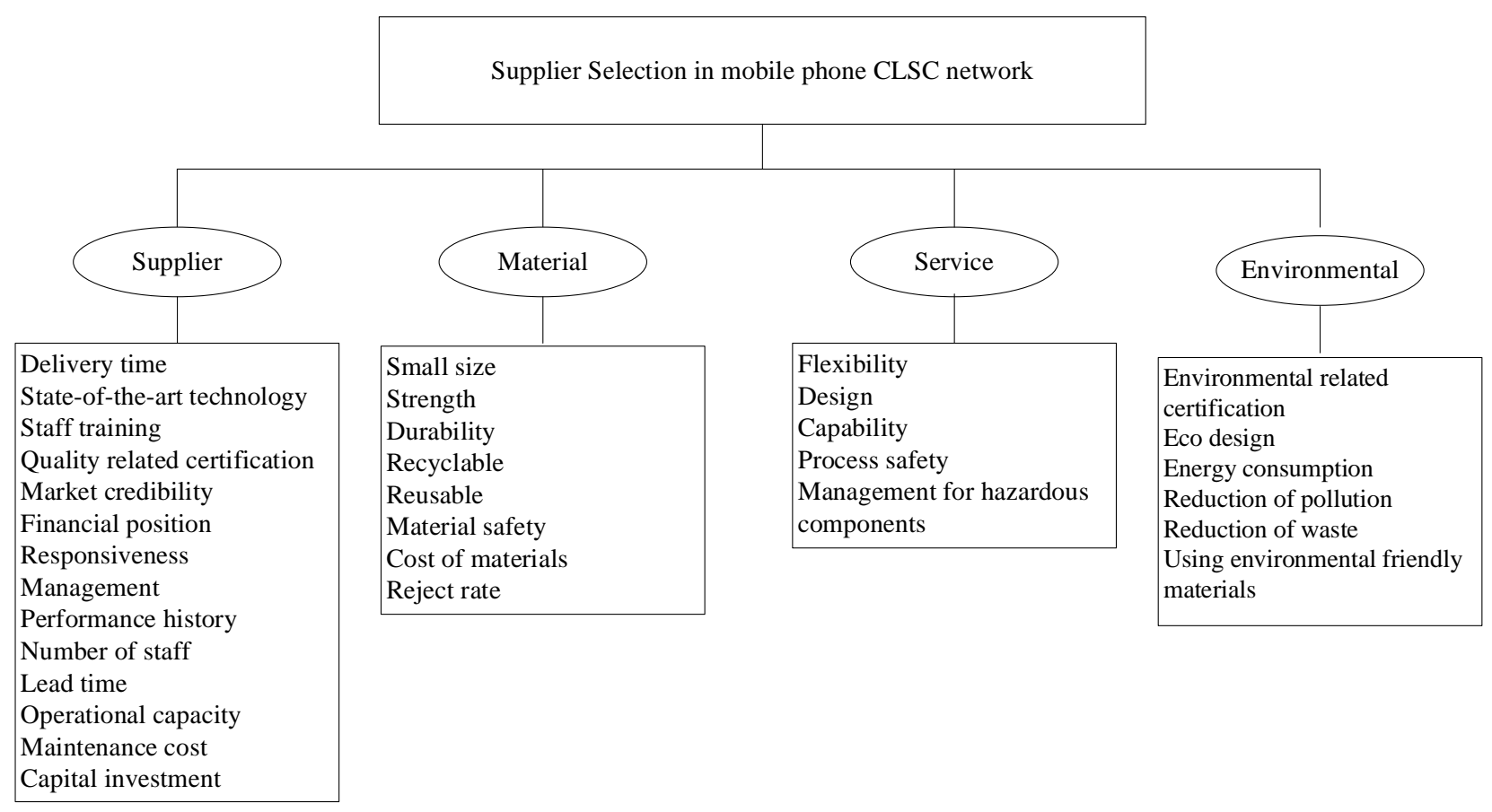

Fig. 4.3. Supplier selection framework in mobile phone CLSC network

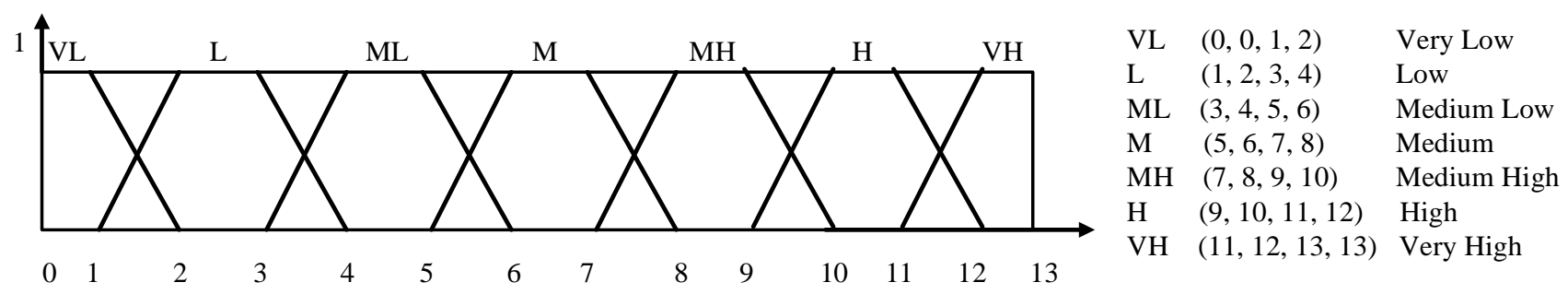

Fig. 4.4. Linguistic scale

$\lambda_{p}=\frac{\left(\omega e_{1} \times \lambda_{p 1}\right)+\left(\omega e_{2} \times \lambda_{p 2}\right)+\cdots+\left(\omega e_{D} \times \lambda_{p D M}\right)}{D M}$

Step 3: If $U_{p n D M}$ is defined as the weight of criterion $n$ in category $p$ provided by decisionmaker $D M$, the aggregated weight of each criterion can be calculated using Eq. (4.2) (see Table $4.2)$. 
$U_{p n}=\frac{\left(\omega e_{1} \times U_{p n 1}\right)+\left(\omega e_{2} \times U_{p n 2}\right)+\cdots+\left(\omega e_{D M} \times U_{p n D M}\right)}{D M}$

Step 4: Assume that the evaluation of supplier $s$ which provides material $j$ regarding criterion $n$ in category $p$ established by decision-maker $D M$ is represented by $F t_{\text {sjpnDM }}$. The aggregated level of importance of supplier $s$ according to criterion $n$ and material $j$ in category $p$ is determined by Eq. (4.3). Table 4.3 illustrates decision-makers' ranking related to supplier 1 who provides material 1.

$F t_{s j p n}=\frac{\left(\omega e_{1} \times F t_{s j p n 1}\right)+\left(\omega e_{2} \times F t_{s j p n 2}\right)+\cdots+\left(\omega e_{D M} \times F t_{s j p n D M}\right)}{D M}$

Step 5: In this step, all calculated weights in the previous steps are multiplied as shown in Eq. (4.4). The results are provided in Table 4.4. Since the calculated number, $\zeta_{j s}=(a, b, c, d)$, is a TFN, it is required to be defuzzified using Eq. (4.5) (Chou and Chang, 2008).

$\zeta_{s j}=\sum_{p=1}^{4} \sum_{n=1}^{N} \lambda_{p} \times U_{p n} \times F t_{s j p n}$

$\psi_{s j}=\frac{a+b+c+d}{4}$

Step 6: In the final step, each supplier is ranked by normalizing its level of importance according to each criterion using Eq. (4.6). The rank of each supplier for each material is written in Table 4.5.

$\pi_{s j}=\frac{\psi_{s j}}{\sum_{s=1}^{S} \psi_{s j}}$ 
Table 4.1.

Weights of categories

\begin{tabular}{llllllll}
\hline Category & \multirow{2}{*}{$\mathrm{DM}_{1}$} & $\mathrm{DM}_{2}$ & $\mathrm{DM}_{3}$ & $\omega e_{1} \times \lambda_{p 1}$ & $\omega e_{2} \times \lambda_{p 2}$ & $\omega e_{3} \times \lambda_{p 3}$ & $\lambda_{p}$ \\
\hline Supplier & $\mathrm{H}$ & $\mathrm{MH}$ & $\mathrm{M}$ & $(0,30,99,144)$ & $(42,72,108,120)$ & $(30,54,84,96)$ & $(24,52,97,120)$ \\
Material & $\mathrm{MH}$ & $\mathrm{H}$ & $\mathrm{H}$ & $(0,24,81,120)$ & $(54,90,132,144)$ & $(54,90,132,144)$ & $(36,68,115,136)$ \\
Service & $\mathrm{MH}$ & $\mathrm{M}$ & $\mathrm{H}$ & $(0,24,81,120)$ & $(30,54,84,96)$ & $(54,90,132,144)$ & $(28,56,99,120)$ \\
Environmental & $\mathrm{M}$ & $\mathrm{M}$ & $\mathrm{MH}$ & $(0,18,63,96)$ & $(30,54,84,96)$ & $(42,72,108,120)$ & $(24,48,85,104)$ \\
\hline
\end{tabular}

Table 4.2.

Weights of criteria

\begin{tabular}{llllllll}
\hline Criteria & $\mathrm{DM}_{1}$ & $\mathrm{DM}_{2}$ & $\mathrm{DM}_{3}$ & $\omega e_{1} \times U_{p n 1}$ & $\omega e_{2} \times U_{p n 2}$ & $\omega e_{3} \times U_{p n 3}$ & $U_{p n}$ \\
\hline State-of-the-art technology & $\mathrm{H}$ & $\mathrm{VH}$ & $\mathrm{H}$ & $(36,68,115,136)$ & $(36,68,115,136)$ & $(36,72,127,148)$ & $(40,76,129,148)$ \\
Market credibility & $\mathrm{H}$ & $\mathrm{M}$ & $\mathrm{H}$ & $(0,30,99,144)$ & $(30,54,84,96)$ & $(54,90,132,144)$ & $(28,58,105,128)$ \\
Performance history & $\mathrm{H}$ & $\mathrm{MH}$ & $\mathrm{VH}$ & $(0,30,99,144)$ & $(42,72,108,120)$ & $(66,108,156,156)$ & $(36,70,121,140)$ \\
Strength & $\mathrm{MH}$ & $\mathrm{H}$ & $\mathrm{MH}$ & $(0,24,81,120)$ & $(54,90,132,144)$ & $(42,72,108,120)$ & $(32,62,107,128)$ \\
Durability & $\mathrm{MH}$ & $\mathrm{M}$ & $\mathrm{M}$ & $(0,24,81,120)$ & $(30,54,84,96)$ & $(30,54,84,96)$ & $(20,44,83,104)$ \\
Recyclable & $\mathrm{H}$ & $\mathrm{MH}$ & $\mathrm{H}$ & $(0,30,99,144)$ & $(42,72,108,120)$ & $(54,90,132,144)$ & $(32,64,113,136)$ \\
Flexibility & $\mathrm{H}$ & $\mathrm{VH}$ & $\mathrm{H}$ & $(0,30,99,144)$ & $(66,108,156,156)$ & $(54,90,132,144)$ & $(40,76,129,148)$ \\
Design & $\mathrm{H}$ & $\mathrm{MH}$ & $\mathrm{MH}$ & $(0,30,99,144)$ & $(42,72,108,120)$ & $(42,72,108,120)$ & $(28,58,105,128)$ \\
Process safety & $\mathrm{MH}$ & $\mathrm{MH}$ & $\mathrm{H}$ & $(0,24,81,120)$ & $(42,72,108,120)$ & $(54,90,132,144)$ & $(32,62,107,128)$ \\
Energy consumption & $\mathrm{VL}$ & $\mathrm{ML}$ & $\mathrm{L}$ & $(0,0,9,24)$ & $(18,36,60,72)$ & $(6,18,36,48)$ & $(8,18,35,48)$ \\
Environmental friendly & $\mathrm{MH}$ & $\mathrm{H}$ & $\mathrm{H}$ & $(0,24,81,120)$ & $(54,90,132,144)$ & $(54,90,132,144)$ & $(36,68,115,136)$ \\
Lead time & $\mathrm{MH}$ & $\mathrm{H}$ & $\mathrm{H}$ & $(0,24,81,120)$ & $(54,90,132,144)$ & $(54,90,132,144)$ & $(36,68,115,136)$ \\
Cost of materials & $\mathrm{VH}$ & $\mathrm{H}$ & $\mathrm{H}$ & $(0,36,117,156)$ & $(54,90,132,144)$ & $(54,90,132,144)$ & $(36,72,127,148)$ \\
Reject rate & $\mathrm{L}$ & $\mathrm{VL}$ & $\mathrm{L}$ & $(0,6,27,48)$ & $(0,0,12,24)$ & $(6,18,36,48)$ & $(2,8,25,40)$ \\
\hline
\end{tabular}

Table 4.3.

Evaluation of supplier 1 for material 1

\begin{tabular}{llllllll}
\hline Criteria & $\mathrm{DM}_{1}$ & $\mathrm{DM}_{2}$ & $\mathrm{DM}_{3}$ & $\omega e_{1} \times F t_{\text {smjpn } 1}$ & $\omega e_{2} \times F t_{\text {smjpn } 2}$ & $\omega e_{3} \times F t_{\text {smjpn } 3}$ & $F t_{\text {smjpn }}$ \\
\hline State-of-the-art technology & $\mathrm{H}$ & $\mathrm{MH}$ & $\mathrm{M}$ & $(0,30,99,144)$ & $(42,72,108,120)$ & $(30,54,84,96)$ & $(24,52,97,120)$ \\
Market credibility & $\mathrm{H}$ & $\mathrm{VH}$ & $\mathrm{H}$ & $(0,30,99,144)$ & $(66,108,156,156)$ & $(54,90,132,144)$ & $(40,76,129,148)$ \\
Performance history & $\mathrm{MH}$ & $\mathrm{H}$ & $\mathrm{MH}$ & $(0,24,81,120)$ & $(54,90,132,144)$ & $(42,72,108,120)$ & $(32,62,107,128)$ \\
Strength & $\mathrm{H}$ & $\mathrm{MH}$ & $\mathrm{VH}$ & $(0,30,99,144)$ & $(42,72,108,120)$ & $(66,108,156,156)$ & $(36,70,121,140)$ \\
Durability & $\mathrm{M}$ & $\mathrm{M}$ & $\mathrm{MH}$ & $(0,18,63,96)$ & $(30,54,84,96)$ & $(42,72,108,120)$ & $(24,48,85,104)$ \\
Recyclable & $\mathrm{H}$ & $\mathrm{VH}$ & $\mathrm{H}$ & $(0,30,99,144)$ & $(66,108,156,156)$ & $(54,90,132,144)$ & $(40,76,129,148)$ \\
Flexibility & $\mathrm{MH}$ & $\mathrm{MH}$ & $\mathrm{H}$ & $(0,24,81,120)$ & $(42,72,108,120)$ & $(54,90,132,144)$ & $(32,62,107,128)$ \\
Design & $\mathrm{M}$ & $\mathrm{M}$ & $\mathrm{M}$ & $(0,18,63,96)$ & $(30,54,84,96)$ & $(30,54,84,96)$ & $(20,42,77,96)$ \\
Process safety & $\mathrm{H}$ & $\mathrm{MH}$ & $\mathrm{H}$ & $(0,30,99,144)$ & $(42,72,108,120)$ & $(54,90,132,144)$ & $(32,64,113,136)$ \\
Energy consumption & $\mathrm{VL}$ & $\mathrm{VL}$ & $\mathrm{L}$ & $(0,0,9,24)$ & $(0,0,12,24)$ & $(6,18,36,48)$ & $(2,6,19,32)$ \\
Environmental friendly & $\mathrm{MH}$ & $\mathrm{M}$ & $\mathrm{M}$ & $(0,24,81,120)$ & $(30,54,84,96)$ & $(30,54,84,96)$ & $(20,44,83,104)$ \\
Lead time & $\mathrm{M}$ & $\mathrm{M}$ & $\mathrm{M}$ & $(0,18,63,96)$ & $(30,54,84,96)$ & $(30,54,84,96)$ & $(20,42,77,96)$ \\
Cost of materials & $\mathrm{H}$ & $\mathrm{VH}$ & $\mathrm{VH}$ & $(0,30,99,144)$ & $(66,108,156,156)$ & $(66,108,156,156)$ & $(44,82,137,152)$ \\
Reject rate & $\mathrm{L}$ & $\mathrm{ML}$ & $\mathrm{L}$ & $(0,6,27,48)$ & $(18,36,60,72)$ & $(6,18,36,48)$ & $(8,20,41,56)$ \\
\hline
\end{tabular}


Table 4.4.

Final score for supplier 1 according to material 1

\begin{tabular}{|c|c|c|c|c|}
\hline Criteria & $\lambda_{p}$ & $U_{p n}$ & $F t_{\text {smjpn }}$ & Final score \\
\hline State-of-the-art technology & $(24,52,97,120)$ & $(40,76,129,148)$ & $(24,52,97,120)$ & 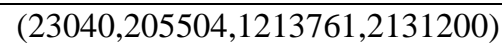 \\
\hline Market credibility & $(24,52,97,120)$ & $(28,58,105,128)$ & $(40,76,129,148)$ & $(26880,229216,1313865,2273280)$ \\
\hline Performance history & $(24,52,97,120)$ & $(36,70,121,140)$ & $(32,62,107,128)$ & $(27648,225680,1255859,2150400)$ \\
\hline Strength & $(36,68,115,136)$ & $(32,62,107,128)$ & $(36,70,121,140)$ & $(41472,295120,1488905,2437120)$ \\
\hline Durability & $(36,68,115,136)$ & $(20,44,83,104)$ & $(24,48,85,104)$ & $(17280,143616,811325,1470976)$ \\
\hline Recyclable & $(36,68,115,136)$ & $(32,64,113,136)$ & $(40,76,129,148)$ & $(46080,330752,1676355,2737408)$ \\
\hline Flexibility & $(28,56,99,120)$ & $(40,76,129,148)$ & $(32,62,107,128)$ & $(35840,263872,1366497,2273280)$ \\
\hline Design & $(28,56,99,120)$ & $(28,58,105,128)$ & $(20,42,77,96)$ & $(15680,136416,800415,1474560)$ \\
\hline Process safety & $(28,56,99,120)$ & $(32,62,107,128)$ & $(32,64,113,136)$ & $(28672,222208,1197009,2088960)$ \\
\hline Energy consumption & $(24,48,85,104)$ & $(8,18,35,48)$ & $(2,6,19,32)$ & $(384,5184,56525,159744)$ \\
\hline Environmental friendly & $(24,48,85,104)$ & $(36,68,115,136)$ & $(20,44,83,104)$ & $(17280,143616,811325,1470976)$ \\
\hline Lead time & $(24,52,97,120)$ & $(36,68,115,136)$ & $(20,42,77,96)$ & $(17280,148512,858935,1566720)$ \\
\hline Cost of materials & $(36,68,115,136)$ & $(36,72,127,148)$ & $(44,82,137,152)$ & $(57024,401472,2000885,3059456)$ \\
\hline \multirow[t]{2}{*}{ Reject rate } & $(36,68,115,136)$ & $(2,8,25,40)$ & $(8,20,41,56)$ & $(576,10880,117875,303640)$ \\
\hline & \multicolumn{4}{|c|}{$\zeta_{111}=(355136,2762048,14969536,25598720), \psi_{111}=10921360$} \\
\hline
\end{tabular}

Table 4.5.

Weight of supplier $s$ according to material $j$

\begin{tabular}{lccccc}
\hline$j$ & 1 & 2 & 3 & 4 & 5 \\
\hline 1 & 0.36 & 0.34 & 0.35 & 0.35 & 0.35 \\
2 & 0.33 & 0.36 & 0.35 & 0.35 & 0.36 \\
3 & 0.35 & 0.39 & 0.34 & 0.32 & 0.35 \\
4 & 0.29 & 0.25 & 0.21 & 0.23 & 0.27 \\
5 & 0.33 & 0.35 & 0.35 & 0.36 & 0.33 \\
6 & 0.21 & 0.21 & 0.38 & 0.35 & 0.36 \\
\hline
\end{tabular}




\subsubsection{Mathematical model}

The model presented in chapter 3 can be extended as follows:

$$
\begin{aligned}
\operatorname{Max} z_{1}=\sum_{r} \sum_{k} & \sum_{l} \sum_{i} \sum_{t}\left(P_{i}^{n} a_{r k i t}^{n}+P_{i}^{u} a_{r l i t}^{u}+P_{i}^{c} a_{r l i t}^{c}\right) \\
& -\left[\sum_{m} f a_{m} y a_{m}+\sum_{s} f b_{s} y b_{s}+\sum_{r} f c_{r} y c_{r}+\sum_{d} f d_{d} y d_{d}+\sum_{g} f e_{g} y g_{g}\right. \\
& +\sum_{s} \sum_{m} \sum_{j} \sum_{t}\left(\omega_{s j t}+k a_{s m t} \theta_{s m}\right) q_{s m j t} \\
& +\sum_{m} \sum_{r} \sum_{i} \sum_{t}\left(\mu_{m i t}+k b_{m r t} \theta_{m r}\right) a_{m r i t}+\sum_{r} \sum_{i} \sum_{t} \rho_{i} I n_{r i t} \\
& +\sum_{r} \sum_{m} \sum_{k} \sum_{i} \sum_{t}\left(\left(d w_{r i t}+\sigma_{i t}\right) b_{k r i t}^{c}+d w_{r i t} b_{k r i t}^{u}+\left(d w_{r i t}+k c_{r m t} \theta_{m r}\right) a_{r m i t}^{l}\right) \\
& +\sum_{d} \sum_{g} \sum_{i} \sum_{t}\left(\gamma_{g i t}+k d_{d g t} \theta_{d g}\right) n_{d g i t} \\
& \left.+\sum_{m} \sum_{g} \sum_{x} \sum_{j} \sum_{t}\left(\left(k e_{g m t} \theta_{g m}-\eta_{j}\right) \varphi_{g m j t}+\left(k f_{g x t} \theta_{g x}+d h_{x j t}\right) u_{g x j t}\right)\right]
\end{aligned}
$$

$\operatorname{Max} z_{2}=\sum_{s} \sum_{m} \sum_{j} \sum_{t} \pi_{s j} q_{s m j t}$

The first objective function is designed to maximize the entire profit in the mobile phone CLSC network whereas the second objective function maximizes the weights of eligible suppliers which are estimated based on the developed fuzzy method. Constraints (3.1) to (3.22) can be considered for this multi-objective mixed-integer linear programming model. However, it is assumed that demand ( $\widehat{A c_{k l t}}$ and $\left.\widehat{A s_{l l t}}\right)$ and return $\left(\widehat{z c_{k l t}}\right.$ and $\left.z \widehat{s_{l l t}}\right)$ are stochastic. Therefore, Constraints (3.3), (3.4), (3.10), and (3.11) can be written as follows:

$$
\begin{array}{lr}
\sum_{r} a_{r k i t}^{n} \leq \widehat{A c_{k l t}} & \forall i, k, t \\
\sum_{r} a_{r l i t}^{u}+\sum_{r} a_{r l i t}^{c} \leq \widehat{A s_{l l t}} & \forall i, l, t \\
\sum_{d} e f_{k d i t}=\widehat{Z c_{k l t}} & \forall i, k, t \\
\sum_{d} e s_{l d i t}=Z \widehat{s_{l l t}} & \forall i, l, t
\end{array}
$$




\subsection{Chance-constraint programming}

Some methodologies can be taken into account to deal with stochastic parameters in optimization models. One of the methods that has been used in many studies is ChanceConstrained Programming (CCP) proposed by Charnes et al. (1990). Assume a mathematical programming with stochastic parameters as follows:

$$
\left\{\begin{array}{c}
\max f(x) \\
\text { subject to: } \\
g_{v}(x, \xi) \leq 0, v=1,2, \ldots, p
\end{array}\right.
$$

where $x$ and $\xi$ are a decision vector and a stochastic vector, respectively. $f(x)$ is a non-stochastic objective function and $g_{v}(x, \xi)$ is a stochastic constraint. A stochastic decision problem can be also written as follows (Liu, 1999):

$$
\left\{\begin{array}{c}
\max f(x) \\
\text { subject to: } \\
\operatorname{Pr}\left\{\xi \mid g_{v}(x, \xi) \leq 0\right\} \geq \alpha_{v}, v=1,2, \ldots, p
\end{array}\right.
$$

where $\alpha_{v}$ is a predetermined confidence level to the respective stochastic constraint and $\operatorname{Pr}\{$. indicates the probability of the event in $\{$.$\} . It ensures that the probability of a certain constraint$ is above a certain level. In other words, it restricts the feasible region so that the confidence level of the solution is high ( $\mathrm{Li}$ et al., 2008). The stochastic constraint is required to be converted to its deterministic equivalent.

In this study, $\widehat{A c_{k l t}}, \widehat{A S_{l l t}}, \widehat{Z c_{k l t}}$, and $z \widehat{S_{l l t}}$ are stochastic parameters which are in some constraints. In order to deal with them, they are transferred to their respective deterministic equivalents based on their predetermined confidence levels. Hence, a deterministic programming model will be acquired which can be solved with typical solution approaches. Although this process sounds hard and can be only favourable for some special cases, the stochastic constraints can be dealt with the aid of some identified results.

Case I: Assume that the chance-constrained programming is as follows:

$\operatorname{Pr}\left\{\xi_{v} \mid h_{v}(x) \leq \xi_{h}\right\} \geq \alpha_{h} \quad h=1,2, \ldots, p$ 
where $h_{v}(x)$ and $\xi_{h}$ are decision functions and stochastic parameters, respectively. $F_{v}\left(\xi_{v}\right), v=$ $1,2, \ldots, p$ is defined as a cumulative distribution function. Therefore, the deterministic equivalent of Eq. (4.13) can be calculated by Eq. (4.14) (Moheb-Alizadeh and Handfield, 2017).

$h_{v}(x) \leq f_{v}^{-1}\left(1-\alpha_{v}\right)$

where $f_{v}^{-1}$ is the inverse of cumulative distribution function.

On the other hand, if the chance-constrained programming is as follows:

$\operatorname{Pr}\left\{\xi_{v} \mid h_{v}(x) \geq \xi_{v}\right\} \geq \alpha_{v} \quad v=1,2, \ldots, p$

The deterministic equivalent of Eq. (4.15) can be written as Eq. (4.16).

$h_{v}(x) \geq f_{v}^{-1}\left(\alpha_{v}\right)$

Thus, the stochastic Constraints (4.7), (4.8), (4.9), and (4.10) can be reformulated as follows:

$\operatorname{Pr}\{g(x, \widehat{A c}) \leq 0\}=\operatorname{Pr}\left\{\sum_{r} a_{r k i t}^{n} \leq \widehat{A c_{k l t}}\right\} \geq \alpha_{1} \quad \forall i, k, t$

$\operatorname{Pr}\{g(x, \widehat{A s}) \leq 0\}=\operatorname{Pr}\left\{\sum_{r} a_{r l i t}^{u}+\sum_{r} a_{r l i t}^{c} \leq \widehat{A s_{l l t}}\right\} \geq \alpha_{2} \quad \forall i, l, t$

$\operatorname{Pr}\{g(x, \widehat{z c}) \leq 0\}=\operatorname{Pr}\left\{\sum_{d} e f_{k d i t}=\widehat{z C_{k l t}}\right\} \geq \alpha_{3} \quad \forall i, k, t$

$\operatorname{Pr}\{g(x, \widehat{Z S}) \leq 0\}=\operatorname{Pr}\left\{\sum_{d} e s_{l d i t}=z \widehat{s_{l l t}}\right\} \geq \alpha_{4} \quad \forall i, l, t$

Then, the deterministic equivalent of the stochastic constraints can be derived:

$$
\begin{array}{lr}
\sum_{r} a_{r k i t}^{n} \leq f_{\overline{A c_{k l t}}}^{-1}\left(1-\alpha_{1}\right) & \forall i, k, t \\
\sum_{r} a_{r l i t}^{u}+\sum_{r} a_{r l i t}^{c} \leq f_{\overline{A s_{l l t}}}^{-1}\left(1-\alpha_{2}\right) & \forall i, l, t \\
\sum_{d} e f_{\text {kdit }}=f_{\overline{z c_{k l t}}}^{-1}\left(\alpha_{3}\right) & \forall i, k, t \\
\sum_{d} e s_{l d i t}=f_{\overline{z S_{l l t}}}^{-1}\left(\alpha_{4}\right) & \forall i, l, t
\end{array}
$$




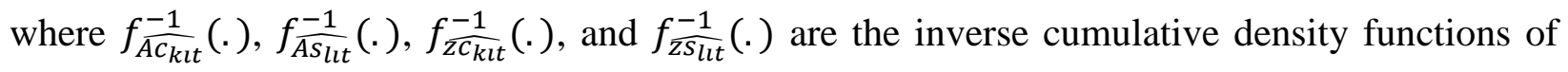
$\widehat{A c_{k l t}}, \widehat{A s_{l l t}}, \widehat{Z c_{k l t}}$, and $z \widehat{s_{l l t}}$, respectively. Now, the proposed multi-objective mixed-integer linear programming model can be solved considering Constraints (3.1), (3.2), (3.5) - (3.9), (3.12) - (3.22), (4.21) - (4.24).

Chance-constrained programming is a unique method compared to other stochastic programming methods especially for supplier selection frameworks since a high level of reliability is provided by assigning the probability of satisfying constraints, i.e. the predetermined confidence level to be feasible (Moheb-Alizadeh and Handfield, 2017).

\subsection{Solution Approach}

All the assumptions are the same as explained in Chapter 3. Therefore, there are 44 first and 22 second demand markets. There exist 4 potential manufacturer locations, 5 eligible suppliers, 15 locations for retailers, 7 locations for drop-off centres, 5 locations for consolidation centres, and 3 potential sites for disposal centres. Moreover, 4 types of mobile phones and 6 types of materials are considered in the model. The stochastic demand and return are modeled using lognormal density function. Not only lognormal distribution maintains the non-negativity of the values of both demand and return, but also Kamath and Pakkala (2002) proved that the most suitable distribution to model some stochastic parameters such as demand is lognormal. The parameters of demand and return lognormal density functions are calculated as follows: $\widehat{A c_{k \imath t}}$ and $\widehat{A s_{l l t}} \sim \operatorname{lognormal}(7.82,0.17)$, and $\widehat{Z c_{k l t}}$ and $z \widehat{s_{l l t}} \sim \operatorname{lognormal}(5.52,0.12)$. It is assumed that all of the stochastic constraints have a confidence level of 0.95. Moreover, distances among various facilities are estimated using Google Maps. The values of other parameters are presented in Table 4.6.

Table 4.6.

Values of some parameters defined to solve the mathematical model

\begin{tabular}{lll}
\hline$M=4$ & $f a_{m}=100,000,000$ & $\sigma_{i t}=20$ \\
$S=5$ & $f b_{s}=100,000$ & $\operatorname{mcap}_{m j}=500,000$ \\
$R=15$ & $f c_{r}=f d_{d}=f e_{g}=150,000$ & $\operatorname{rcap}_{r i}=14,000$ \\
$K=44$ & $P_{i}^{n}=100$ & $\operatorname{dcap}_{d i}=10,000$ \\
$L=22$ & $P_{i}^{n}=100$ & $\operatorname{gcap}_{g i}=10,000$ \\
$D=7$ & $P_{i}^{u}=50$ & $s c a p_{s j}=150,000$ \\
$I=4$ & $P_{i}^{c}=80$ & $\eta_{j}=10$ \\
$J=6$ & $k a_{s m t}=k e_{g m t}=k f_{g x t}=0.002$ & $\varepsilon_{j}=0.1$ \\
$G=5$ & $k b_{m r t}=k c_{r m t}=k d_{d g t}=0.005$ & $\rho_{i}=35$ \\
$T=2$ & $\mu_{m i t}=15$ & \\
\hline
\end{tabular}




\subsection{1. $\varepsilon$-constrained method and results}

The application of $\varepsilon$-constraint method is to transfer a multi-objective model to a singleobjective one. The methodology is that the most privilege objective function is taken into account as the main objective and other objectives are supposed to be as constraints (Ehrgott, 2005). The obtained single objective model is as follows:

$\operatorname{Max} z_{3}=z_{1}$

s.t.

$z_{2} \geq \varepsilon_{1}$

Eq. (3.1), (3.2), (3.5) - (3.9), (3.12) - (3.22), (4.21) - (4.24)

Various values of $\varepsilon$ are examined in order to obtain the trade-off solution. $\varepsilon$ is changed from 800,000 to 856,709 . For the values of $\varepsilon$ under 800,000 , the value of the main objective function (maximization of the profit) is equal to 24,236,760.294. However, for every $\varepsilon$ higher than 856,709, the solution is unbounded or infeasible. The values of first and second objective functions for the values of $\varepsilon$ in the mentioned range are illustrated in Table 4.7.

Table 4.7.

Values of objective functions obtained by $\varepsilon$-constraint method

\begin{tabular}{lllllll}
\hline$\varepsilon$ & 850,000 & 845,000 & 840,000 & 835,000 & 830,000 & 825,000 \\
& & & & & \\
\hline First objective & $5,817,150.987$ & $10,152,341.026$ & $14,487,531.065$ & $18,822,721.105$ & $23,157,911.144$ & $24,236,760.294$ \\
Second objective & 850,000 & 845,000 & 840,000 & 835,000 & 828,430 & 810,780 \\
& & & & & & \\
\hline
\end{tabular}

\subsubsection{Distance method and results}

The distance method is an approach to deal with a multi-objective CLSC network in order to obtain an approximate solution close to the perfect one. In this method, the perfect solution is the best value achieved for each objective function while other functions are ignored (Branke and 
Miettinen, 2008). According to Eq. (4.26), $W_{o}$ is utilized as the distance metric representing the weight of each segment mentioned in the objective function (Mirzapour Al-E-Hashem et al., 2011). A set of solutions named Pareto or efficient solutions will be created as the result of solving the multi-objective model. The final set of solutions acquired by completion of exploration is named the Trade-off surface or Pareto front (Collette and Siarry, 2003). In this thesis, the goal is to maximize the total profit along with maximization of the weights of suppliers. Hence, the model can be presented as follows:

$z=\left(\sum_{o} W_{o}^{\tau a}\left(\frac{z_{o}-z_{o}^{*}}{z_{o}^{*}}\right)^{\tau a}\right)^{\frac{1}{\tau a}} \quad \forall o=1,2, \ldots$

$\operatorname{Max} z=\left(W_{1}^{\tau a}\left(\frac{z_{1}-z_{1}^{*}}{z_{1}^{*}}\right)^{\tau a}+W_{2}^{\tau a}\left(\frac{z_{2}-z_{2}^{*}}{z_{2}^{*}}\right)^{\tau a}\right)^{\frac{1}{\tau a}}$

s.t.

Eq. (3.1), (3.2), (3.5) - (3.9), (3.12) - (3.22), (4.21) - (4.24)

First of all, the value of each objective function is calculated separately. The optimal values of the total profit and weights of suppliers are 24,236,760.294 and 828,778.368, respectively. Next, the distance method is implemented to solve the multi-objective problem.

Various values of $W_{o}$ are examined while satisfying $\sum_{o} W_{o}=1$ condition in order to obtain the trade-off solution between two objective functions. The values for the first and second objective functions are shown in Table 4.8 with respect to different values of $W_{1}$.

Table 4.8.

Values of objective functions obtained by distance method

\begin{tabular}{lllllllll}
\hline$W_{1}$ & 0 & 0.2 & 0.3 & 0.4 & 0.5 & 0.6 & 0.8 & 1 \\
\hline First objective & 987,500 & $3,246,700$ & $9,607,100$ & $11,550,000$ & $18,764,000$ & $20,411,000$ & $22,832,000$ & $22,954,000$ \\
Second objective & 863,390 & 861,390 & 847,750 & 775,460 & 642,630 & 472,190 & 336,980 & 80,255 \\
\hline
\end{tabular}




\subsection{Value Path Approach (VPA)}

In this section, the Value Path Approach (VPA) is investigated in order to describe the tradeoffs among various objectives of a multi-objective problem (Schilling et al., 1983; Wadhwa and Ravindran, 2007; Amin and Zhang, 2014; Tosarkani and Amin, 2018b). The display consists of a set of parallel scales, one for each criterion, on which is drawn the value path for each of the alternatives. Each element of Table 4.9 is the value of non-dominated solutions which is calculated as the value of each objective function divided by the best value of that objective. Hence, 1 will be the minimum value for each axis. The results are depicted in Fig. 4.5. Based on VPA, value paths that intersect are considered as non-dominated, while inferior solutions are non-intersecting paths, where one lies above the other one. Therefore, Fig. 4.5 illustrates that all solutions are non-dominated.

Table 4.9.

Results of Value Path Approach (VPA)

\begin{tabular}{lllllllll}
\hline$W_{1}$ & 0 & 0.2 & 0.3 & 0.4 & 0.5 & 0.6 & 0.8 & 1 \\
\hline First objective & 1 & 3.287 & 9.728 & 11.696 & 19.001 & 20.67 & 23.121 & 23.244 \\
Second objective & 10.758 & 10.733 & 10.563 & 9.662 & 8.007 & 5.883 & 4.198 & 1 \\
\hline
\end{tabular}

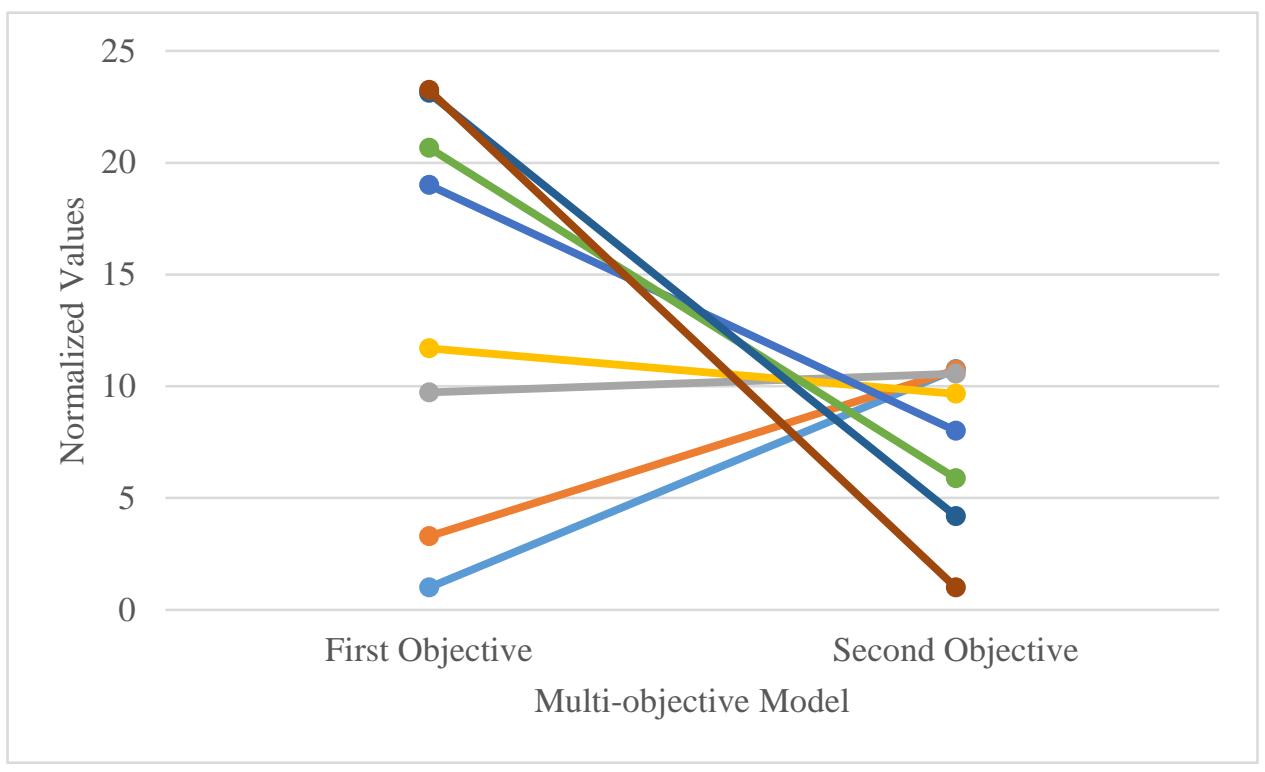

Fig. 4.5. Value Path Approach (VPA) 


\subsection{Sensitivity analysis}

The sensitivity analysis is discussed in this section. To do so, it is assumed that $\varepsilon$ is equal to 825,000. Table 4.10 indicates the results of some variables of the model. Fig. 4.6. depicts the optimal mobile CLSC network considering Product 1 (to avoid complexity).

Table 4.10.

Some values of the model for $i=j=t=1$

\begin{tabular}{|c|c|c|}
\hline Single Variables & Value & Binary Variables \\
\hline First objective & $24,236,760.294$ & Suppliers: 3, 4 \\
\hline Second objective & 810,780 & Manufacturers: 2, 3 \\
\hline$a_{r k i t}^{n}$ & $1,036.45$ & Retailers: 1, 2, 3, 4, 6, 12, 13, 14,15 \\
\hline$a_{\text {rlit }}^{c}$ & 210.5 & Drop-off centres: 2, 6 \\
\hline$a_{\text {rlit }}^{u}$ & 235.6 & Consolidation centres: 5 \\
\hline$q_{s m j t}$ & $56,789.86$ & \\
\hline$a_{m r i t}$ & $21,753.235$ & \\
\hline$b_{k r i t}^{c}$ & 699.853 & \\
\hline$b_{k r i t}^{u}$ & 945.9 & \\
\hline$a_{r m i t}^{l}$ & 148.73 & \\
\hline$e f_{k d i t}$ & 279.2 & \\
\hline$e s_{\text {ldit }}$ & 237.35 & \\
\hline$\varphi_{g m j t}$ & $6,348.4$ & \\
\hline$u_{g x j t}$ & $9,732.24$ & \\
\hline
\end{tabular}

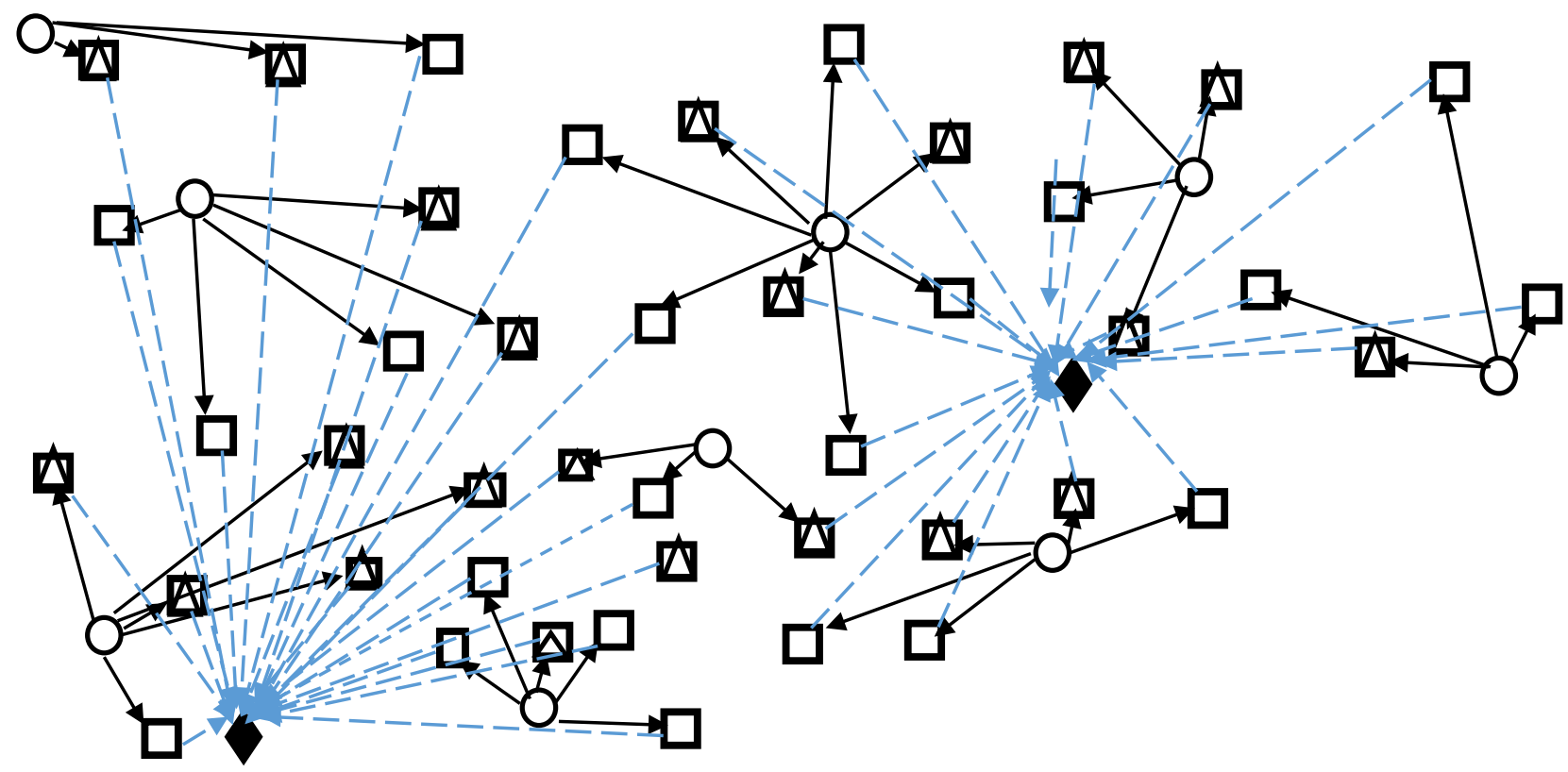

Fig. 4.6 The optimal mobile CLSC network $(\rightarrow$ forward supply chain, $\rightarrow$ reverse supply chain) Retailer $\bigcirc$, First customers $\square$, Second customers $\Delta$, Drop-off centre 
One of the most important parameters that can be changed to evaluate the sensitivity of the model is customers' demand. Hence, $\alpha$ as a parameter determined by decision-maker and effective for demand is examined. In the previous section, the confidence level was set to 0.95. Now, the effect of a decrease in $\alpha$ on profit regarding both first and second customers' demand for Product 1 in the first ward (to avoid complexity) is investigated. The changes in the profit according to the changes in $\alpha$ are illustrated in Fig. 4.7. It is clear that as $\alpha$ decreases, the demand increases, resulting in a rise in the profit.

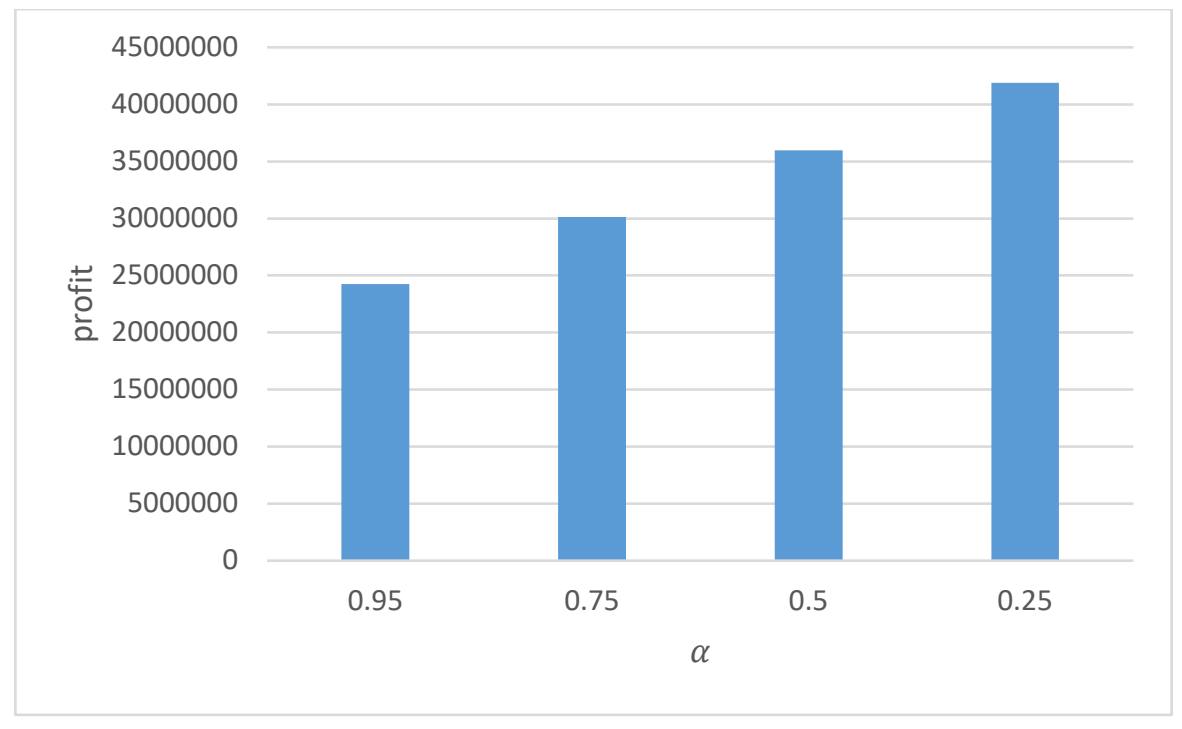

Fig. 4.7. The changes of the profit due to the change in $\alpha$

\subsection{Conclusions}

In this chapter, a framework based on the network presented in Chapter 3 was introduced. Accordingly, a stochastic, multi-objective, mixed-integer linear programming model was proposed. It was assumed that demand and return are stochastic parameters. Moreover, as an extension to the model, supplier selection and order allocation have been applied to the model. A fuzzy method was developed to estimate the weights of qualified suppliers. Therefore, the objectives are the maximization of the whole profit as well as maximization of the weights of suppliers. Chance-constrained programming has been employed to deal with uncertainty in the proposed model. The operation of the proposed mathematical model has been illustrated in Toronto, Canada using real maps. In addition, $\varepsilon$-constraint and distance methods have been 
utilized to solve the multi-objective model. The value path approach has been described in order to analyze the tradeoffs among various objectives. Furthermore, the level of confidence has been changed in order to investigate the sensitivity of the model.

Because of the complexity of applying supplier selection and order allocation to closed-loop networks, metaheuristic approaches such as genetic algorithms can be utilized as a future research. Besides, additional factors including various prices can also be considered as uncertain parameters. Moreover, the return was assumed as a stochastic parameter and to deal with that chance-constraint programming was applied. However, a propensity model such as logistic regression model can be developed based on several predictive variables in order to forecast the probability of return. 


\section{CHAPTER 5. CONCLUSIONS AND FUTURE RESEARCH}

\subsection{Research contributions}

The main research contributions of this study in CLSC field are as follows:

- Development of a mathematical formulation to configure a CLSC network for mobile phone recovery and recycling in a multi-period and multi-product situation with considering different types of returned products in Toronto, Canada.

- Investigating reselling commercial and EOU returned products to the second customers with different selling prices.

- Applying chance-constrained programming to deal with stochastic sources in the CLSC network such as demand and rate of returned products

- Developing a fuzzy method to estimate the quantitative and qualitative weights for supplier selection and order allocation in the proposed model and therefore extending the model to a multi-objective programming model in order to maximize the weight of suppliers along with the maximization of the profit

- Employment of distance method and $\varepsilon$-constraint technique to conclude the trade-off surface of solutions

- Providing real distances in the proposed multi-echelon model using Google maps.

\subsection{Conclusions}

The goal of this study was to design and optimize a Closed-Loop Supply Chain (CLSC) network for a mobile phone network considering different types of product returns. Commercial, end of life, and end-of-use returns are well-known in practice. To do so, a network has been analyzed and a mathematical formulation along with solution approaches have been proposed.

In Chapter 3, a deterministic mathematical model for mobile phone industry has been developed. A multi-period, multi-product, multi-echelon, and multi-customer model considering different types of product returns is considered. Moreover, the application of the proposed mathematical model was illustrated in Toronto, Canada using real maps. The optimal solution of 
the objective function, as well as the values of different decision variables, have been provided with respect to multiple periods. Furthermore, the sensitivity of the model was investigated in order to evaluate the proposed model. According to the sensitivity analysis, the capacity of suppliers can be considered as a very sensitive parameter.

In Chapter 4, a framework based on the network presented in Chapter 3 was extended in order to consider the uncertainty. Accordingly, a stochastic, multi-objective, mixed-integer linear programming model was proposed. It was assumed that demand and return are stochastic parameters. Moreover, as an extension to the model, supplier selection and order allocation have been applied. A fuzzy method was developed to estimate the weights of qualified suppliers. Therefore, the objectives are the maximization of the whole profit as well as maximization of the weights of suppliers. Chance-constrained programming has been employed to deal with uncertainty in the proposed model. The operation of the proposed mathematical model has been illustrated in Toronto, Canada using real maps. In addition, $\varepsilon$-constraint and distance methods have been utilized to solve the multi-objective model. Furthermore, the level of confidence has been changed in order to investigate the sensitivity of the model.

\subsection{Future research}

Various potential research subjects can be mentioned as the extensions to this study in which environmental issues, metaheuristic solution approaches, probabilistic uncertainty, and different financial factors can be investigated.

\section{- Considering environmental issues}

In Chapter 4, the proposed model was extended to a multi-objective model in order to consider the supplier selection and order allocation. However, the proposed mobile phone CLSC network can be developed to a multi-objective optimization model to take into account the environmental factors. Several environmental objectives including minimizing of waste, energy consumption, and carbon emission can be added to the mathematical model. 


\section{- Considering metaheuristic solution approaches}

In real world, we deal with non-linear programming optimization models with complicated constraints as well as large-size problems. In these cases, metaheuristic algorithms such as genetic algorithm or particle swarm can be applied to achieve the best solution, although there is no assurance to achieve the optimal solution.

\section{- Considering probabilistic uncertainty}

In this study, the return was assumed as a stochastic parameter and to deal with that chanceconstraint programming was applied. However, a propensity model such as logistic regression model can be developed based on several predictive variables in order to forecast the probability of return.

\section{- Considering financial factors}

Various financial parameters including interest rate, energy price, inflation and exchange rate, etc. can affect the total profit of a CLSC network. All these parameters can be taken into account throughout the design of an optimization model along with the maximization of the total profit.

\section{- Considering other sources of uncertainty}

In this thesis, I focused on two sources of uncertainty including demand and return. However, other parameters such as price, capacity of facilities, and costs can be considered as uncertain. Therefore, uncertainty can be reflected in the objective functions as well. 


\section{References}

Alumur, S. A., Nickel, S., Saldanha-Da-Gama, F., \& Verter, V. (2012). Multi-period reverse logistics network design. European Journal of Operational Research, 220(1), 67-78.

Amid, A., Ghodsypour, S. H., \& O’Brien, C. (2011). A weighted maxmin model for fuzzy multiobjective supplier selection in a supply chain. International Journal of Production Economics, 131(1), 139-145.

Amin, S. H. (2012). Scholarship at UWindsor Design and Optimization of Closed-Loop Supply Chain Management Design and Optimization of Closed-Loop Supply Chain Management.

Amin, S. H., \& Razmi, J. (2009). An integrated fuzzy model for supplier management: A case study of ISP selection and evaluation. Expert Systems with Applications, 36(4), 8639-8648.

Amin, S. H., \& Zhang, G. (2012a). A proposed mathematical model for closed-loop network configuration based on product life cycle. International Journal of Advanced Manufacturing Technology, 58(5-8), 791-801.

Amin, S. H., \& Zhang, G. (2012b). An integrated model for closed-loop supply chain configuration and supplier selection: Multi-objective approach. Expert Systems with Applications, 39(8), 6782-6791.

Amin, S. H., \& Zhang, G. (2013). A multi-objective facility location model for closed-loop supply chain network under uncertain demand and return. Applied Mathematical Modelling, 37(6), 4165-4176.

Amin, S.H., \& Zhang, G. (2014). Closed-loop supply chain network configuration by a multiobjective mathematical model. Int. J. Business Performance and Supply Chain Modelling, 6(1), 1-15.

Amin, S. H., Zhang, G., \& Akhtar, P. (2017). Effects of uncertainty on a tire closed-loop supply chain network. Expert Systems with Applications, 73, 82-91.

Amin, S. H., Wu, H., \& Karaphillis, G. (In Press). A perspective on reverse logistics of plastic pallets in Canada, Journal of Remanufacturing.

Argenta, A. B., Reis, C. M., Mello, G. P., Dotto, G. L., Tanabe, E. H., \& Bertuol, D. A. (2017). Supercritical CO2 extraction of indium present in liquid crystal displays from discarded cell phones using organic acids. Journal of Supercritical Fluids, 120, 95-101.

Babbar, C., \& Amin, S. H. (2018). A multi-objective mathematical model integrating environmental concerns for supplier selection and order allocation based on fuzzy QFD in beverages industry. Expert Systems with Applications, 92, 27-38. 
Batarfi, R., Jaber, M. Y., \& Aljazzar, S. M. (2017). A profit maximization for a reverse logistics dual-channel supply chain with a return policy, Computers \& Industrial Engineering, 106, 58-82.

Bevilacqua, M., Ciarapica, F. E., \& Giacchetta, G. (2006). A fuzzy-QFD approach to supplier selection. Journal of Purchasing and Supply Management, 12(1), 14-27.

Branke, J., Deb, K., \& Miettinen, K. (2008). Multiobjective optimization: Interactive and evolutionary approaches. Springer Science \& Business Media, 5252.

Cao, J., Chen, Y., Shi, B., Lu, B., Zhang, X., Ye, X., ... Zhou, G. (2016). WEEE recycling in Zhejiang Province, China: generation, treatment, and public awareness. Journal of Cleaner Production, 127, 311-324.

Cardoso, S. R., Barbosa-Póvoa, A. P. F., \& Relvas, S. (2013). Design and planning of supply chains with integration of reverse logistics activities under demand uncertainty. European Journal of Operational Research, 226(3), 436-451.

Charnes, A., Cooper, W. W., Huang, Z. M., \& Sun, D. B. (1990). Polyhedral Cone-Ratio DEA Models with an illustrative application to large commercial banks. Journal of Econometrics, 46(1-2), 73-91.

Chen, Y. W., Wang, L. C., Wang, A., Chen, T. L. (2017). A particle swarm approach for optimizing a multi-stage closed loop supply chain for the solar cell industry. Robotics and Computer-Integrated Manufacturing, 43, 111-123.

Cho, S. J., Jun, H. B., \& Kiritsis, D. (2017). Heuristic algorithms for maximising the total profit of end-of-life computer remanufacturing. International Journal of Production Research, 55(5), 1350-1367.

Collette, Y., \& Siarry, P. (2003). Multiobjective Optimization: Principles and case studies. New York: Springer-Verlag.

Cooper, M. C., Lambert, D. M., \& Pagh, J. D. (1997). Supply Chain Management: More Than a New Name for Logistics. The International Journal of Logistics Management.

Das, K., \& Rao Posinasetti, N. (2015). Addressing environmental concerns in closed loop supply chain design and planning. International Journal of Production Economics, 163, 34-47.

Dat, L. Q., Truc Linh, D. T., Chou, S. Y., \& Yu, V. F. (2012). Optimizing reverse logistic costs for recycling end-of-life electrical and electronic products. Expert Systems with Applications, 39(7), 6380-6387.

Davis, T. (1993). Effective Supply Chain Management. Sloan Management Review, 34(4), 3546. 
Dutta, P., Das, D., Schultmann, F., Fröhling, M. (2016). Design and planning of a closed-loop supply chain with three-way recovery and buy-back offer. Journal of Cleaner Production, 135, 604-619.

Dweiri, F., Kumar, S., Khan, S. A., \& Jain, V. (2016). Designing an integrated AHP based decision support system for supplier selection in automotive industry. Expert Systems with Applications, 62, 273-283.

Ehrgott, M. (2005). Multicriteria optimization (2nd ed.). New York: Springer.

Feitó-Cespón, M., Sarache, W., Piedra-Jimenez, F., \& Cespón-Castro, R. (2017). Redesign of a sustainable reverse supply chain under uncertaintyA case study. Journal of Cleaner Production, 151, 206-217.

Fleischmann, M., Beullens, P., Bloemhof-Ruwaard, J. M., \& Van Wassenhove, L. N. (2001). The impact of product recovery on logistics network design. Production and Operations Management, 10(2), 156-173.

Francie, K. A., Jean-Pierre, K., Pierre, D., Victor, S., \& Vladimir, P. (2015). Stochastic models and numerical solutions for manufacturing/remanufacturing systems with applications to the printer cartridge industry. Journal of Manufacturing Systems, 37, 662-671.

Franke, C., Basdere, B., Ciupek, M., \& Seliger, S. (2006). Remanufacturing of mobile phonescapacity, program and facility adaptation planning. Omega, 34(6), 562-570.

Garg, K., Kannan, D., Diabat, A., \& Jha, P. C. (2015). A multi-criteria optimization approach to manage environmental issues in closed loop supply chain network design. Journal of Cleaner Production, 100, 297-314.

Georgiadis, P., \& Besiou, M. (2010). Environmental and economical sustainability of WEEE closed-loop supply chains with recycling: A system dynamics analysis. International Journal of Advanced Manufacturing Technology, 47(5-8), 475-493.

Geyer, R., \& Blass, V. D. (2010). The economics of cell phone reuse and recycling. The International Journal of Advanced Manufacturing Technology, 47(5-8), 515-525.

Ghassemi, A., Asl-Najafi, J., \& Yaghoubi, S. (2018). A dynamic bi-objective closed-loop supply chain network design considering supplier selection and remanufacturer subcontractors. Uncertain Supply Chain Management, 6, 117-134.

Govindan, K., Jafarian, A., Khodaverdi, R., \& Devika, K. (2014). Two-echelon multiple-vehicle location-routing problem with time windows for optimization of sustainable supply chain network of perishable food. International Journal of Production Economics, 152, 9-28. 
Govindan, K., Soleimani, H., \& Kannan, D. (2015). Reverse logistics and closed-loop supply chain: A comprehensive review to explore the future. European Journal of Operational Research, 240(3), 603-626.

Guide, V. D. R., Jr., \& Van Wassenhove, L. N. (2009). The Evolution of Closed-Loop Supply Chain Research. Operations Research, 57 (1), 10-18.

Guide, V. D. R., Neeraj, K., Newman, C., \& Van Wassenhove, L. N. (2005). Cellular telephone reuse: The ReCellular Inc. case. Managing Closed-Loop Supply Chains, 151-156.

Guide, V.D.R. Jr, Harrison, T.P. Wassenhove, V. (2003). The challenge of closed-loop supply chains. Interfaces, 33(6), 3-6.

Haddadsisakht, A., \& Ryan, S. M. (2018). Closed-loop supply chain network design with multiple transportation modes under stochastic demand and uncertain carbon tax. International Journal of Production Economics, 195(June 2017), 118-131.

Huisman, J. (2004). QWERTY and Eco-Efficiency analysis on cellular phone treatment in Sweden. Delft, April.

Inderfurth, K. (2005). Impact of uncertainties on recovery behavior in a remanufacturing environment. A numerical analysis. International Journal of Physical Distribution and Logistics Management, 35(5), 318-336.

Jafari Songhori, M., Tavana, M., Azadeh, A., \& Khakbaz, M. H. (2011). A supplier selection and order allocation model with multiple transportation alternatives. International Journal of Advanced Manufacturing Technology, 52(1-4), 365-376.

Jayant, A., Gupta, P., Garg, S. K., \& Khan, M. (2014). TOPSIS-AHP based approach for selection of reverse logistics service provider: A case study of mobile phone industry. Procedia Engineering, 97, 2147-2156.

Jeihoonian, M., Zanjani, M. K., \& Gendreau, M. (2016). A stochastic programming approach for closed-loop supply chain network design under uncertain quality status, 1-10.

Jeihoonian, M., Zanjani, M. K., Gendreau, M. (2017). Closed-loop supply chain network design under uncertain quality status: Case of durable products. International Journal of Production Economics, 183, 470-486.

John, S. T., Sridharan, R., \& Ram Kumar, P. N. (2017). Reverse logistics network design: a case of mobile phones and digital cameras. International Journal of Advanced Manufacturing Technology, 94, 615-631.

Kadambala, D. K., Subramanian, N., Tiwari, M. K., Abdulrahman, M., \& Liu, C. (2017). Closed loop supply chain networks: Designs for energy and time value efficiency. International Journal of Production Economics, 183, 382-393. 
Kahraman, C., Cebeci, U., and Ulukan, Z. (2003). Multi-criteria supplier selection using fuzzy AHP, Logistics Information Management, 16 (6), 382-394.

Kamath, K. R., \& Pakkala, T. P. M. (2002). A Bayesian approach to a dynamic inventory model under an unknown demand distribution. Computers and Operations Research, 29(4), 403422.

Kamath, K. R., \& Pakkala, T. P. M. (2002). A Bayesian approach to a dynamic inventory model under an unknown demand distribution. Computers and Operations Research, 29(4), 403422.

Kannan, D., Khodaverdi, R., Olfat, L., Jafarian, A., \& Diabat, A. (2013). Integrated fuzzy multi criteria decision making method and multiobjective programming approach for supplier selection and order allocation in a green supply chain. Journal of Cleaner Production, 47, 355-367.

Kannan, G., Noorul Haq, A., \& Devika, M. (2009). Analysis of closed loop supply chain using genetic algorithm and particle swarm optimisation. International Journal of Production Research, 47(5), 1175-1200.

Karsak, E. E., \& Dursun, M. (2014). An integrated supplier selection methodology incorporating QFD and DEA with imprecise data. Expert Systems with Applications, 41, 6995-7004.

Kenne, J. P., Dejax, P., \& Gharbi, A. (2012). Production planning of a hybrid manufacturingremanufacturing system under uncertainty within a closed-loop supply chain. International Journal of Production Economics, 135(1), 81-93.

Keyvanshokooh, E., Ryan, S. M., \& Kabir, E. (2016). Hybrid robust and stochastic optimization for closed-loop supply chain network design using accelerated Benders decomposition. European Journal of Operational Research, 249(1), 76-92.

Kim, T., Glock, C. H., \& Kwon, Y. (2014). A closed-loop supply chain for deteriorating products under stochastic container return times. Omega (United Kingdom), 43, 30-40.

Krikke, H., Bloemhof-Ruwaard, J., \& Van Wassenhove, L. N. (2003). Concurrent product and closed-loop supply chain design with an application to refrigerators. International Journal of Production Research, 41(16), 3689-3719.

Kumar, A., Jain, V., \& Kumar, S. (2014). A comprehensive environment friendly approach for supplier selection. Omega (United Kingdom), 42(1), 109-123.

Lee, D. H., \& Dong, M. (2008). A heuristic approach to logistics network design for end-of-lease computer products recovery. Transportation Research Part E: Logistics and Transportation Review, 44(3), 455-474. 
Lee, J. E., Gen, M., \& Rhee, K. G. (2009). Network model and optimization of reverse logistics by hybrid genetic algorithm, Computers \& Industrial Engineering, 56 (3), 951-964.

Li, P., Garcia, H., \& Gunter, W. (2008). Chance constrained programming approach to process optimization under uncertainty, Computer Aided Chemical Engineering, 32(1), 1245-1250.

Lieckens, K., \& Vandaele, N. (2007). Reverse logistics network design with stochastic lead times. Computers and Operations Research, 34(2), 395-416.

Life Cycle Environmental Issues of Mobile Phones (2005) Nokia Corporation. http://ec.europa.eu/environment/ipp/pdf/nokia_mobile_05_04.pdf/ Accessed 11 November 2017.

Lin, C. T., Chen, C. B., \& Ting, Y. C. (2011). An ERP model for supplier selection in electronics industry. Expert Systems with Applications, 38(3), 1760-1765.

Listeş, O. (2007). A generic stochastic model for supply-and-return network design. Computers and Operations Research, 34(2), 417-442.

Liu, B. (1999). Uncertain Programming. New York: Wiley.

Mendoza, A., \& Ventura, J. A. (2012). Analytical models for supplier selection and order quantity allocation. Applied Mathematical Modelling, 36(8), 3826-3835.

Mirzapour Al-E-Hashem, S. M. J., Malekly, H., \& Aryanezhad, M. B. (2011). A multi-objective robust optimization model for multi-product multi-site aggregate production planning in a supply chain under uncertainty. International Journal of Production Economics, 134(1), 2842.

Mitra, S. (2012). Inventory management in a two-echelon closed-loop supply chain with correlated demands and returns. Computers and Industrial Engineering, 62(4), 870-879.

Mobile Phone Partnership Initiative (2008). Guidance document on the environmentally sound management of used and end-of-life mobile phones. Mobile Phone Partner Initiative. Basel Convention, UNEP.

Mohajeri, A., \& Fallah, M. (2016). A carbon footprint-based closed-loop supply chain model under uncertainty with risk analysis: A case study. Transportation Research Part D: Transport and Environment, 48, 425-450.

Moheb-Alizadeh, H., \& Handfield, R. (2017). An integrated chance-constrained stochastic model for efficient and sustainable supplier selection and order allocation. International Journal of Production Research, 7543, 1-27.

Noman, R., \& Amin, S. H. (2017). Characteristics of cellphones reverse logistics in Canada. Journal of Remanufacturing, 7(2-3), 181-198. 
Oguchi, M., Sakanakura, H., \& Terazono, A. (2013). Toxic metals in WEEE: Characterization and substance flow analysis in waste treatment processes. Science of the Total Environment, 463-464, 1124-1132.

Ordoobadi, S. M. (2010). Application of AHP and Taguchi loss functions in supply chain. Industrial Management \& Data Systems, 110(8), 1251-1269.

Özceylan, E., Demirel, N., Çetinkaya, C., \& Demirel, E. (2017). A closed-loop supply chain network design for automotive industry in Turkey. Computers \& Industrial Engineering, $113,727-745$.

Özkir, V., \& Başligil, H. (2013). Multi-objective optimization of closed-loop supply chains in uncertain environment. Journal of Cleaner Production, 41, 114-125.

Paksoy, T., Bektaş, T., \& Özceylan, E. (2011). Operational and environmental performance measures in a multi-product closed-loop supply chain. Transportation Research Part E: Logistics and Transportation Review, 47(4), 532-546.

Pandian, G. P. R. R. S. (2015). Performance Evaluation of a Reverse Logistics Enterprise - An Agent-Based Modelling Approach. Electronic Theses and Dissertations, 5276.

Peidro, D., Mula, J., Poler, R., \& Verdegay, J. L. (2009). Fuzzy optimization for supply chain planning under supply, demand and process uncertainties. Fuzzy Sets and Systems, 160(18), 2640-2657.

Pham, T., Yenradee, P. (2017). Optimal supply chain network design with process network and BOM under uncertainties: A case study in toothbrush industry. Computers \& Industrial Engineering, 108, 177-191.

Pishvaee, M. S., \& Razmi, J. (2012). Environmental supply chain network design using multiobjective fuzzy mathematical programming. Applied Mathematical Modelling, 36(8), 3433-3446.

Pishvaee, M. S., Farahani, R. Z., \& Dullaert, W. (2010). A memetic algorithm for bi-objective integrated forward/reverse logistics network design. Computers and Operations Research, 37(6), 1100-1112.

Ponce-cueto, E., González Manteca, J. Á., \& Carrasco-gallego, R. (2011). Reverse Logistics Practices for Recovering Mobile Phones in Spain. Supply Chain Forum, 12(2), 104-114.

Ramezani, M., Bashiri, M., \& Tavakkoli-Moghaddam, R. (2013). A new multi-objective stochastic model for a forward/reverse logistic network design with responsiveness and quality level. Applied Mathematical Modelling, 37(1-2), 328-344.

Ramezani, M., Kimiagari, A. M., Karimi, B., \& Hejazi, T. H. (2014). Closed-loop supply chain network design under a fuzzy environment. Knowledge-Based Systems, 59, 108-120. 
Ruimin, M. A., Lifei, Y. A. O., Maozhu, J. I. N., Peiyu, R. E. N., Zhihan, L. V. (2016). Robust environmental closed-loop supply chain design under uncertainty. Chaos, Solitons \& Fractals, 89, 195-202.

Salema, M.I.G., Barbosa-Povoa, A. P., Novais, A. Q. (2006). An integrated model for the design and planning of supply chains with product return. Computer Aided Chemical Engineering, 21, 2129-2134.

Schilling, D.A., Revelle, C., \& Cohon, J. (1983). An approach to the display and analysis of multi-objective problems, Socio-Econ. Plann. Sci. 17 (2), 57-63.

Scott, J., Ho, W., Dey, P. K., \& Talluri, S. (2015). A decision support system for supplier selection and order allocation in stochastic, multi-stakeholder and multi-criteria environments. International Journal of Production Economics, 166, 226-237.

Shakourloo, A., Kazemi, A., Javad, M. O. M. (2016). A new model for more effective supplier selection and remanufacturing process in a closed-loop supply chain. Applied Mathematical Modelling, 40 (23), 9914-9931.

Shaw, K., Shankar, R., Yadav, S. S., \& Thakur, L. S. (2012). Supplier selection using fuzzy AHP and fuzzy multi-objective linear programming for developing low carbon supply chain. Expert Systems with Applications, 39(9), 8182-8192.

Shirkouhi, S., Shakouri, H., Javadi, B., \& Keramati, A. (2013). Supplier selection and order allocation problem using a two-phase fuzzy multi-objective linear programming. Applied Mathematical Modelling, 37(22), 9308-9323.

Soleimani, H., \& Kannan, G. (2015). A hybrid particle swarm optimization and genetic algorithm for closed-loop supply chain network design in large-scale networks. Applied Mathematical Modelling, 39(14), 3990-4012.

Statistics Canada. Materials diverted, by type, Canada, provinces, and territories. (2014). http://www5.statcan.gc.ca/cansim/a26?lang=eng\&retrLang=eng\&id=1530043\&\&pattern=\& stByVal=1\&p1=1\&p2=31\&tabMode=dataTable\&csid/ Accessed 9 November 2017.

Subulan, K., Taşan, A. S., \& Baykasoğlu, A. (2015). Designing an environmentally conscious tire closed-loop supply chain network with multiple recovery options using interactive fuzzy goal programming. Applied Mathematical Modelling, 39, 2661-2702.

Talaei, M., Farhang Moghaddam, B., Pishvaee, M. S., Bozorgi-Amiri, A., \& Gholamnejad, S. (2016). A robust fuzzy optimization model for carbon-efficient closed-loop supply chain network design problem: A numerical illustration in electronics industry. Journal of Cleaner Production, 113, 662-673.

Tosarkani, B. M., \& Amin, S. H. (2018a). A possibilistic solution to configure a battery closedloop supply chain: Multi-objective approach. Expert Systems with Applications, 92, 12-26. 
Tosarkani, B. M., Amin, S. H. (2018b). A multi-objective model to configure an electronic reverse logistics network and third party selection, Journal of Cleaner Production, 198, 662682.

Uster, H., Easwaran, G., Akçali, E., \& Çetinkaya, S. (2007). Benders Decomposition with Alternative Multiple Cuts for a Multi-Product Closed-Loop Supply Chain Network Design Model. Naval Research Logistics, 54, 890-907.

Vahdani, B., \& Mohammadi, M. (2015). A bi-objective interval-stochastic robust optimization model for designing closed loop supply chain network with multi-priority queuing system. International Journal of Production Economics, 170, 67-87.

Velmurugan, M. S. (2016). Environmental and health aspects of mobile phone production and use: Suggestions for innovation and policy. Environmental Innovation and Societal Transitions, 21, 69-79.

Wadhwa, V., \& Ravindran, A.R. (2007). Vendor selection in outsourcing. Computers and Operations Research, 34 (12), 3725-3737.

Weber, C. a., Current, J., \& Desai, A. (2000). An optimization approach to determining the number of vendors to employ. Supply Chain Management: An International Journal, 5(2), 90-98.

Wu, D. (2009). Supplier selection: A hybrid model using DEA, decision tree and neural network. Expert Systems with Applications, 36(5), 9105-9112.

Xu, Z., Elomri, A., Pokharel, S., Zhang, Q., Ming, X. G., \& Liu, W. (2017). Global reverse supply chain design for solid waste recycling under uncertainties and carbon emission constraint. Waste Management, 64, 358-370.

Yazdani, M., Chatterjee, P., Zavadskas, E. K., \& Hashemkhani Zolfani, S. (2017). Integrated QFD-MCDM framework for green supplier selection. Journal of Cleaner Production, 142, 3728-3740.

Yu, H., \& Solvang, W. D. (2016). A general reverse logistics network design model for product reuse and recycling with environmental considerations. International Journal of Advanced Manufacturing Technology, 87(9-12), 2693-2711.

Zadeh, L. A. (1965). Fuzzy sets, Information and Control, 8 (1), 338-353.

Zeballos, L. J., Méndez, C. A., Barbosa-Povoa, A. P., \& Novais, A. Q. (2014). Multi-period design and planning of closed-loop supply chains with uncertain supply and demand. Computers and Chemical Engineering, 66, 151-164.

Zhang, G., \& Ma, L. (2009). Optimal acquisition policy with quantity discounts and uncertain demands. International Journal of Production Research, 47(9), 2409-2425. 
Zhou, X., Pedrycz, W., Kuang, Y., \& Zhang, Z. (2016). Type-2 fuzzy multi-objective DEA model: An application to sustainable supplier evaluation. Applied Soft Computing Journal, 46, 424-440.

Zimmerman, H. J. (2001). Fuzzy Set Theory and its Applications. Boston: Kluwer Academic Publishers. 